\title{
IUCN
}

Sports and urban biodiversity A framework for achieving mutual benefits for nature and sports in cities

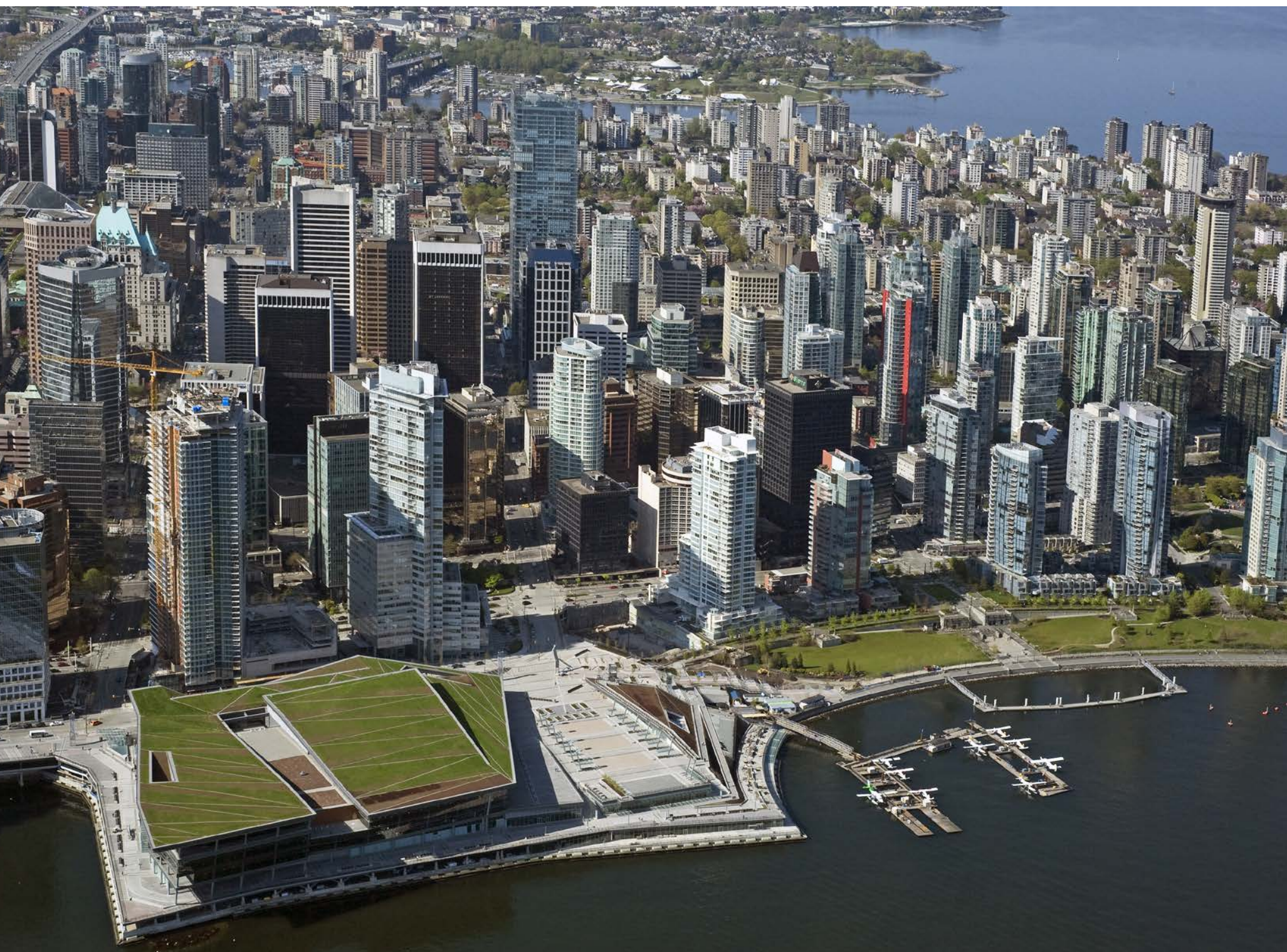




\section{About IUCN}

IUCN is a membership Union uniquely composed of both government and civil society organisations. It provides public, private and non-governmental organisations with the knowledge and tools that enable human progress, economic development and nature conservation to take place together.

Created in 1948, IUCN is now the world's largest and most diverse environmental network, harnessing the knowledge, resources and reach of more than 1,400 Member organisations and some 15,000 experts. It is a leading provider of conservation data, assessments and analysis. Its broad membership enables IUCN to fill the role of incubator and trusted repository of best practices, tools and international standards.

IUCN provides a neutral space in which diverse stakeholders including governments, NGOs, scientists, businesses, local communities, indigenous peoples organisations and others can work together to forge and implement solutions to environmental challenges and achieve sustainable development.

www.iucn.org

https://twitter.com/IUCN/

\section{About SFEI}

The San Francisco Estuary Institute is a center for independent environmental science. SFEl was established in 1993 to provide public resource management agencies and policy makers at all levels of government with sound, objective scientific knowledge for decision making. We now provide technical assistance and scientific support related to water quality management, urban sustainability, and ecological resilience to public agencies, NGOs, communities, and business leaders. SFEl's Urban Nature Lab uses the quantitative science of nature in cities to help advance innovative, ecologically based urban planning and design.

www.sfei.org/rl/unl

https://twitter.com/sfei_asc/ 
Sports and urban biodiversity

A framework for achieving mutual benefits for nature and sports in cities 
The designation of geographical entities in this publication, and the presentation of the material, do not imply the expression of any opinion whatsoever on the part of IUCN concerning the legal status of any country, territory, or area, or of its authorities, or concerning the delimitation of its frontiers or boundaries. The views expressed in this publication do not necessarily reflect those of IUCN.

IUCN is pleased to acknowledge the support of its Framework Partners who provide core funding: Ministry for Foreign Affairs of Finland; Government of France and the French Development Agency (AFD); the Ministry of Environment, Republic of Korea; the Norwegian Agency for Development Cooperation (Norad); the Swedish International Development Cooperation Agency (Sida); the Swiss Agency for Development and Cooperation (SDC); and the United States Department of State.

This publication has been made possible by funding from the International Olympic Committee.

Published by:

Copyright:

Citation:

ISBN:

DOl:

Cover photo:

Edited by:

Layout by:

Available from:

\section{IUCN, Gland, Switzerland}

(c) 2020 IUCN, International Union for Conservation of Nature and Natural Resources

Reproduction of this publication for educational or other non-commercial purposes is authorised without prior written permission from the copyright holder, provided the source is fully acknowledged.

Reproduction of this publication for resale or other commercial purposes is prohibited without prior written permission of the copyright holder.

Wheeler, M., Grossinger, R., Ndayishimiye, E., Spotswood, E., Galt, R. and Carbone, G. (2020). Sports and urban biodiversity. A framework for achieving mutual benefits for nature and sports in cities. Gland, Switzerland: IUCN and San Francisco, USA: SFEI.

978-2-8317-2078-4 (PDF)

https://doi.org/10.2305/IUCN.CH.2020.14.en

(c) Shutterstock / Josef Hanus

Diwata Hunziker

Imre Sebestyén jr / Unit Graphics

IUCN (International Union for Conservation of Nature)

Business and Biodiversity Programme

Rue Mauverney 28

1196 Gland

Switzerland

Tel +41229990000

Fax +41 229990002

biobiz@iucn.org

www.iucn.org/resources/publications 


\section{Contents}

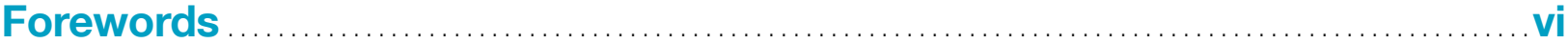

Executive summary .............................................................. vii

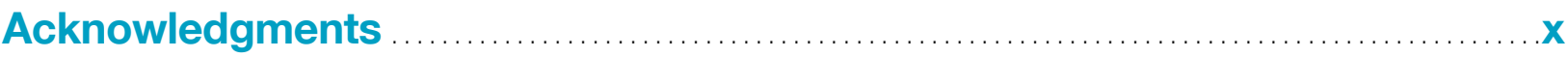

Glossary of terms, abbreviations and acronyms ..................................

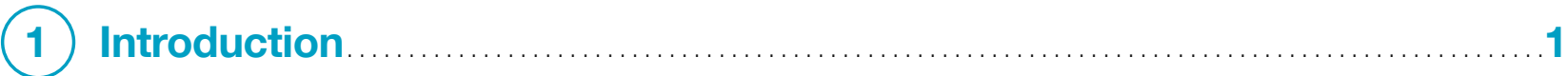

(2) A framework for buillding urban biodiversity ................................ 5

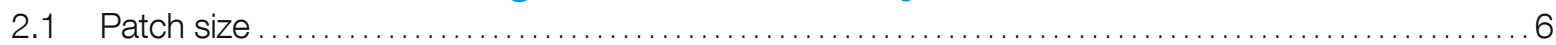

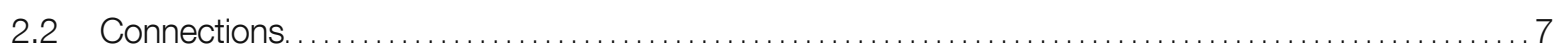

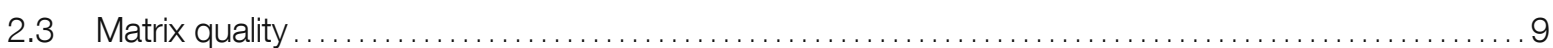

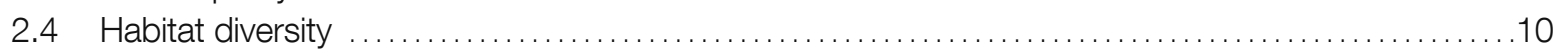

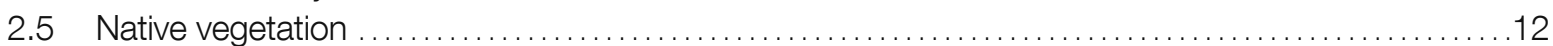

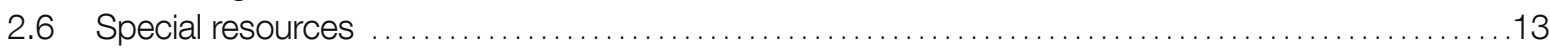

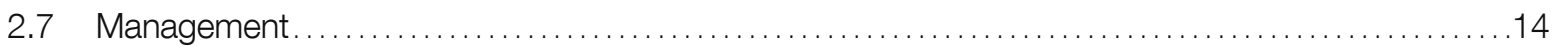

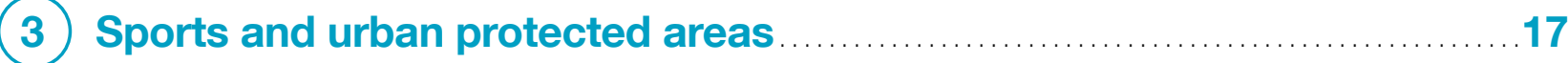

(4) Measuring success in building urban biodiversity ..........................21

(5) Combining elements to support urban biodiversity: Selected case studies from Europe, North America, Australia and South Africa .......................................................25

5.1 France - Implementation of the seven biodiversity elements in planning for

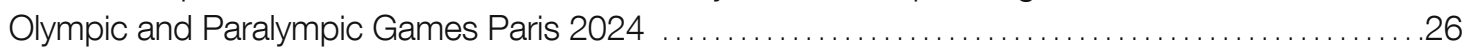

5.2 United Kingdom - Supporting biodiversity at the Olympic and Paralympic Games London 2012 . . . 29

5.3 France - Diverse habitats at Le Golf National ................................................. 31

5.4 Australia - Rowers and restoration at Spring Creek, New South Wales........................33

5.5 Canada - Habitat Island at the Vancouver 2010 Olympic Village .............................. 35

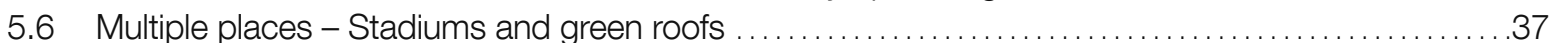

5.7 United States - Oriole Garden at Camden Yards ............................................ 39

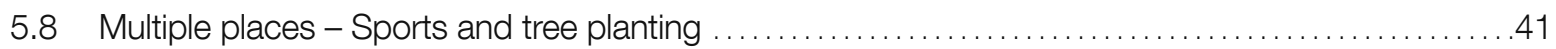

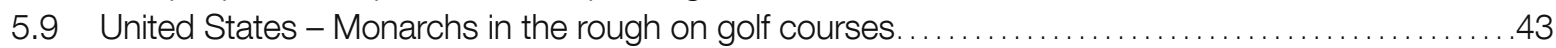

5.10 South Africa - Habitat conservation at the Kenilworth Racecourse ...........................45

5.11 South Africa - Showcasing local biodiversity outside Cape Town Stadium ...................... 46

(6) Conclusions - Every little action counts ...................................... 47

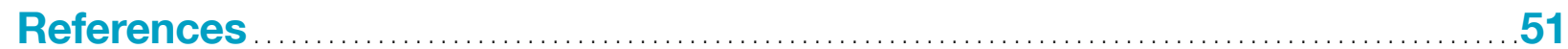




\section{Boxes}

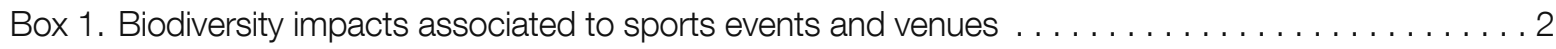

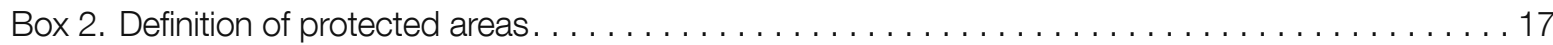

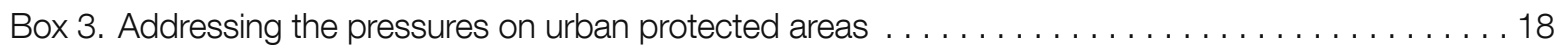

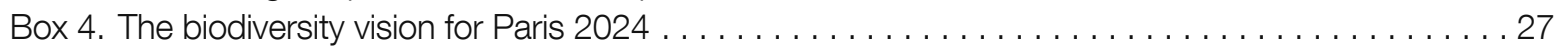

Box 5. Every little action counts. An overview of actions to promote biodiversity in cities associated

to sports events and venues. . . . . . . . . . . . . . . . . . . . . . . . . . . . 48

\section{Figures}

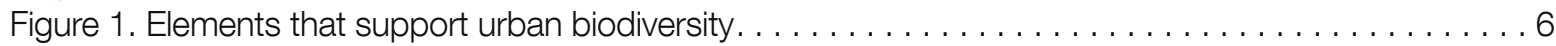

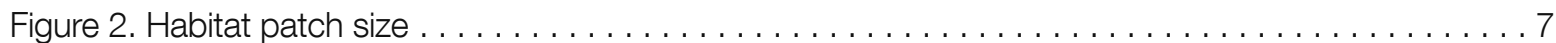

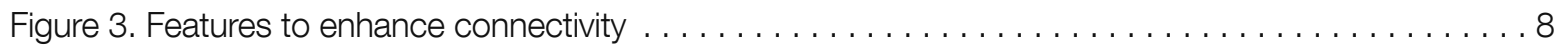

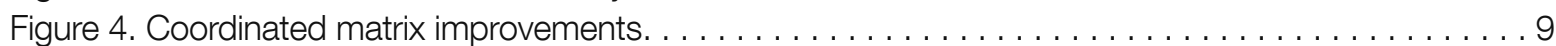

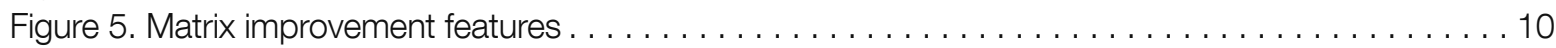

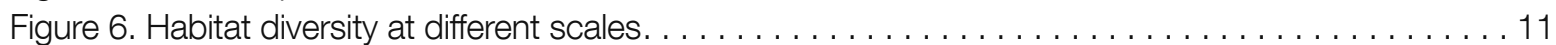

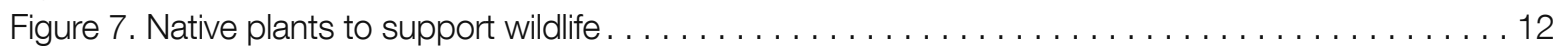

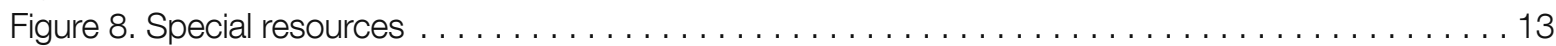

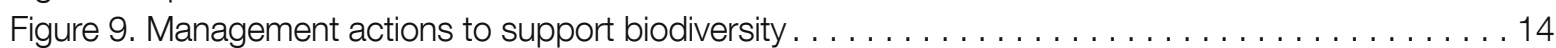

Figure 10. Paris 2020 Olympic Village . . . . . . . . . . . . . . . . . . . . . . . . . . . . . . . 28 


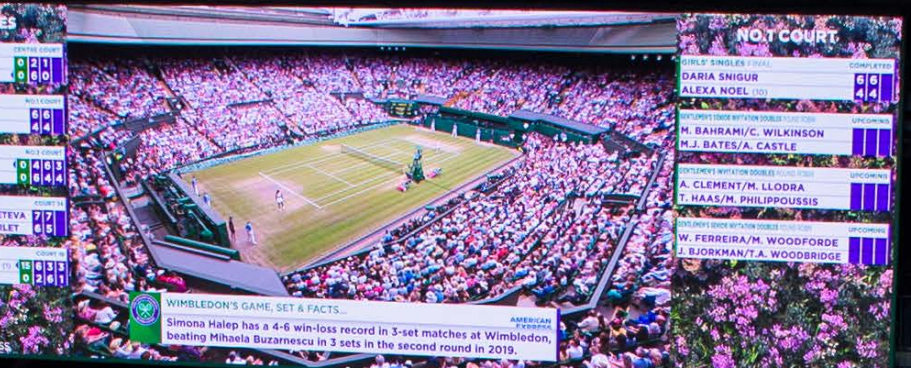

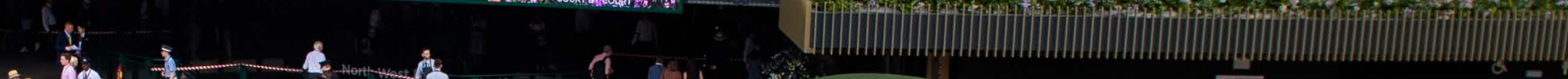

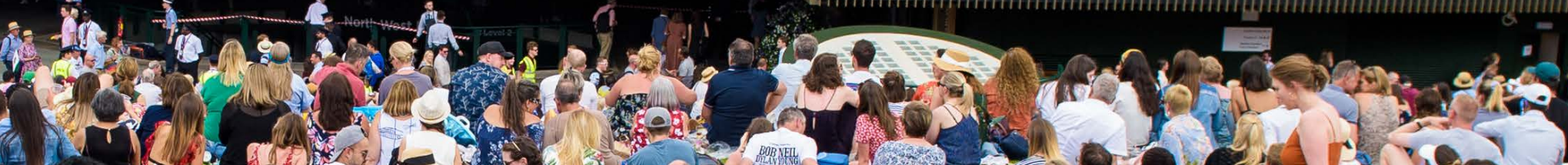

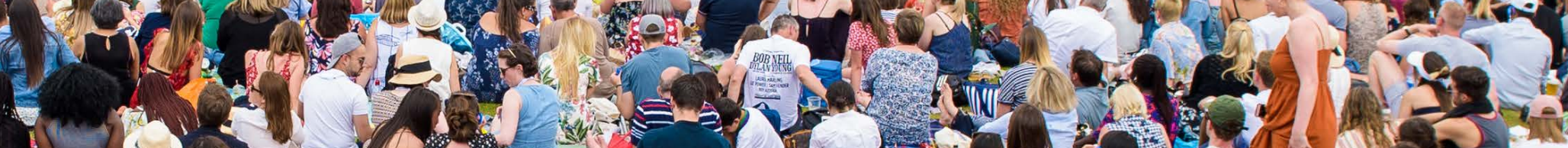
1. a $x$ on con tै

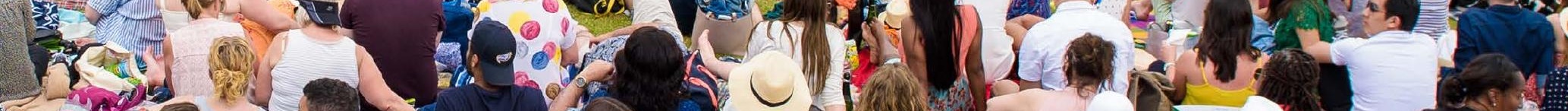

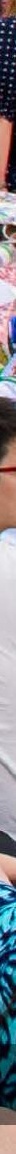




\section{Foreword}

From research into urban ecology, we know sports are a feature of the urban environment that is highly relevant to biodiversity and nature. Sports and nature often occupy the same urban green spaces and can support each. Sports also help drive urban planning efforts and regeneration projects, providing a unique opportunity to create niches for biodiversity and harness the potential of nature's solutions for the health and resilience of our cities.

As urban populations around the world continue to grow, the push to make our cities greener, more natural and healthier is gaining momentum - and the COVID-19 pandemic has only made the need for a more liveable urban environment increasingly evident. Given a chance, nature can thrive in urban settings, and cities can benefit from nature in myriad ways. For instance, Nature-based Solutions offer a cost-effective way to enhance the sustainability, resilience and liveability of cities. Trees absorb pollutants, dampen noise and cool the air; wetlands and rain gardens reduce flood risk; mangroves and marshes buffer storms; green spaces facilitate exercise, spiritual nourishment and community interaction; and greenways support active, eco-friendly travel. Such natural infrastructure may also offer precious lifelines to the long list of species whose survival is threatened by urbanisation.
This IUCN guide, Sports and urban biodiversity, aims to bring sports venue owners and operators, city authorities and environmentalists together as stewards of urban nature. It is the fourth in a series of publications produced in partnership by IUCN and the International Olympic Committee, and on this occasion in cooperation with the San Francisco Estuary Institute.

The guide provides a set of principles to help sports federations, local organising committees, developers, investors and local authorities to incorporate the needs of urban nature and biodiversity into their planning process. From setting up ecological monitoring systems to improving the management of habitats, there is a range of ways in which the sports industry can help urban nature flourish.

IUCN is proud to have collaborated with the International Olympic Committee for the past five years to strengthen the links between sports and conservation communities to create greener and healthier societies, cities and sports events - and make progress towards the Sustainable Development Goals that bring us closer to our vision of a just world that values and conserves nature.

Dr Bruno Oberle, IUCN Director General 


\section{Foreword}

More than half of the world's population lives in cities today, where many sports events take place. According to the United Nations, by 2050, this proportion is likely to rise to $68 \%$.

For national and international sporting events, cities offer the necessary infrastructure, such as stadia, transport and accommodation. However, sport is important for cities at the individual and community-level, too. Besides the economic benefits, sport helps those living in cities to stay physically and mentally healthy. Many cities are making impressive efforts to encourage their citizens to be more physically active through the implementation of bike lanes, walking paths and easy access to scooter and cycle hire.

This symbiotic relationship between sport and cities can only flourish in a healthy environment. Green and healthy surroundings make many activities, such as running, cycling, walking and swimming, more enjoyable. Outdoor sports especially require clean air and water.

If sport needs a healthy environment, cities also do. Healthy ecosystems make cities more resilient and their inhabitants safer. Nature and green spaces boost their physical and mental well-being, and help to protect them from air pollution and heat, as well as floods and landslides.
Sport, therefore, can obviously play an active part in conserving and enhancing urban biodiversity. By doing so, it can deliver important social and public health benefits to a growing urban population.

This guide - which focuses on cities - is the fourth in a series of publications about sport and biodiversity, produced in partnership with IUCN, a world authority on nature and conservation. The guide shows how sports events and the sites and infrastructure used to host them can help enhance nature in urban settings. It aims to help local authorities, clubs, event organisers and sports federations to deliver sports events that meet the needs of people and nature too.

Scientists around the world warn that human activities are destroying our natural environment, placing around one million species under threat of extinction. We hope that this guide, together with other guides in the series, will help the sports community to better understand its relationship with nature and inspire it to take concrete actions to help address today's immense environmental challenges. Sporting activities must benefit nature if we want to continue enjoying them, while striving to achieve our vision of 'building a better world through sport'.

Christophe de Kepper, Director General, International Olympic Committee 


\section{Executive summary}

Investing in nature and nature-based solutions is an important pathway to address the current ecological crisis. The loss of biodiversity, with around one million animal and plant species threatened with extinction, is putting at risk our economies, livelihoods, food security, health, and quality of life worldwide. Diverse and innovative measures are needed to reverse this decline and to restore healthy ecosystems. The magnitude of the challenge calls for the collaboration and contribution of all actors, including non-state actors, such as businesses, local authorities, civil society organisations, and individual citizens.

Drawing on Making Nature's City: A Science-Based Framework for Building Urban Biodiversity by the San Francisco Estuary Institute, this Guide identifies the opportunities for sports federations and sport venue owners and operators to develop the seven elements essential for supporting nature in cities. These elements, which are based on the way natural ecosystems work, are: i) habitat patch size; ii) connectivity across the urban landscape; iii) quality of the landscape matrix surrounding a habitat patch; iv) diversity of habitats available; v) native vegetation; vi) special resources like water and nesting locations; vii) and wildlife-friendly management.

Many diverse types of green spaces in cities are developed and maintained for sporting events, and thus, sports venue owners and operators can contribute as stewards of urban nature. While one sporting venue alone can have a small impact on local biodiversity, several working together can create city-wide beneficial effects. Similarly, improvements focused on a single element of the Framework can have limited benefits, while addressing multiple elements together can create compounding positive outcomes.

Eleven case studies capture the biodiversity actions taken by a variety of sports, from Olympic city planning to local projects at stadiums and practice facilities. These examples also reveal ways in which improvements to urban biodiversity elements can offer a better sporting experience for event participants and spectators. The interventions explored in this Guide range from small to large, and were often conducted with the support of and in collaboration with local government, conservation organisations, non-profits, environmental experts, schools and/or museums.

Sports and urban biodiversity is the fourth in a series of guides published under a collaborative partnership with the International Olympic Committee. The first, Sport and Biodiversity, was published in 2018 and gives a broad overview of the topic. The second, published in 2019, Mitigating biodiversity impacts of new sports venues, looks at the development of new venues for sports and their impacts on biodiversity. The third, published in 2020, focuses on Mitigating biodiversity impacts of sports events. In combination, these Guides highlight the importance of mitigating negative impacts of sport on biodiversity while bringing forward opportunities to leave lasting positive legacies.

The final message of this Guide is that the magnitude of the challenge calls for the collaboration and contribution of all actors, including sport actors, and that every action counts.

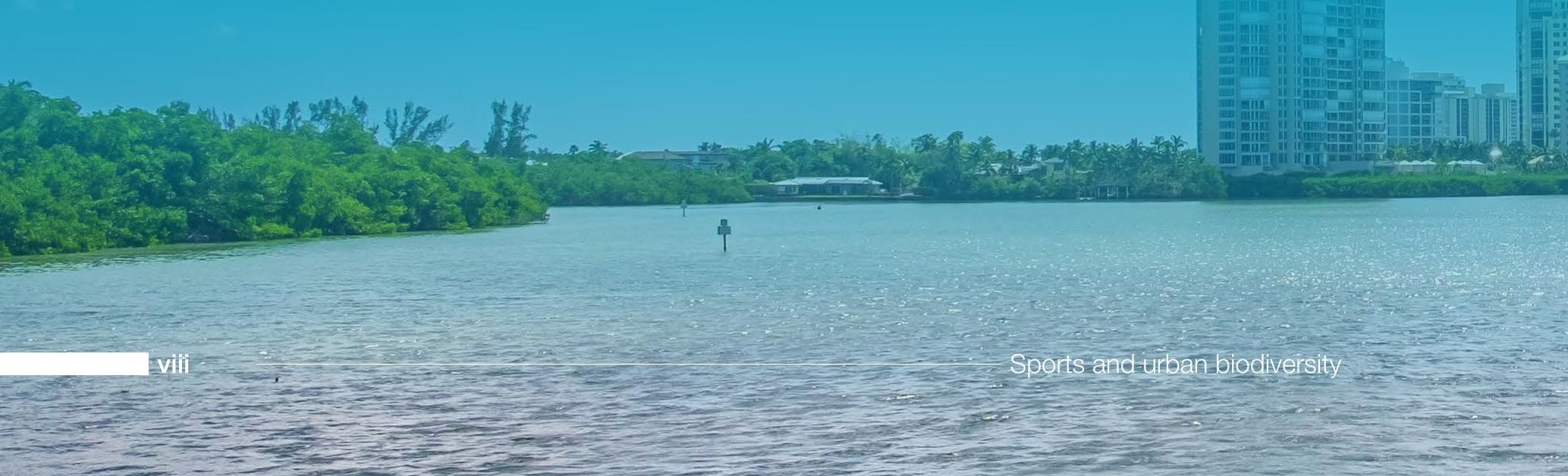


Nature and sports both have the power to bring people outside: to leave their buildings and screens behind for a respite of physical and outdoor experience. In cities, sports and nature often occupy the same green spaces and - as we show in this guide can support each other to mutual benefit.

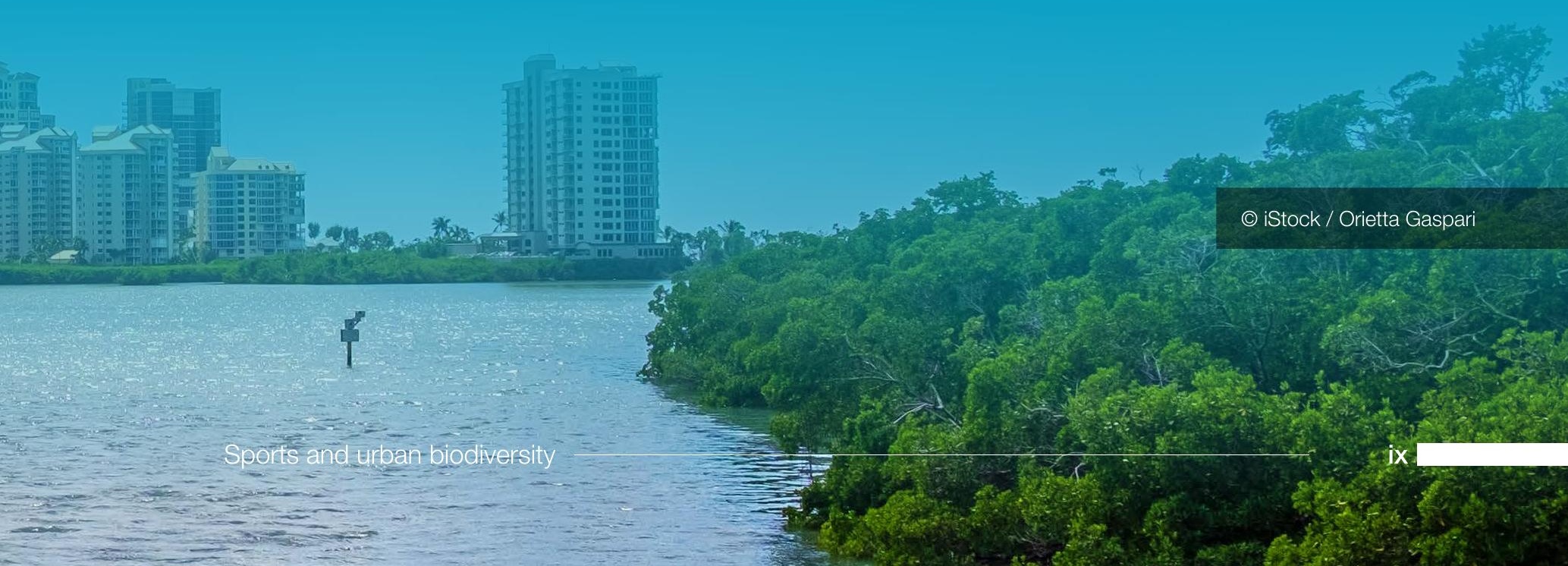




\section{Acknowledgments}

\section{Project design and coordination}

Giulia Carbone, IUCN

\section{Contributors of case studies}

Julie Duffus, International Olympic Committee (IOC)

Holly Gallagher, National Wildlife Federation (NWF)

Patrick Gasser, Union of European Football Associations (UEFA)

Bill Glad, European Athletics

Michelle Lemaître, International Olympic Committee (IOC)

Benjamin Leveque, Olympic and Paralympic Games Paris 2024

Natalie Mills, International Golf Federation

Colleen Orsmond, World Rowing Federation

Dan Reading, World Sailing

Antoine du Souich, SOLIDEO

Donata Taddia, Fédération Internationale de Volleyball (FIVB)

Cole Thompson, United States Golf Association (USGA)

Lilian Tretout, SOLIDEO

Tobias Wehr-Candler, Kinross Wolaroi School

\section{Peer reviewers}

Dr Victor Beumer

David Stubbs 


\section{Glossary of terms, abbreviations and acronyms}

\begin{tabular}{ll} 
Active mobility & $\begin{array}{l}\text { A form of transport of people and sometimes goods that only uses human physical } \\
\text { activity for locomotion. It includes walking, cycling, running and skateboarding among } \\
\text { others. }\end{array}$ \\
\hline Athlete & Used generically to refer to all competitors in sports events. \\
\hline Biodiversity & $\begin{array}{l}\text { The variability among living organisms from all sources including, inter alia, terrestrial, } \\
\text { marine and other aquatic ecosystems and the ecological complexes of which they are } \\
\text { part; this includes diversity within species, between species, and of ecosystems (UN, } \\
\text { 1992, p. 3). }\end{array}$ \\
\hline Certification & $\begin{array}{l}\text { Written assurance of the conformity of a process, product or service to a pre-determined } \\
\text { scope and set of requirements laid out in a standard. The most credible form of } \\
\text { certification is third party, ideally by a certification body accredited to audit the standard in } \\
\text { question. }\end{array}$
\end{tabular}

Commissioning Commissioning (in the context of these guidelines) is the strategic activity of identifying the need for a sports event, allocating resources and procuring a provider to best meet that need, within available means.

\begin{tabular}{ll} 
Conservation status & $\begin{array}{l}\text { Category of threat to, and likelihood of, the continued existence of a species or } \\
\text { ecosystem. }\end{array}$ \\
\hline Direct impact & $\begin{array}{l}\text { An outcome directly attributable to a defined action or project activity; often also called a } \\
\text { primary impact (BBOP, 2012, p. 14). }\end{array}$ \\
\hline Eco-friendly & Not harmful to the natural environment. \\
\hline Ecology & $\begin{array}{l}\text { The branch of biology that deals with the relations of organisms to one another and to } \\
\text { their physical surroundings. It includes the study of the distribution and abundance of } \\
\text { organisms, how their populations function and the structure and function of ecosystems. }\end{array}$
\end{tabular}

Ecosystem A dynamic complex of plant, animal, and micro-organism communities and their nonliving environment interacting as a functional unit (UN, 1992, p. 3).

Ecosystem services The benefits people obtain from ecosystems. These include provisioning services such as food, water, timber, and fibre; regulating services that affect climate, floods, disease, wastes, and water quality; cultural services that provide recreational, aesthetic, and spiritual benefits; and supporting services such as soil formation, photosynthesis, and nutrient cycling (BBOP, 2012, pp. 15-16).

EIA Environmental impact assessment

Event organiser The person/entity responsible for directing and coordinating the planning, promotion and delivery of a sports event.

Event owner The rights holder of a sports event, typically a sport governing body but can also be commercial organisations and public bodies.

Federation A union of (non-governmental) sports associations at national or international level administering and organising a particular sport, namely through competitions, and setting the rules for that sport.

Flagship species A species that acts as an icon or symbol for a particular habitat, issue, campaign or environmental cause.

Habitat fragmentation The disruption and spatial and functional break-up of extensive habitats into isolated and small patches, interspersed with other habitats. Habitat fragments can only support small populations of fauna, which are more vulnerable to extinction. The patches may not even be habitable by species occupying the original undivided habitat. Fragmentation often prevents species migrating between populations and is therefore expected to lead to losses of species diversity in the longer term (CBD 2008: Biodiversity Glossary). 


\begin{tabular}{|c|c|}
\hline GSF & Green Space Factor \\
\hline Habitat & $\begin{array}{l}\text { The place or type of site where an organism or population of a species naturally occurs } \\
(U N, 1992, \text { p. 4). }\end{array}$ \\
\hline Habitat degradation & $\begin{array}{l}\text { The diminishment of habitat quality, which results in a reduced ability to support flora and } \\
\text { fauna species. Human activities leading to habitat degradation include polluting activities } \\
\text { and the introduction of invasive species. Adverse effects can become immediately } \\
\text { noticeable, but can also have a cumulative nature. Biodiversity will eventually be lost if } \\
\text { habitats become degraded to an extent that species can no longer survive (CBD 2008: } \\
\text { Biodiversity Glossary). }\end{array}$ \\
\hline $\begin{array}{l}\text { Important areas for } \\
\text { biodiversity }\end{array}$ & $\begin{array}{l}\text { Areas recognised to be important for the conservation of particular wild species and their } \\
\text { habitats, ecosystems, ecological processes, and/or for maintaining priority ecosystem } \\
\text { services. }\end{array}$ \\
\hline Indirect impact & $\begin{array}{l}\text { Impact triggered in response to the presence of the project, rather than being directly } \\
\text { caused by the project's own operations, often produced away from or as a result of a } \\
\text { complex pathway; sometimes called secondary or induced impacts (BBOP, 2012, pp. } \\
\text { 23-24). }\end{array}$ \\
\hline Invasive alien species & $\begin{array}{l}\text { Invasive alien species (IAS) are species whose introduction and/or spread outside their } \\
\text { natural past or present distribution threaten biological diversity (Convention on Biological } \\
\text { Diversity, 1992). }\end{array}$ \\
\hline IOC & International Olympic Committee \\
\hline IUCN & International Union for Conservation of Nature \\
\hline Modified habitats & $\begin{array}{l}\text { Areas that may contain a large proportion of plant and/or animal species of non- } \\
\text { native origin, and/or where human activity has substantially modified an area's primary } \\
\text { ecological functions and species composition (IFC, 2012, p, 3). }\end{array}$ \\
\hline Natural habitats & $\begin{array}{l}\text { Areas composed of viable assemblages of plant and/or animal species of largely native } \\
\text { origin, and/or where human activity has not essentially modified an area's primary } \\
\text { ecological functions and species composition (IFC, 2012, p. 3). }\end{array}$ \\
\hline $\begin{array}{l}\text { Net gain of } \\
\text { biodiversity or net } \\
\text { positive impact for } \\
\text { biodiversity }\end{array}$ & $\begin{array}{l}\text { A target for a development project in which the impacts on biodiversity caused by } \\
\text { the project are balanced or outweighed by measures taken to avoid and minimise the } \\
\text { project's impacts, to undertake on-site restoration, and finally to offset the residual } \\
\text { impacts, so that no loss remains. Where the gain exceeds the loss, the terms 'net gain' } \\
\text { or 'net positive impact' may be used instead of 'no net loss' (BBOP, 2012, p. 29). }\end{array}$ \\
\hline NFL & National Football League \\
\hline NGO & Non-governmental organisation \\
\hline $\begin{array}{l}\text { No net loss [of } \\
\text { biodiversity] }\end{array}$ & $\begin{array}{l}\text { The point at which the project-related impacts on biodiversity are balanced by measures } \\
\text { taken to avoid and minimise the project's impacts, to undertake on-site restoration, and } \\
\text { finally to offset significant residual impacts, if any, on an appropriate geographic scale } \\
\text { (BBOP, 2012, p. 30). }\end{array}$ \\
\hline $\begin{array}{l}\text { Organising } \\
\text { Committee }\end{array}$ & An entity tasked with planning and implementing a sports event. \\
\hline Overlay & $\begin{array}{l}\text { The temporary elements needed for an event such as seating, tents, barriers, banners, } \\
\text { toilets etc. They are either added to a permanent venue or used to create a temporary } \\
\text { one. }\end{array}$ \\
\hline $\begin{array}{l}\text { Positive outcome for } \\
\text { biodiversity }\end{array}$ & $\begin{array}{l}\text { In the context of these guidelines, going beyond mitigating the impacts of a sporting } \\
\text { event so that there is no lasting harm, and taking additional steps (not necessarily linked } \\
\text { to the event's impacts) to support biodiversity conservation in the host area and further } \\
\text { afield, into the future (also referred to as 'leaving a positive legacy for biodiversity'). }\end{array}$ \\
\hline Protected area & $\begin{array}{l}\text { A clearly defined geographical space, recognised, dedicated, and managed, through } \\
\text { legal or other effective means, to achieve the long-term conservation of nature with } \\
\text { associated ecosystem services and cultural values (Dudley, 2008, p. ii). }\end{array}$ \\
\hline Rain gardens & Small depressions with native plantings designed to catch and infiltrate rainwater. \\
\hline
\end{tabular}




\begin{tabular}{|c|c|}
\hline Restoration & $\begin{array}{l}\text { The return of an ecosystem or habitat to its original community structure, natural } \\
\text { complement of species, and natural functions (CBD, 2008, Biodiversity Glossary). }\end{array}$ \\
\hline Semi-natural & $\begin{array}{l}\text { Habitats and/or landscapes that have been modified by human influence but retain many } \\
\text { natural features. See also modified habitats. }\end{array}$ \\
\hline Significant impact & $\begin{array}{l}\text { An impact that is outside the limit of acceptance or may result in non-compliance with } \\
\text { accepted environmental quality standards, thresholds, or targets. }\end{array}$ \\
\hline SOLIDEO & Société de Livraison des Ouvrages Olympiques \\
\hline Specialist species & $\begin{array}{l}\text { Species adapted to a narrow set of environmental conditions, including limited habitat } \\
\text { types or food resources. }\end{array}$ \\
\hline Sponsor/sponsorship & $\begin{array}{l}\text { Sponsorship is a cash and/or value-in-kind }(\mathrm{VIK}) \text { fee paid to a sports organisation by } \\
\text { a business or organisation in return for the right to associate a brand/location with the } \\
\text { sports event. }\end{array}$ \\
\hline Sports event & Any planned and organised sports competition held at a specific time and place. \\
\hline Threatened species & $\begin{array}{l}\text { Species categorised as Critically Endangered, Endangered, or Vulnerable by The IUCN } \\
\text { Red List of Threatened Species } \\
\text { comprehensive, The Red List is widely recognised as the most } \\
\text { and animal species (IUCN Red List of Threatened Species }{ }^{\mathrm{TM}} \text { ). }\end{array}$ \\
\hline UEFA & Union of European Football Associations \\
\hline Venue & $\begin{array}{l}\text { The place, building, site, route or structure where a sports event is held. In these } \\
\text { guidelines, the term is used broadly to include the land, buildings, equipment, built } \\
\text { infrastructure (e.g. power lines) and services needed to enable events to take place. This } \\
\text { includes natural sites, event routes and open waters where there are no formal venue } \\
\text { boundaries. }\end{array}$ \\
\hline dlife & and plants (fauna and flora). \\
\hline
\end{tabular}




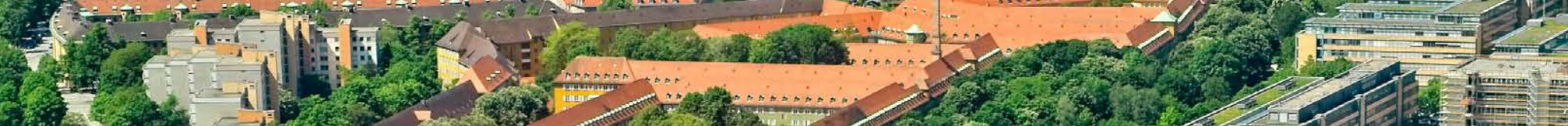

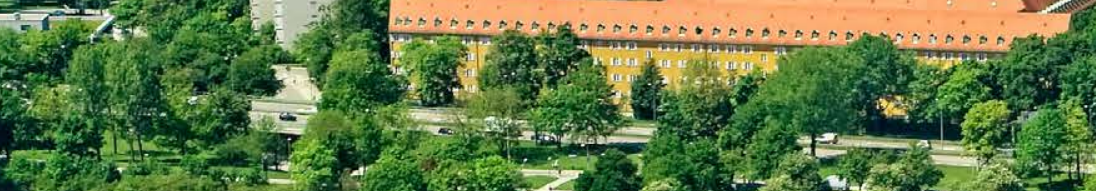

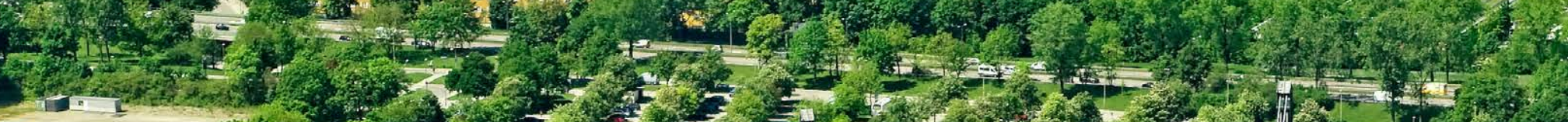

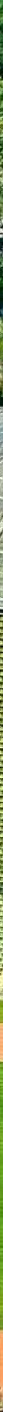

1.7.

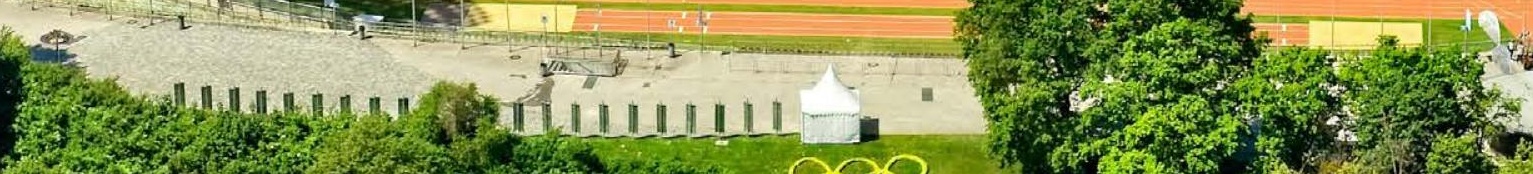

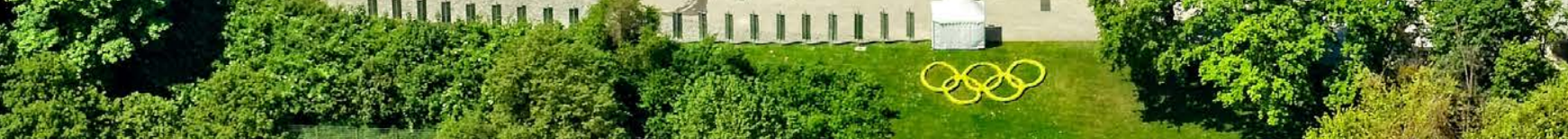

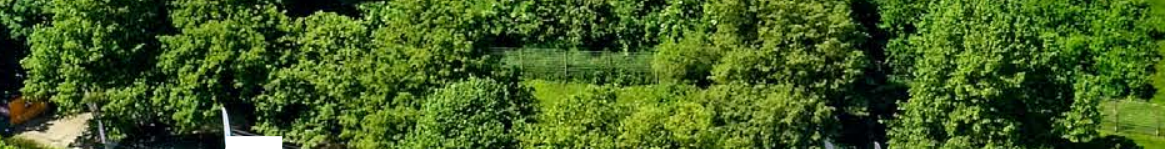

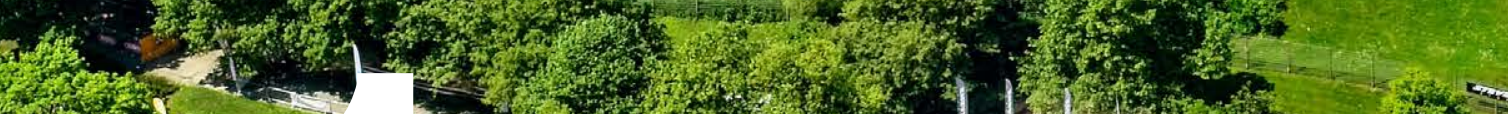

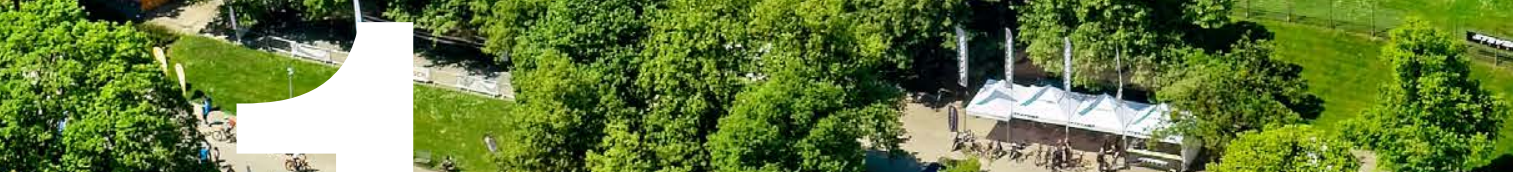

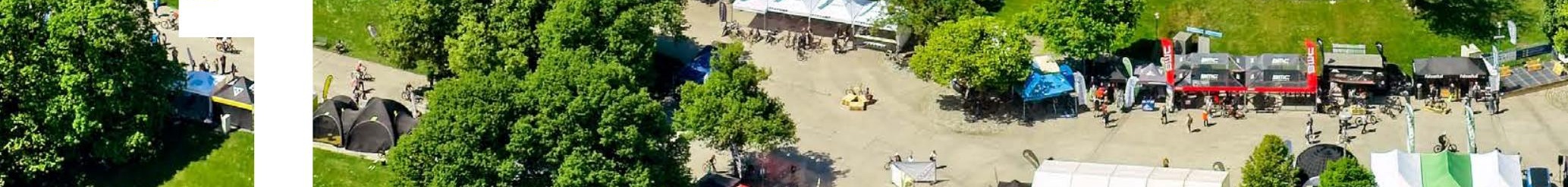

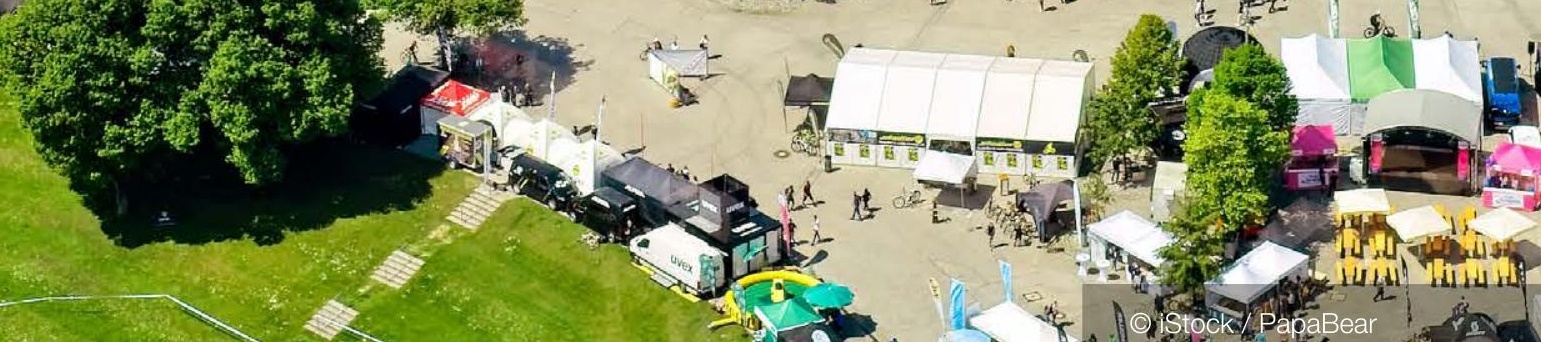

?

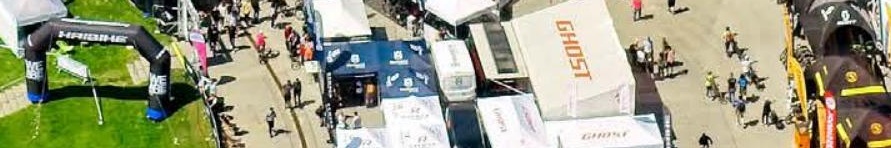
16 


\section{Introduction}

Sports and cities are intrinsically intertwined, as reflected in a multitude of indoor and outdoor sports ${ }^{1}$ practiced daily in urban contexts, and by sports events - local, national and international - regularly staged in cities.

Investing to enhance urban biodiversity provides a potential opportunity for sports to build a long-lasting and socially-positive legacy in cities, as spending time in green spaces - including for outdoor sports activities - has widely-demonstrated physical and mental health benefits for urban dwellers. These benefits also enhance urban areas for athletes: whether they are running, canoeing, rowing, sailing or cycling, athletes depend on a healthy environment.

The benefits associated with biodiversity-rich cities are numerous. Nature in urban areas contributes to a healthier place to live by creating a barrier to noise, absorbing air pollutants and cooling the air during the summer months. It creates a safer place to live by providing protection from floods and landslides, and a more fun and enjoyable place to live by offering recreation, visually pleasing surroundings and education opportunities. Bringing these benefits to the urban population, which today has reached over $55 \%$ of the total world population, makes investing in raising the quality of urban environments a good way also to contribute simultaneously to environmental and social goals, embodied by the Sustainable Development Goals, in particular SDG 3 and SDG $11 .{ }^{23}$

Nature can thrive in urban settings, especially if underpinned by a diversity of species and habitats, and cities can support both people and biodiversity, if they are designed and managed with conservation goals in mind. In comparison to other highly human-impacted landscapes such as intensive agriculture, cities can include diverse and functional habitats for many species. In recent years, scientific research in urban ecology has provided new insight into the specific features of the urban environment which are most relevant to biodiversity and conservation objectives. Spaces dedicated to the practice of sports can promote these objectives with purposeful design and management.

The urban regeneration projects that can sometimes occur with large sports-driven urban planning efforts are rare opportunities to introduce the ecological elements critical to urban health and resilience. In particular, sports fields, pitches and the areas around sports venues constitute an important component of unpaved, preserved green space in cities, where the opportunity to increase their value for biodiversity is significant. Many cities have expanded and grown around open sports grounds, leaving them as potential ecologically rich oases in an urban context.

This guide focuses on how existing and new sport venues both indoors and outdoors, as well as sports events of all sizes, can contribute to the restoration and enhancement of biodiversity in cities by integrating specific structural and management elements that will increase suitable habitats for plants and animals to thrive. The guide also highlights the benefits that protected areas play in urban settings and how these can be amplified by sports, as well as a number of tools that could be deployed to measure success.

These initiatives do not replace the responsibility of sports stakeholders to address the direct and indirect impacts on biodiversity associated with the construction and operation of sports venues and sports events (Box 1). The negative impacts have to be mitigated (avoided, minimised, restored and as a last resort offset) as described in the previous IUCN Sport and Biodiversity guidelines, published

1 Sports venues are grouped into four main categories: i) outdoor sports taking place in the natural landscape; ii) outdoor sports taking place in purposely modified landscapes; iii) urban sports parks; and iv) sports buildings. For a detailed description including the type of biodiversity impacts associated to each category, please see: Mitigating biodiversity impacts of new sports venues https://doi.org/10.2305/IUCN.CH.2019.02.en

2 The Sustainable Development Goals (SDGs) are the blueprint to achieve a better and more sustainable future for all. In particular, SDG 3 calls for "Good health and well-being" and SDG 11 calls for "Sustainable cities and communities". See https://www.un.org/sustainabledevelopment/sustainable-development-goals/

3 https://sustainabledevelopment.un.org/?menu=1300 


\section{Box 1. Biodiversity impacts associated to sports events and venues}

Although sport events held in urban venues or in natural landscapes can bring many benefits, they can also negatively impact biodiversity through large numbers of spectators, who increase noise, vibration, and lighting, produce large quantities of solid waste and wastewater, and generate traffic that can increase pollution and road kills of wildlife. Furthermore, outdoor venues in or near urban areas that are used for recreation and leisure activities are frequently highly managed environments.

When a sporting event is staged, there can be a significant increase in management activities, such as increased cutting of grass, brush, undergrowth, or borders. The removal of this vegetation (e.g. cut grass, fallen leaves, dead wood) can disrupt or destroy habitats. The application of chemical fertilisers, pesticides, and mosquito control measures, can further affect, reduce, or limit the opportunities for species survival in these intensively managed environments. The risks to biodiversity from both summer and winter sporting events conducted outdoors in natural environments come from many sources, including oil or fuel spills; solid waste generation; the use of cleaning products, pesticides or herbicides; discharge of sewage into the water or on land; the introduction of invasive species; noise, lighting and vibration; traffic and road kills; and the need, even temporarily, to erect fencing and communication infrastructure, and expand and/or construct new start and finish areas, viewing points, media points, medical stations, refuelling stations, commercial outlets to service the event, and water reserve ponds for snowmaking. Spectators can also damage natural habitats through the sheer numbers of people trampling the grounds. Littering, walking on non-designated paths and into sensitive areas, and car and bike parking where not permitted can all have negative impacts on biodiversity, such as disturbing breeding, nesting, and feeding animals. These behaviours in fragile outdoor spaces can impact both biodiversity and habitats negatively and, in some cases, irreversibly.

The construction of sports venues - including their associated supporting facilities, infrastructure, and services - and temporary facilities can potentially have a range of both positive and negative impacts on biodiversity. The potential negative impacts on biodiversity from new sports venues can arise either directly through conversion of critical or natural habitat, or indirectly through pollution and the disturbance of wildlife. Direct impacts of new sports venues may include changes such as physical alteration to habitats, loss of trees and other vegetation, and increased disturbance to wild animals from people and traffic, affecting their breeding or feeding patterns and general chances of survival. Impacts on natural drainage systems, changes to soil conditions, fragmentation of habitats, and noise or light pollution may be less obvious effects, but can be equally detrimental to biodiversity. The artificial lighting, noise, or vibrations that may be associated with these venues and sporting events can disorientate animals or discourage them from staying in the area. Aside from the physical 'footprint' of a new sports venue, features associated with a sports venue, such as security fences, roads, and parking lots, can create barriers to the movement of wild animals to important breeding, watering, or feeding sites; overhead cables can present a collision or electrocution hazard to certain bird species; and the introduction of invasive and alien species and diseases can harm or oust native plants and animals.

Extracted from: Mitigating biodiversity impacts of new sports venues (2019) and Mitigating biodiversity impacts of sports events (2020). 
in 2018, which give a broad overview of the topic. ${ }^{4}$ The second guide in the series, Mitigating biodiversity impacts of new sports venues (2019), looks at the development of new venues for sports and their impacts on biodiversity. ${ }^{5}$ The third guide, Mitigating biodiversity impacts of sports events (2020), focuses on ways to mitigate biodiversity impacts associated with sports events. ${ }^{6}$ With adverse effects addressed, sports stakeholders can look to the positive impacts these spaces can have on urban biodiversity, which is the focus of this guide.

This guide is aimed at all stakeholders who have a direct or indirect role in promoting sports events in an urban context, in particular local authorities dedicated to the promotion of sports, but also sport events owners and organisers, sports federations, venue designers, developers and investors and schools, universities and corporations with significant areas of playing fields. Collaboration and partnerships among these actors will greatly reinforce the chance of success in bringing to life a different urban vision with people and nature at its core. Diverse organisations and actors can collaborate by playing different roles in pursuing goals of biodiversity conservation and urban enhancement, helping to overcome obstacles and challenges.

Local conservation organisations will play a crucial role for the successful implementation of these goals. They can contribute valuable knowledge on local biodiversity and existing resources, propose suggestions and mitigation recommendations, and take the lead in implementing conservation projects. Some improvements, such as the choice of native vegetation for landscaping, will depend on the local context, and consultation with local experts will be a necessary part of applying these strategies in a regionally appropriate way. Key opportunities may also differ by location and can be identified with help from local organizations. For example, sport venues in cities along important bird migration pathways may prioritize bird-safe design and creation of stop-over habitat. Ideally, collaborations should be formed early in the planning stage, so that input from diverse partners can help shape the design of sports venues and the measures for enhancing biodiversity.

4 https://doi.org/10.2305/IUCN.CH.2018.04.en

5 https://doi.org/10.2305/IUCN.CH.2019.02.en

6 https://doi.org/10.2305/IUCN.CH.2020.04.en 
7.

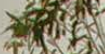

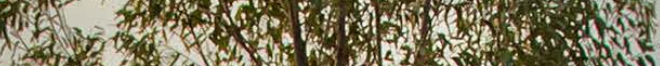

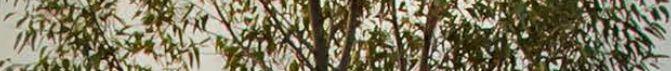

7i,

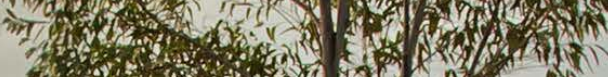
"ning

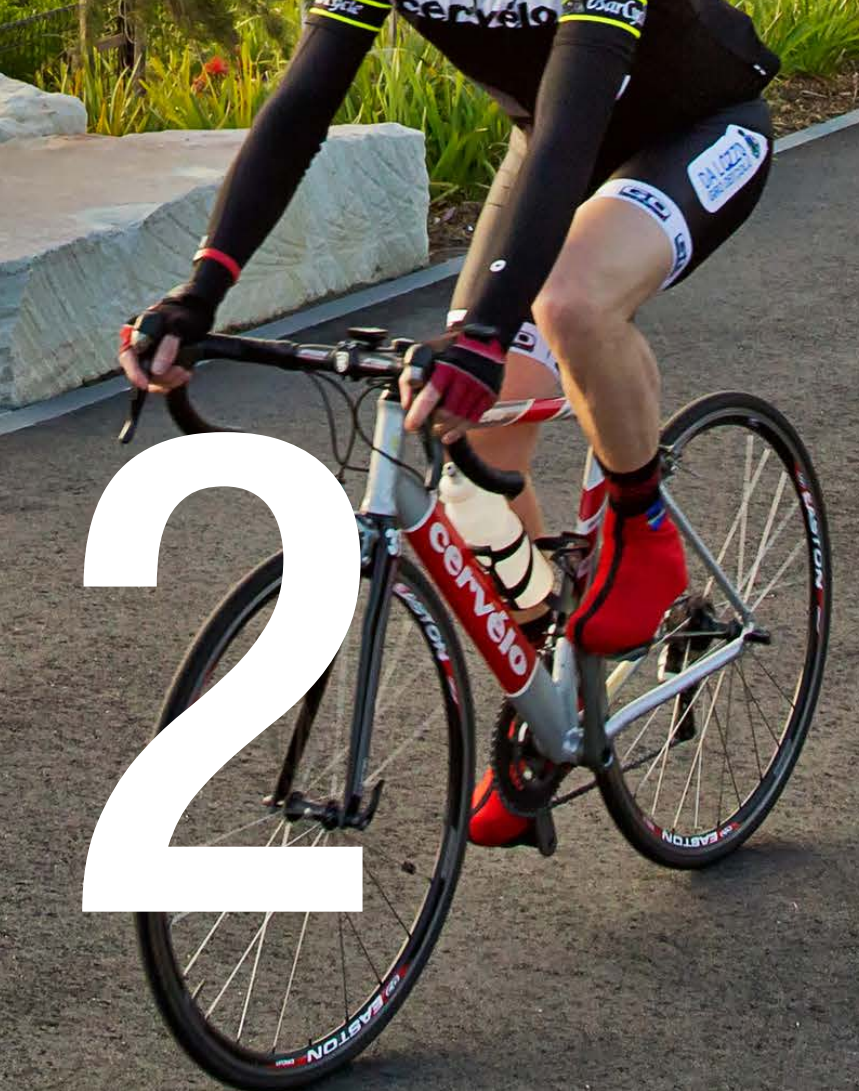




\section{A framework for building urban biodiversity}

Cities are sometimes considered to have little ecological value, but they can actually support substantial biodiversity when designed to reflect features present in natural ecosystems. In a recent report, seven elements of urban form and function essential for supporting nature in cities were identified. Drawing on research from cities around the world, Making Nature's City: A Science-Based Framework for Building Urban Biodiversity (hereafter referred to as 'Framework') has synthesised findings from global scientific literature and highlights the following elements: habitat patch size, connectivity across the urban landscape, quality of the landscape matrix surrounding a habitat patch, diversity of habitats available, native vegetation, special resources like water and nesting locations, and wildlife-friendly management (SFEI, 2019).

Combined together, these elements can help cities meet the basic needs of wildlife, such as food, water, shelter and places to raise their young. Including these elements will also allow wildlife to move through the urban landscape and fulfil the needs of different life stages, maintain genetic connectivity across the landscape, and adapt to seasonal and long-term environmental changes. Cities with these features in place can support nature by providing sufficient, connected and high-quality habitat. While quantification of biodiversity in cities can be challenging, scientific research suggests that improvements to the seven elements in urban areas will help promote greater diversity and abundance of wildlife in cities. Case studies show that they are already being implemented in many cities around the world, and that they can be readily incorporated into the broader green infrastructure of cities. The benefits are not just for wildlife but also for cities' ecosystem services, and include cleaner air and water, temperature regulation, improved physical and mental health, and better outdoor experiences (Taylor \& Hochuli, 2015). Thus, the seven elements can be used to guide planning efforts and identify opportunities to support the many benefits of well-functioning urban nature (Figure 1).

Sports federations and venue owners and operators have a special opportunity to improve and expand elements to support biodiversity. Many diverse types of green spaces in cities are developed and maintained for sport events, and thus, sports, venue owners and operators, and cities can work together as stewards of urban nature. While one sport venue alone can have a small impact on local biodiversity, the combined efforts of many actors can create city-wide beneficial effects. Similarly, improvements focused on a single element of the Framework can have limited benefits, while addressing multiple elements together can create compounding positive outcomes.

Local knowledge is an important part of applying the Framework to achieve positive biodiversity outcomes. While these elements have been shown to increase biodiversity in a wide range of cities, choices such as which native plants to include, what special resources are most beneficial and what types of habitat should be added are location specific. The specific context of a sport site, such as its location near a busy road or existing habitat for a rare species, will also determine which types of intervention are most important. Consulting with local experts can help guide interventions to be more impactful in the regional context.

Some elements may be easier than others for particular sports to address. For example, creating new urban habitat patches might only be feasible for larger-scale urban regeneration projects such as the development of urban sports parks. However, other elements like making small improvements to local habitat quality and providing special resources can be applied during retrofitting of existing sports facilities or by changing management practices at the local scale such as around fields in municipal green spaces. Indoor sports venues can contribute to urban biodiversity improvements through the addition of features on the outsides of venues, such as green roofs, planters, and living walls.

Even where events owners and organisers and sport federations have limited ability to make physical infrastructure changes, such as for events held in temporary venues, the prioritisation of the seven elements when selecting urban venues and promoting conservation values during event planning and staging can contribute to positive biodiversity 
outcomes. With the influence that sports can have on city residents, sports federations and events owners and organisers have the opportunity to communicate about urban biodiversity, as well as to make physical changes to the landscapes they manage (McCullough \& Kellison, 2014).
In the following sub-sections, each element of the Framework is described in detail, including how different sports can apply some of the elements alone or in combination to create a positive legacy for urban biodiversity. Each element is linked to relevant case studies included in section 5.

Figure 1. Elements that support urban biodiversity

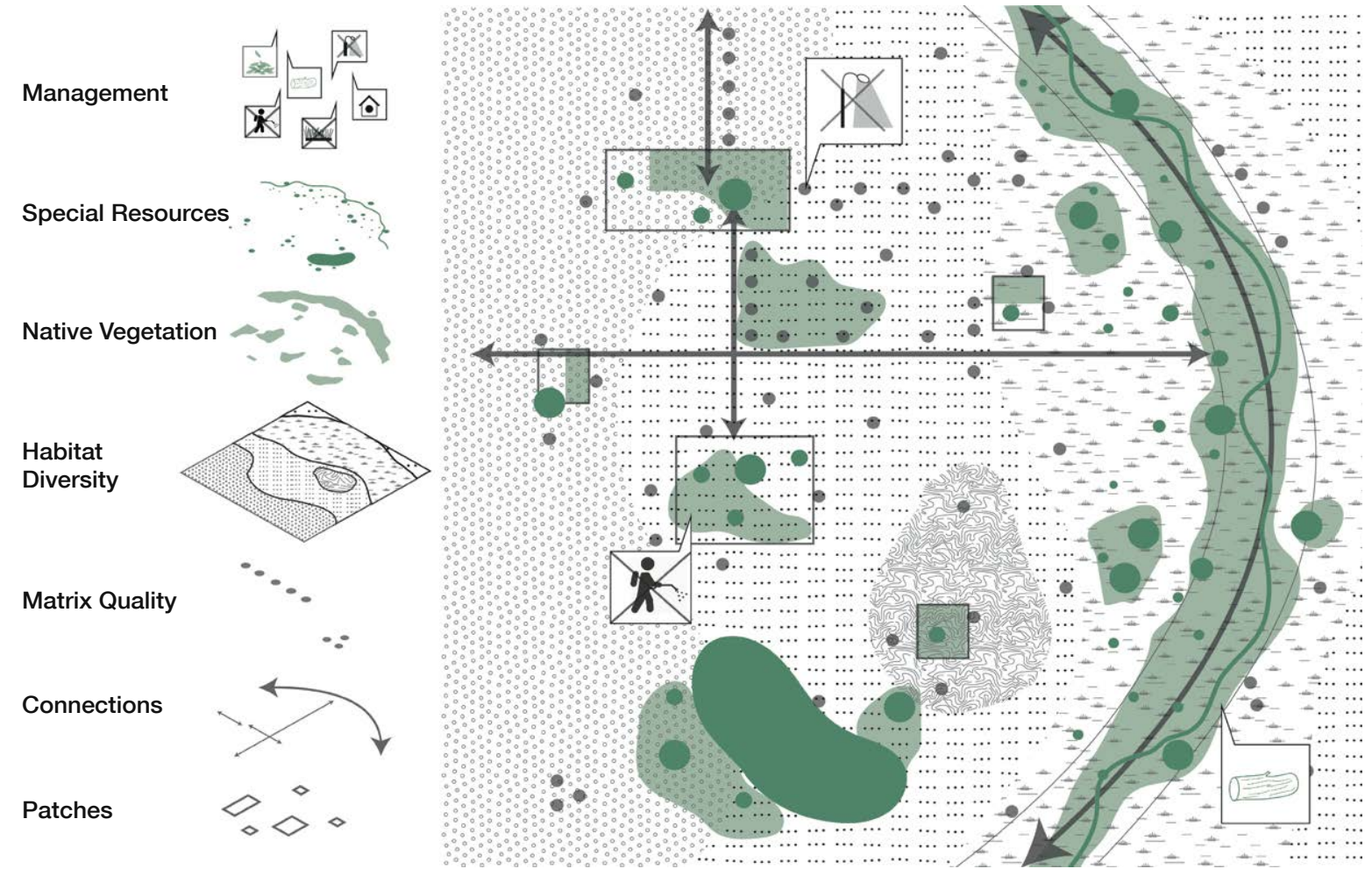

Source: Adapted by the authors from SFEl (2019).

Notes: These elements work at different spatial scales and overlap on the landscape to create a city that supports both people and biodiversity.

\subsection{Patch size}

Patch size, or the size of a green space in a city, is a fundamental determinant of how much biodiversity a space can support (Beninde et al., 2015). Larger patches tend to have greater habitat diversity and larger, more resilient wildlife populations. Green spaces over 4 hectares (10 acres or about five and a half soccer fields) in size can support significant biodiversity and act as local biodiversity hubs. Smaller green spaces can function effectively as habitat patches down to 0.8 ha (two acres, or slightly larger than a soccer field), below which species richness rapidly declines. Patches over 53 ha (130 acres, or about the area of 72 soccer fields) in size can have special significance for supporting regional biodiversity, and some species may only be found in these very large patches. Migratory and highly-mobile species, such as songbirds, hedgehogs and bobcats, particularly benefit from bigger patches.

Opportunities for sports: When choosing locations for new urban sporting facilities, consider how the facility can impact patch size. Locating a new sports venue with biodiversity-supporting features near existing green spaces can enhance the effective patch size of both the existing and new spaces, especially if the development site started with limited biodiversity value. If remnant natural vegetation exists within the new facility boundaries, prioritise the preservation and expansion of these 


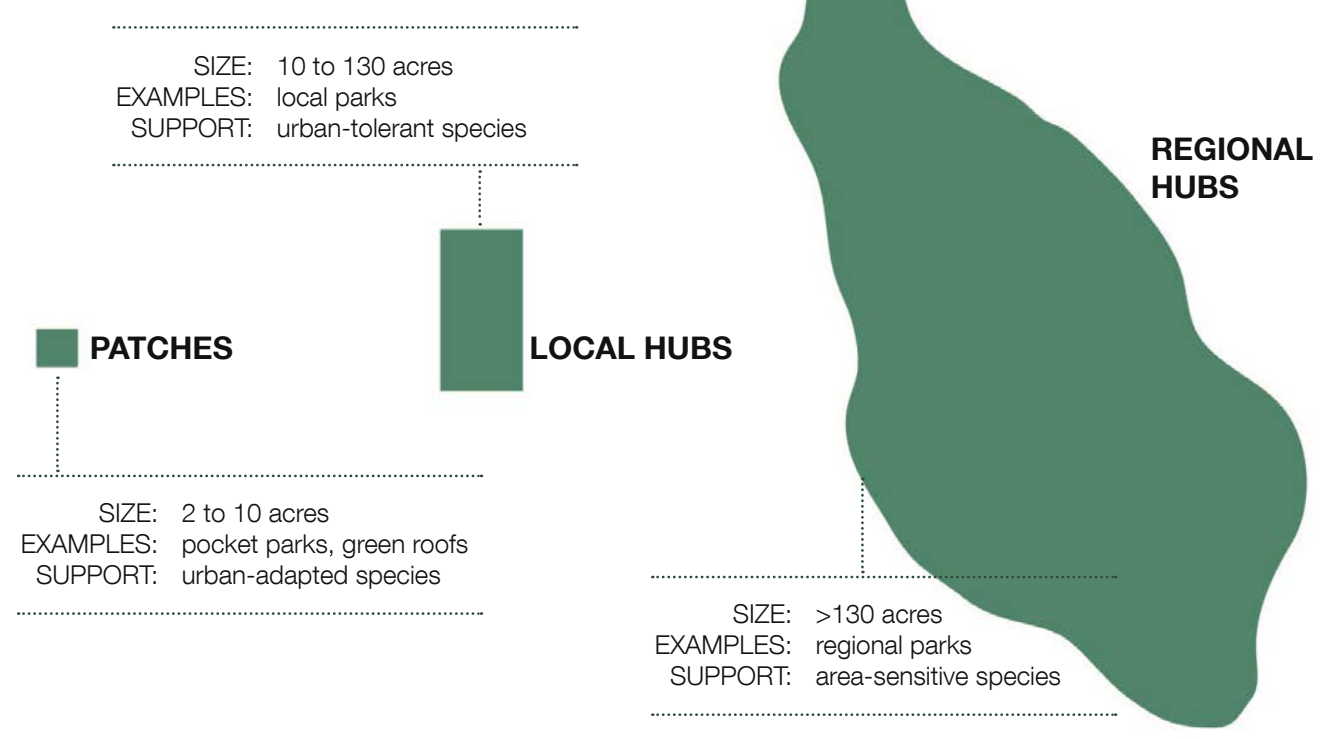

Source: SFEI (2019, p. 25).

Notes: Small patches of 0.8-4 ha (2-10 acres) in size can support some urban-adapted species; medium- sized patches of 4-12 ha (10-130 acres) in size can support more urban-tolerant species, and large regional hubs over 12 ha (130 acres) can support the broadest range of species.

remnant patches to increase their conservation value. Additionally, adding a large new facility in an urban area where no green space previously existed has the potential to create an entirely new local hub for biodiversity, which will have compounding benefits with increased connectivity and matrix quality in the surrounding area. Balancing hardscapes with green landscaping, planting contiguous areas of native species, preserving native habitat where it exists, and employing conservation-friendly management practices can help transform a sporting facility into a habitat patch for biodiversity.

\section{Case studies:}

- 5.1: Paris 2024 Planning (France)

- 5.2: Queen Elizabeth Olympic Park (United Kingdom)

- 5.3: Le Golf National (France)

- 5.4: Spring Creek Rowers (Australia)

- 5.5: Vancouver Olympic Village Habitat Island (Canada)

- 5.10: Habitat conservation at the Kenilworth Racecourse (South Africa)

\subsection{Connections}

Connectivity is one of the most important features for preserving urban wildlife populations (Beninde et al., 2015). Connections are features that facilitate the movement of plants or animals across the landscape and through the urban environment, such as green corridors along waterways, minimally maintained vegetation along railways, or strips of vegetation linking larger green spaces. Green roofs, living walls, coordinated private garden improvements, and closely spaced parks can also increase connectivity through the urban landscape by creating stepping stones for mobile organisms like birds and flying pollinators. In cities, buildings, hard surfaces and vehicle traffic can present barriers to wildlife movement, which can lead to small, isolated and less resilient populations. Enhancing connectivity through urban spaces can especially benefit larger, wide-roaming animals, such as bobcats and dingoes, species that rely on different types of habitat across seasons or life stages, such as salamanders and frogs, and species that are unable to move across urban barriers, such as hedgehogs. 


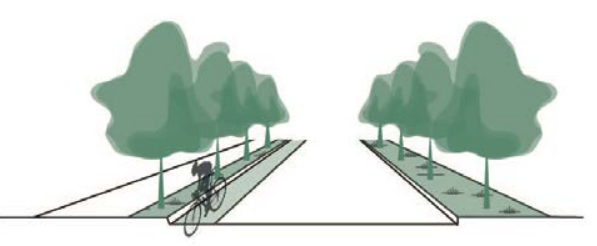

GREEN STREETS

LEVEL: Local Corridor

FUNCTION: Promote local movements and connect patches or larger corridors

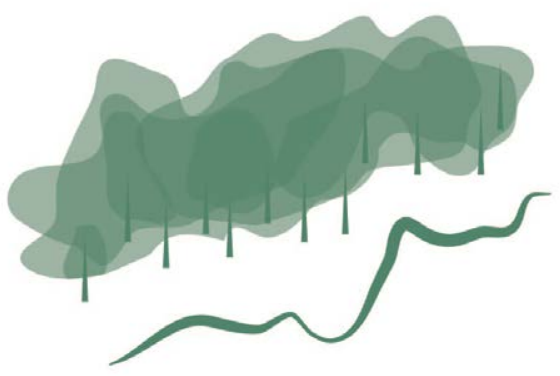

RIPARIAN CORRIDORS

LEVEL: Regional Corridor

FUNCTION: Promote regional movement across cities

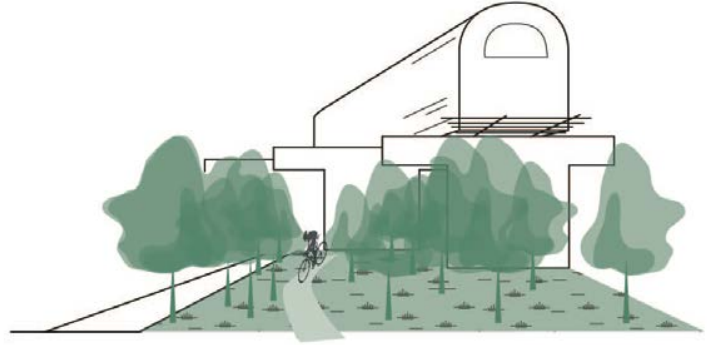

GREENWAYS

LEVEL: Local Corridor

FUNCTION: Promote local movements and connect patches or larger corridors

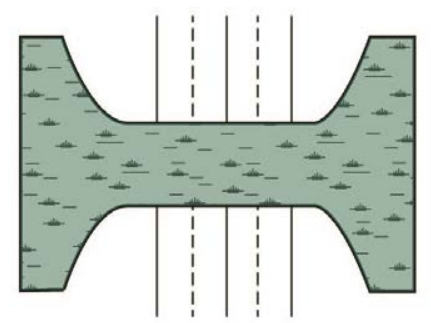

WILDLIFE CROSSINGS

LEVEL: Barrier Reducer

FUNCTION: Reduce road-related mortality

Source: SFEI (2019, p. 31).

Notes: The suitability of these features for enhancing urban connectivity depends on the existing barriers and the species of interest.

Opportunities for sports: Urban corridors that benefit biodiversity are also often preferred routes for urban sports, such as marathons and cycling events. High-quality greenways that enhance connectivity across the landscape can be ideal spaces for sport, as they can have improved air quality, reduced temperatures, and greater aesthetic appeal compared to urban roads (Livesley et al. 2016). They can also be part of sustainable transportation plans for sports venues by encouraging pedestrian and bicycle transportation to events. In collaboration with cities, landowners and local conservation groups, sporting events like road races or cycling events can provide a rallying point around which to design improved green infrastructure, such as street trees, native plantings and rain gardens (small depressions with native plantings designed to catch and infiltrate rainwater) along event pathways. Similarly, construction of new venues can include connectivity corridors as part of active mobility strategies. In addition to providing usable corridors for wildlife dispersal, designing attractive, healthy and shaded routes may boost venue or event reputations and be especially valuable in regions subject to frequent heat waves.

\section{Case studies:}

- 5.1: Paris 2024 Planning (France)

- 5.2: Queen Elizabeth Olympic Park (United Kingdom)

- 5.3: Le Golf National (France)

- 5.6: Stadium Green Roofs (Multiple countries)

- 5.7: Oriole Garden (United States) 


\subsection{Matrix quality}

Matrix quality refers to the diverse, smaller habitat elements in the urban environment that can work together to support ecological processes, increase overall connectivity between green spaces and enhance the ability of larger patches to support biodiversity. Because they are smaller than patches or corridors, these elements may not support large wildlife populations themselves, but they are important for the ability of wildlife to move through and forage in cities (Baum et al., 2004). Matrix elements can be aligned around patches or corridors to improve their value, or placed in groups to form habitat complexes. Some examples of features that improve matrix quality include street trees, green roofs, commercial landscaping and improvements to residential yards or private gardens. Flying animals like birds, bats and pollinating insects can especially benefit from improved matrix quality, as can other species that are able to live in and move through cities and thus take advantage of small favourable patches.
Opportunities for sports: Grassy playing fields dot the urban landscape and, accordingly, have significant potential to improve the overall matrix quality of a city. While playing surfaces are maintained for sport performance, opportunities abound at the periphery. Using grass rather than artificial turf has far more potential for supporting biodiversity (Francis, 2018), although this difference includes maintenance trade-offs as well. Reducing mowing frequency and chemical use on lawns and grassy fields to allow slightly longer grass and flowers can benefit pollinators like bees and butterflies, while also reducing pest problems and maintenance costs (Watson et al., 2019). Complementary native plantings around the edges of sport fields can further transform these spaces into pollinator habitats and improve overall urban matrix quality for species like birds and bees. Strategic tree planting can shade viewing areas for spectators, while also supporting other species. Green roofs and living walls on sports buildings can provide food and

Figure 4. Coordinated matrix improvements

Between patches can increase patch connectivity

Around patches can increase the effective size of patches

Grouped between patches can create habitat complexes that act as stepping stones
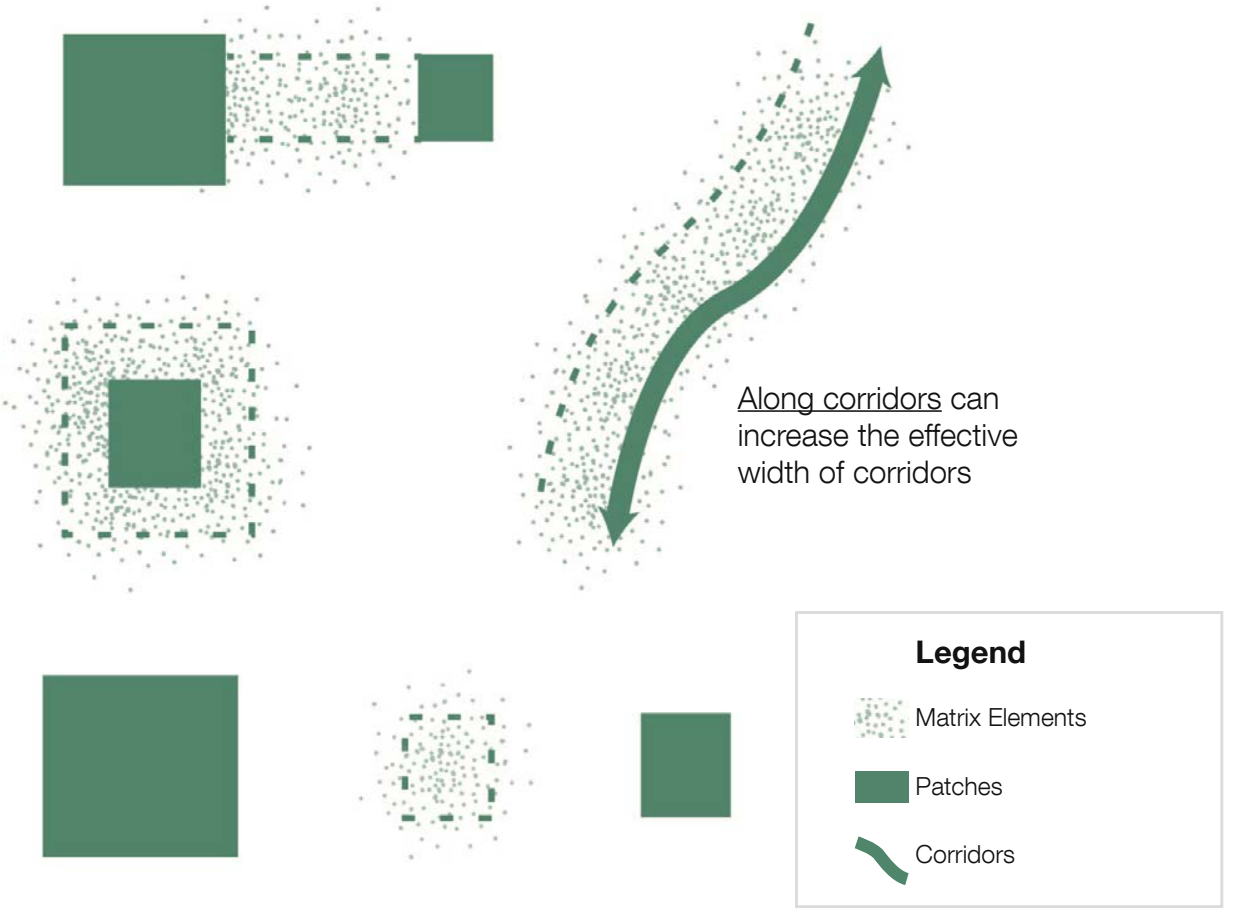


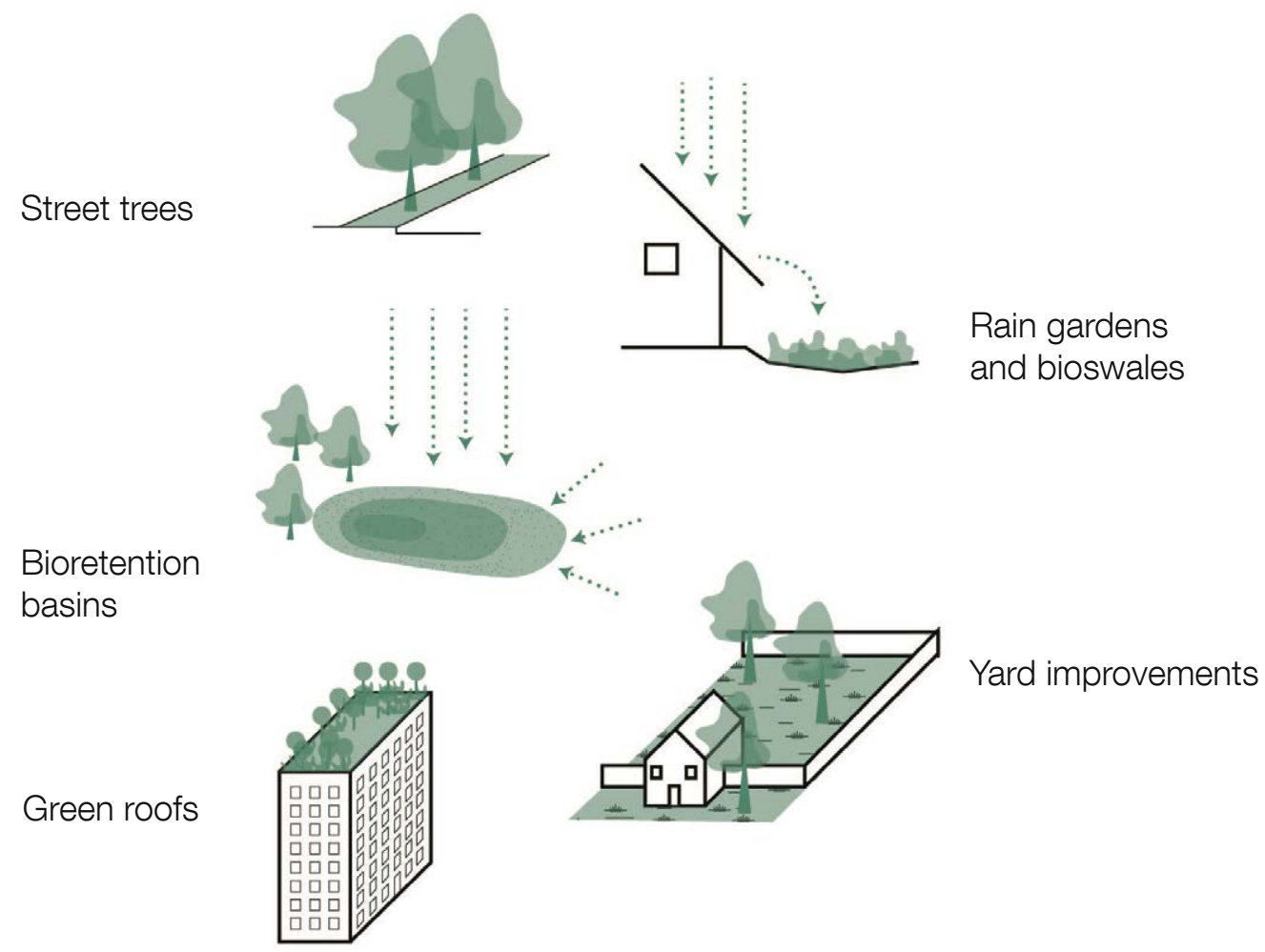

Source: SFEI (2019, p. 37).

Notes: Grouped improvements can create habitat complexes that act as stepping stones between larger patches, increasing connectivity and effective patch size.

shelter for birds and pollinators, too. Rain gardens in parking lots and around fields can provide further habitat improvements, while containing run-off and improving drainage. Improving the biodiversity value of the many pitch-based sports fields in cities is a clear opportunity to make advances in urban matrix quality.

\section{Case studies:}

- 5.1: Paris 2024 Planning (France)

- 5.5: Vancouver Olympic Village Habitat Island (Canada)

- 5.6: Stadium Green Roofs (Multiple countries)

- 5.7: Oriole Garden (United States)

- 5.8: Tree Planting (Multiple countries)

\subsection{Habitat diversity}

Urban biodiversity depends on habitat diversity, which refers to the type, number and spatial arrangement of habitats within the urban area, as well as the structural complexity of habitats. Many species need access to multiple types of habitat across days, across seasons or as they move through their life cycle. Therefore, landscapes with diverse habitat types can support greater overall biodiversity (Tews et al., 2004). Fine-scale habitat diversity, such as the presence of woody debris on the ground, an intermediate shrub layer and a tree canopy layer in a wooded park, is also associated with greater local biodiversity. Including native habitats that are uncommon can be particularly influential for supporting specialist species, which rely exclusively on a particular type of habitat and may be especially vulnerable to habitat destruction. For example, many species of salamanders and frogs need very specific habitats and cannot survive without them. Local experts can identify key habitat types for a particular area, which may include habitats that were historically present in the region. 
Figure 6. Habitat diversity at different scales

Zone A

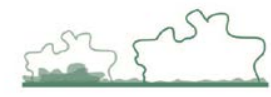

LEVEL: site scale

BENEFITS: provides habitat

heterogeneity and structure

Zone B
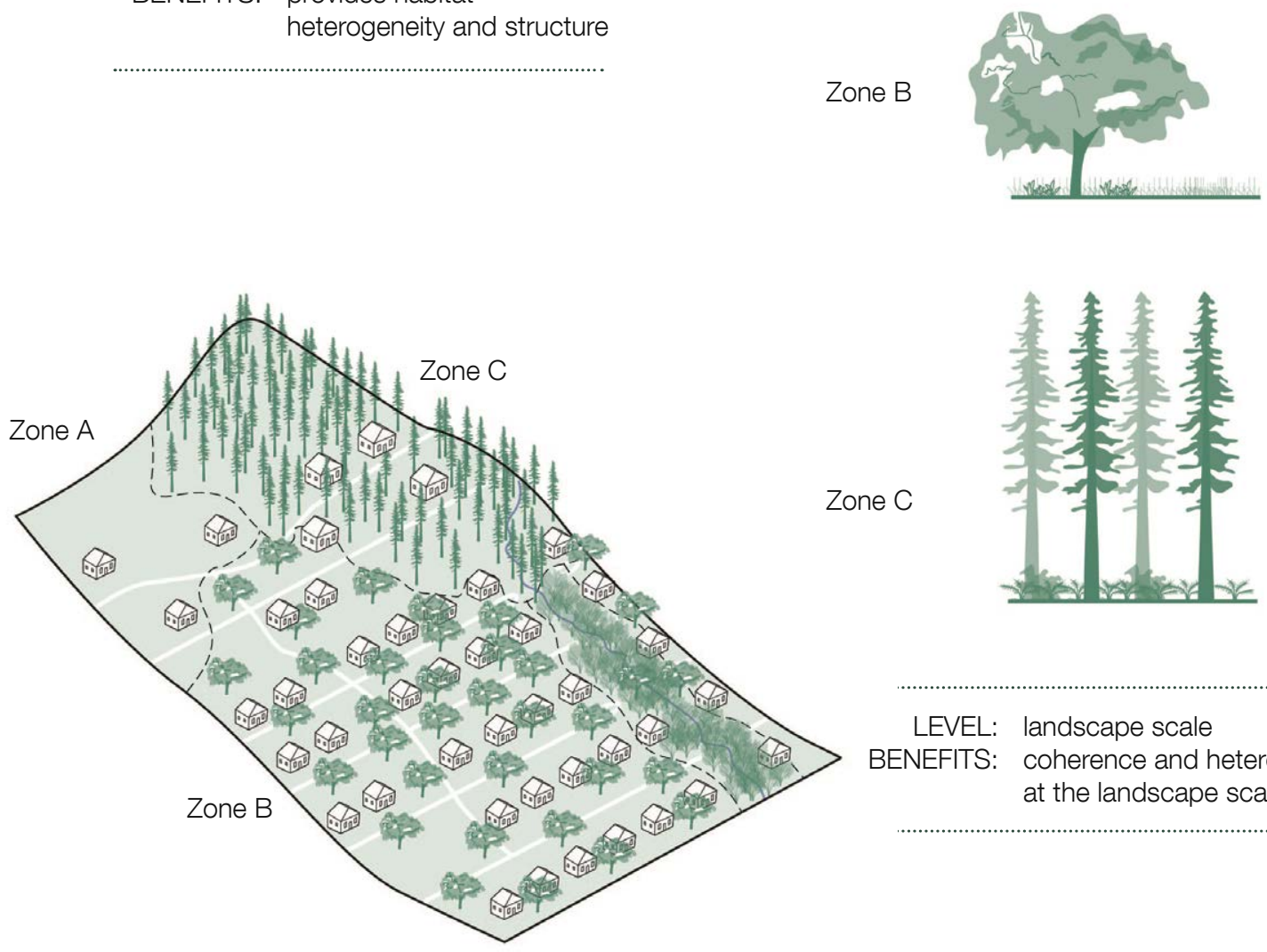

LEVEL: landscape scale

BENEFITS: coherence and heterogeneity at the landscape scale

Source: SFEI (2019, p. 40).

Notes: Different habitat types and structures, as shown by Zones A, B, and C, can provide an array of resources to support a variety of species at the site and landscape scale.

Opportunities for sports: Golf courses are large urban or semi-urban spaces that by design typically contain grassy, wooded and water features. With attention to how these features function for biodiversity, golf courses can readily provide a range of share habitats for urban wildlife. Some of the challenges for improving diverse habitats on golf courses include decreasing chemical run-off and pond eutrophication to support healthy aquatic and riparian habitat, and locating features like shrub patches strategically to improve rather than hinder course aesthetics and playability. As with grassy playing fields, decreased mowing frequency off the fairway can support pollinators, and unmowed wildflower meadows can create beautiful vistas where space allows. Beyond golf courses, other sporting venues can provide diverse habitats by varying the types of landscaping used in different spaces. For example, a venue might highlight different types of native habitat in an exhibition garden, or provide a water feature near grassland and shrub habitat. Training facilities may have additional space available to support a variety of natural habitats or combinations of native and other functional habitats, such as food gardens and playing fields.

\section{Case studies:}

- 5.1: Paris 2024 Planning (France)

- 5.2: Queen Elizabeth Olympic Park (United Kingdom)

- 5.3: Le Golf National (France) 


\subsection{Native vegetation}

Native species are those that have a long evolutionary history in a particular location and so may have special relationships with other species and the local environment. As a result, urban green spaces with more native plants tend to support greater biodiversity (Threlfall et al., 2017). One example of the unique value of native plants to support wildlife is the close relationship between North American monarch butterflies and milkweed, which constitutes the sole source of food for monarch caterpillars. Thus, planting milkweed advances conservation goals of supporting both native vegetation and charismatic native butterflies. The greatest benefits from native plants can be gained by selecting species that are also tolerant of the urban setting and are adaptable to predicted future climate conditions, which depend on local context and the available species native to the region. If native plants cannot be used due to lack of supply or incompatibility with landscape function, non-native species that can support pollinators, birds, and other wildlife should be chosen in favour of those that provide little biodiversity benefit.

Opportunities for sports: Sporting venues have a number of opportunities to add conservation value through native plants, from establishing patches of native habitat around sports venues to the use of native trees to provide shade for event participants. In addition to using native plants to enhance connectivity, improve matrix quality and increase patch diversity, sports have a unique opportunity to engage with native species as a tool to promote education and conservation action. Adoption of mascots that represent native species, especially those that may be less known or are only found in the event or team's location, can increase visibility and feelings of connection with species of conservation

Figure 7. Native plants to support wildlife

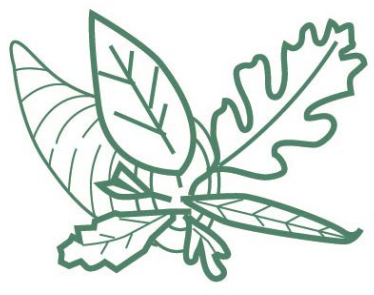

Diversity and abundance

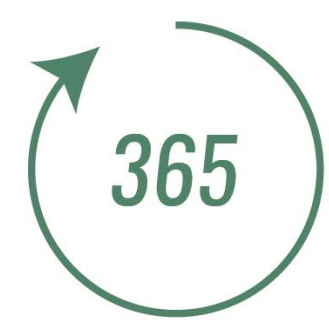

Year-round resources for wildlife
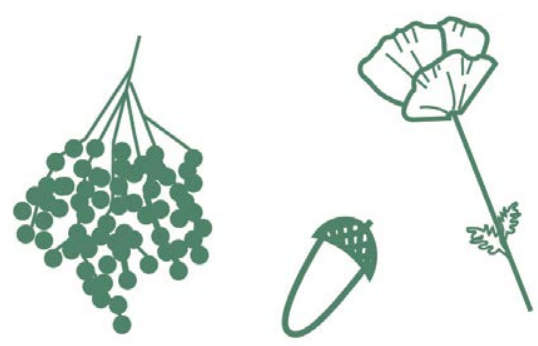

Flowers, fruits, and nuts

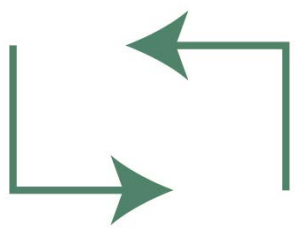

Complementary plants

Source: SFEl (2019, pp. 48-49).

Notes: Diverse native plant species can provide year-round resources to support wildlife. Specialist species may depend on specific complementary plants to meet unique needs. 
concern (Sartore-Baldwin \& McCullough, 2019). They can also provide a central focus around which to deploy other conservation strategies, such as habitat improvements or provision of special resources. Educational campaigns hosted by sport federations and event organisers can emphasise the importance of planting native species to promote positive action by fans beyond the bounds of the venue. Fostering a local sense of connection can be an important goal for urban conservation, and sports can act as an ideal institution through which to build connections with local nature (McCullough \& Kellison, 2016).

\section{Case studies:}

- 5.1: Paris 2024 Planning (France)

- 5.2: Queen Elizabeth Olympic Park (United Kingdom)

- 5.3: Le Golf National (France)

- 5.4: Spring Creek Rowers (Australia)

- 5.5: Vancouver Olympic Village Habitat Island (Canada)

- 5.6: Stadium Green Roofs (Multiple countries)

- 5.7: Oriole Garden (United States)

- 5.9: Monarchs in the Rough (United States)

- 5.10: Habitat conservation at the Kenilworth Racecourse (South Africa)

- 5.11: Showcasing local biodiversity outside Green Point Stadium (South Africa)

\subsection{Special resources}

Many species rely on special resources to meet their daily needs or during particular times of the year or stages of their life cycle. These resources are unique habitat features in the landscape, such as large trees, wetlands and open water. Water is necessary for nearly all species, and large trees can have disproportionate impacts on both ecological function and people's experience of a place (Stagoll et al., 2012; Hill et al., 2017; Cox et al., 2019). Some resources, such as holes in trees for cavity-nesting birds and woody debris piles for reptiles and insects, are typically removed in urban environments, but are important for specialist species that depend on these micro-habitats. Where possible,

Figure 8. Special resources
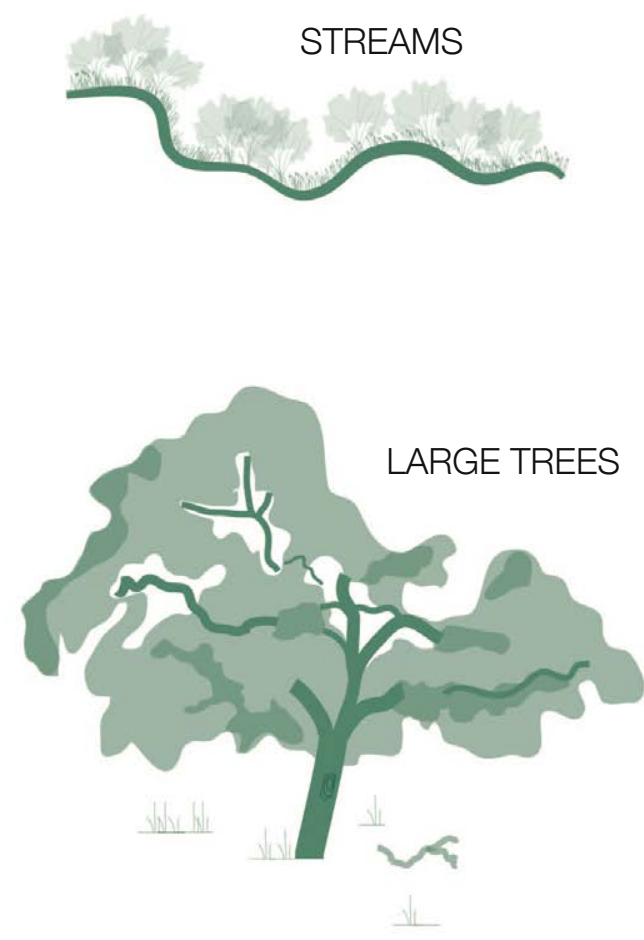
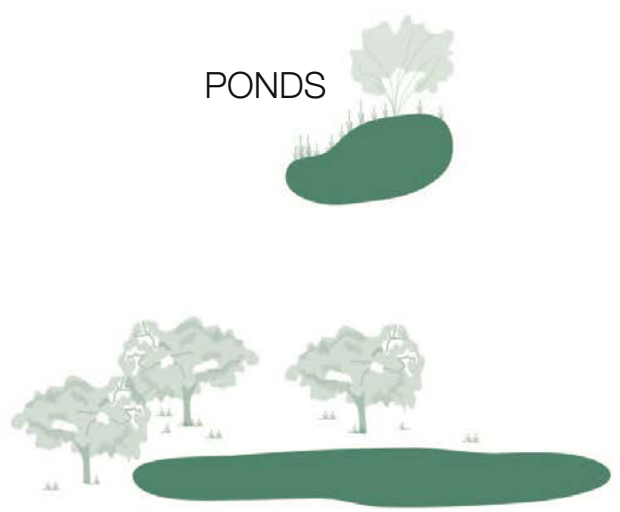

LAKES

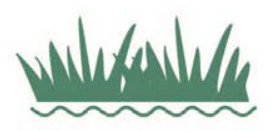

WETLANDS

Source: SFEI (2019, p. 52).

Notes: Special resources, such as large trees, ponds and wetlands, are important for a variety of species in the urban landscape. 
dead trees and wood can be valuable micro-habitats for a wide range of species if retained on the landscape. Adding features like large trees and water, or artificial structures approximating natural features like nest boxes, nesting bricks, and wood piles, can support these species and increase biodiversity in otherwise limited areas. Species in different areas have different special needs, which local conservation experts can help identify.

Opportunities for sports: Rowing, swimming, canoeing and sailing events held in urban waterways can serve as focal points for improving water and habitat quality through the removal of invasive species and the restoration of river, lake, estuary or harbour habitats. Enhancing the special resources provided by waterways and riparian areas can benefit urban biodiversity, while also improving sporting experiences through cleaner, more appealing venues. Providing bird boxes or materials and locations suitable for nest-building can be popular activities, especially for teams with birds as mascots who want to develop strategies around these species. These types of features can be added to courtbased sporting events as well as on the exterior of indoor venues, where other improvements may be more difficult. In wet locations, rain gardens or bioswales in parking lots and around fields and courts can contain and filter excess water, while also providing habitat and resources to pollinators and wetland organisms.

\section{Case studies:}

- 5.1: Paris 2024 Planning (France)

- 5.2: Queen Elizabeth Olympic Park (United Kingdom)

- 5.3: Le Golf National (France)

- 5.5: Vancouver Olympic Village Habitat Island (Canada)

- 5.8: Tree Planting (Multiple countries)

- 5.9: Monarchs in the Rough (United States)

- 5.10: Habitat conservation at the Kenilworth Racecourse (South Africa)

\subsection{Management}

Improving the many ways people manage urban landscape features can promote positive biodiversity outcomes. Management actions are many and varied, including pesticide and herbicide use, vegetation and soil maintenance, and the design of urban infrastructure. Often, beneficial changes to management can be made without major retrofitting and sometimes with a reduction in management costs. Where habitat cannot be added without negatively impacting other functions of an urban location, management changes are a key opportunity to improve the value of all kinds of landscaping for biodiversity. While many management choices are made to promote functional and

Figure 9. Management actions to support biodiversity

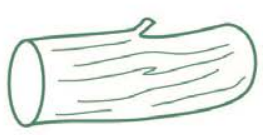

Downed logs

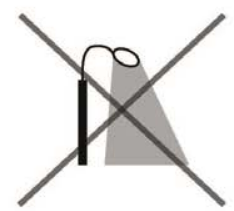

Limit light pollution

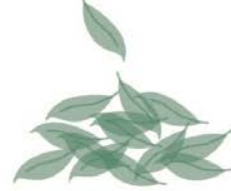

Leaf litter

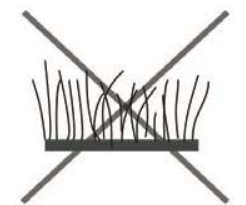

Minimize lawns \begin{tabular}{|llll}
\hline. & $\cdot$ & $\cdot$ & $\cdot$ \\
. &. &. & $:$ \\
. &. &. &. \\
. &. &. &. \\
. &. &. &. \\
\hline
\end{tabular}

Bird-safe windows

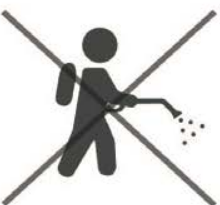

Reduce chemical inputs

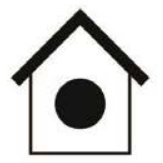

Bird \& bat nests

Source: SFEI (2019, p. 56).

Notes: Management actions can support nature by removing hazards and improving habitat quality 
recreational landscape uses, there are often opportunities for change that can meet the same goals while positively impacting biodiversity.

Opportunities for sports: When designing or renovating sports facilities, architectural considerations for biodiversity would include installation of bird-safe windows, incorporation of green roofs and use of water collection features. Bird-safe window choices can reduce fatal collisions and are an effective and simple strategy for retrofitting existing structures. Sporting events often attract large crowds and continue into the night, which can impact biodiversity via noise and light pollution. Designing spaces for athletic and biodiversity uses should consider these effects, and use sound barriers, reduced lighting, or blue/green lighting where possible, and particularly around features intended to attract or support wildlife. Using directed lighting and avoiding light near areas intended to support wildlife, such as bird boxes, pollinator gardens, etc., can help light-sensitive wildlife (Gaston et al., 2012). The value of water features to wildlife as a special resource or for habitat diversity improvement relies on management decisions about chemical inputs, which should be minimised around these features. Soil health, as the foundation of plant communities and wildlife support, can be improved in playing fields by leaving grass clippings in place where doing so would not negatively impact gameplay. If clippings are collected, they should be disposed such that excess nutrients from decomposing plant material do not drain into waterways. Reduced management, such mowing and chemical maintenance, of sections of golf courses and sports fields that are beyond the main playing surfaces can both decrease maintenance costs and benefit biodiversity.

\section{Case studies:}

- 5.1: Paris 2024 Planning (France)

- 5.2: Queen Elizabeth Olympic Park (United Kingdom)

- 5.3: Le Golf National (France)

- 5.7: Oriole Garden (United States)

- 5.9: Monarchs in the Rough (United States)

- 5.10: Habitat conservation at the Kenilworth Racecourse (South Africa)

- 5.11: Showcasing local biodiversity outside Green Point Stadium (South Africa) 


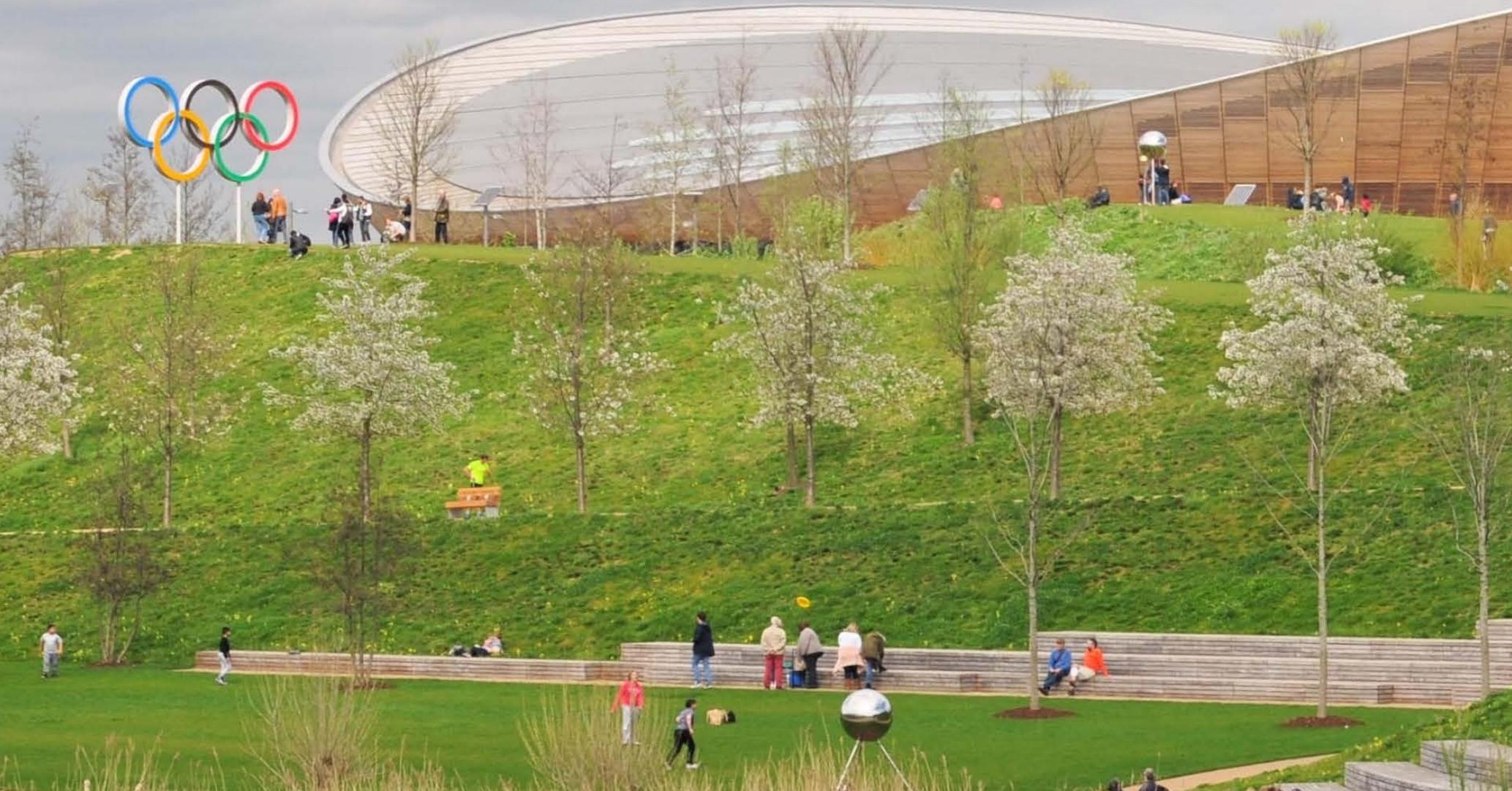

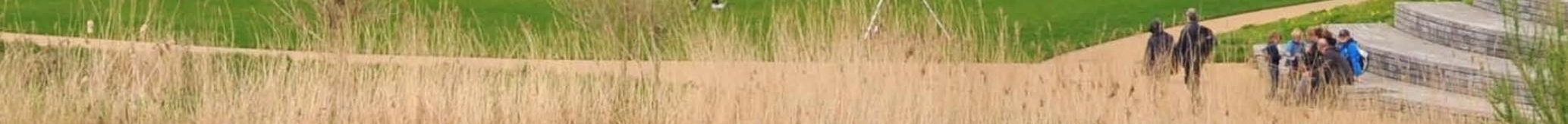
$=0$

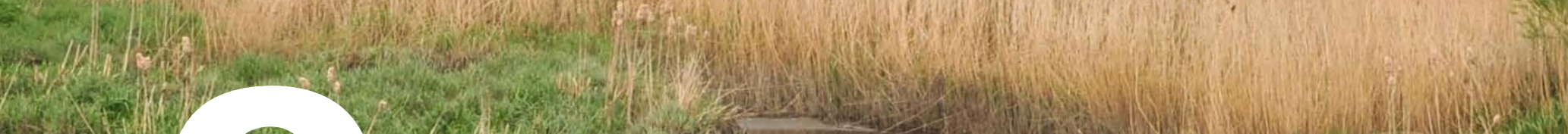

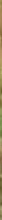
(2)

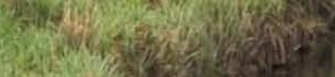

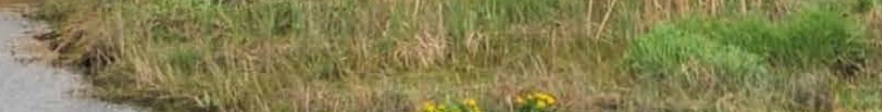
$x$ W (6006)

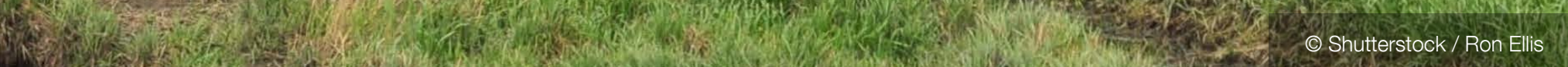

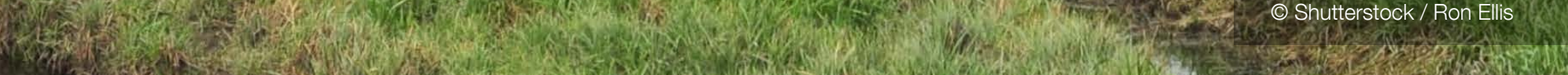

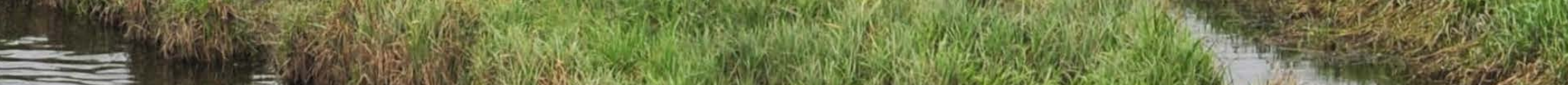

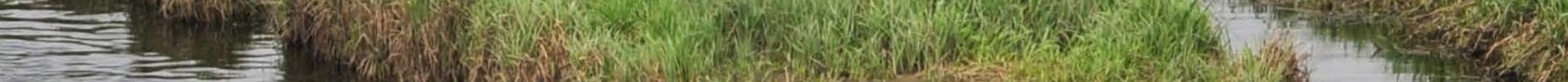




\section{Sports and urban protected areas}

Whether they are climbing cliffs, running trails or surfing breaks, people are drawn to protected areas to practice a range of sports with the promise of excitement, adventure and beauty. Protected areas (Box 2) generate and mediate flows of ecosystem products and services: medicine, food, clean air and fresh water. In addition to buffering the effects of climate change, such as heat stress, flash flooding and storm surges, protected areas give meaning - spiritual and physical - to proud cultures and cherished places.

By virtue of their ever-increasing proximity to population centres, urban protected areas are especially well placed to benefit society. Not only can they help relieve cities from the worst effects of climate change, these parks also provide relatively clean and restorative surroundings in which to exercise and escape the pressures of urban life. Their contribution to the physical and mental health of urban people is well-documented, profound and likely to grow in importance. Furthermore, urban protected areas offer the nearest and most authentic forms of nature that can be readily visited by urban people. In the face of rapid urbanisation, they serve as bridges to the natural world: a means by which to experience and appreciate biodiversity, and over time develop a conservation ethic (Box 3).

Certain objectives of urban protected areas - notably, to conserve native biodiversity while facilitating awareness and appreciation thereof - can strike a chord with the objectives of sports, unlocking powerful synergies. The below examples are intended to offer inspiration. While their collective scope extends far beyond the strictly urban realm, every example does at least include urban dimensions.
A reconnection with nature. Positive experiences in nature are known to engender a sense of ecological connection whilst fostering pro-environmental attitudes and behaviours (Teisl \& O'Brien, 2003). Urban protected areas are well-placed to facilitate such experiences, thereby building public and political support for nature conservation. For many people, the opportunity to participate in sports like hiking, climbing, trail-running and kayaking serves as a primary motivating factor for visiting protected areas and reconnecting with nature.

A spotlight on sites of natural wonder. By showcasing biodiversity to event participants and fans alike, sports practiced in natural areas can draw attention to the value and wonder of nature, as well as the threats facing it. For instance, on each of its 21 stages, the 2020 Tour de France promoted a Natura 2000 site to millions of viewers, including several urban Natura 2000 sites (Tour de France, n.d.). Meanwhile, sports stars are actively campaigning for a variety of conservation initiatives. Their efforts stand to benefit urban protected areas. Basketballer Yao Ming's repeated calls to end illegal wildlife trade (WildAid, n.d.), tennis player Nick Kyrgios's fundraising to aid recovery from the Australian bushfires (The Guardian, 2020), and sailor Hannah Mill's 'Big Plastic Pledge' campaign to beat plastic pollution $(I O C, 2019)$ are cases in point. Some sports spur new and additional safeguards for nature. By establishing a network of World Surfing Reserves, each supported by a Local Stewardship Council, the Save The Waves Coalition has effectively shored up protection for "outstanding waves, surf zones and surrounding environments around the world" (Save the Waves, n.d.). Some of the World Surfing Reserves including Punta De Lobos in Chile, lie adjacent to urban areas.

\section{Box 2. Definition of protected areas}

IUCN characterises a protected area as "a clearly defined geographical space, recognised, dedicated and managed, through legal or other effective means, to achieve the long-term conservation of nature with associated ecosystem services and cultural values" (Dudley, 2008). Urban protected areas are simply those that occur within or adjacent to cities. They do not include conventional urban parks, lawns, flowerbeds or sports fields. However, in terms of size, ecology and governance, they vary widely and may fit within any one of IUCN's six protected area management categories, from 'Strict nature reserve' (la) to 'Protected area with sustainable use of natural resources' (VI) (Trzyna, 2013). 


\section{A powerful partner for conservation action.} By partnering with conservation organisations on the ground, sports institutions can directly contribute towards biodiversity conservation in protected areas. Whether it is the National Football League (NFL) restoring degraded coral reefs off the coast of Key Biscayne, USA (Luscombe, 2020), the International Volleyball Federation (FIVB) retrieving and upcycling ghost fishing nets to use at urban tournaments (Good Net Project, n.d.), the 2020 Miami Superbowl Host Committee supporting the eradication of invasive alien species in urban protected areas such as the Florida Everglades (Luscombe, 2020), or an amateur lawn tennis club in Leicester, United Kingdom donating balls to create make-shift nests for flood-stricken urban harvest mice (BBC, 2013), sports institutions across the world increasingly recognise the benefits of a clean local environment and are prepared to play a part in protecting it.

A league of passionate teams. The practice of sport in urban protected areas increases eyes and ears on the ground to monitor wildlife and report hazards or early warning signs. Some enthusiasts collect and share environmental data to support the work of scientists and policymakers. Some volunteer to assist protected area managers in carrying out essential conservation work. Through the Shedd Aquarium's Kayak for Conservation programme, biodiversity experts guide volunteers along the Chicago River (Shedd Aquarium, n.d.) as they paddle and remove litter, spotting wildlife and employing monitoring protocols to collect species data. Their reports inform local conservation authorities on the health of the river ecosystem.

An essential source of revenue. It has been estimated that the world's protected areas, including urban protected areas, receive over eight billion visits a year, generating as much as US\$ 600 billion of spending and US $\$ 250$ billion in consumer surplus (Balmford et al., 2015). By paying entrance fees, purchasing activity permits, making donations, organising fundraising events and sponsoring conservation work, sports can bolster the budgets of urban protected areas. Indeed, in the pursuit of funding, urban protected areas may have a distinct advantage over more remote protected areas, given their relatively high visibility and visitation levels.

\section{Box 3. Addressing the pressures on urban protected areas}

As they inch closer, cities subject protected areas to intensifying 'urban edge effects' including light and noise pollution, air and water degradation, and the introduction of invasive species. Direct human impacts including trampling, poaching, littering, arson and vandalism also rise sharply (McDonald et al., 2009). Depending on where and how they are practiced, sports can have the potential to exacerbate or ameliorate these impacts. By 2030, $40 \%$ of protected areas are expected to lie within $50 \mathrm{~km}$ of a city (McDonald et al., 2018). To remain effective in the face of such rapid urbanisation, the management of protected areas must be reinforced and, in some cases, rethought entirely. Recognising the unique set of challenges and opportunities facing urban protected areas, the Urban Conservation Strategies Specialist Group of the IUCN World Commission on Protected Areas (WCPA) produced the IUCN Urban Protected Areas Profiles and Best Practice Guidelines (Trzyna, 2014). Drawing from case studies around the world, the guidelines offer practical tips for enhancing management effectiveness, maximising health and educational benefits for local people, and mitigating negative ecological impacts arising from cities. Protected area managers and sports stakeholders seeking to minimize conflict and maximise synergy may derive much value from the guidelines. 
चु 13.

$107 x^{\circ}=$

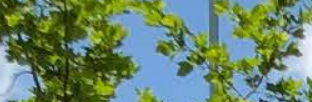

$-1 \times-x^{2}$

$x^{2}+x^{3}+x^{2}+x^{2}$

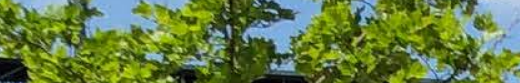

-

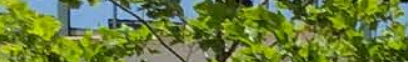

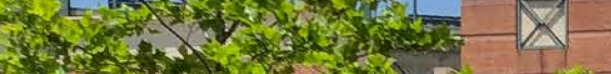

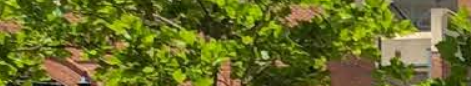

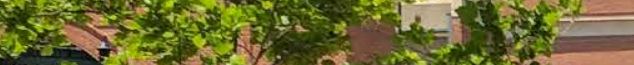

(1)

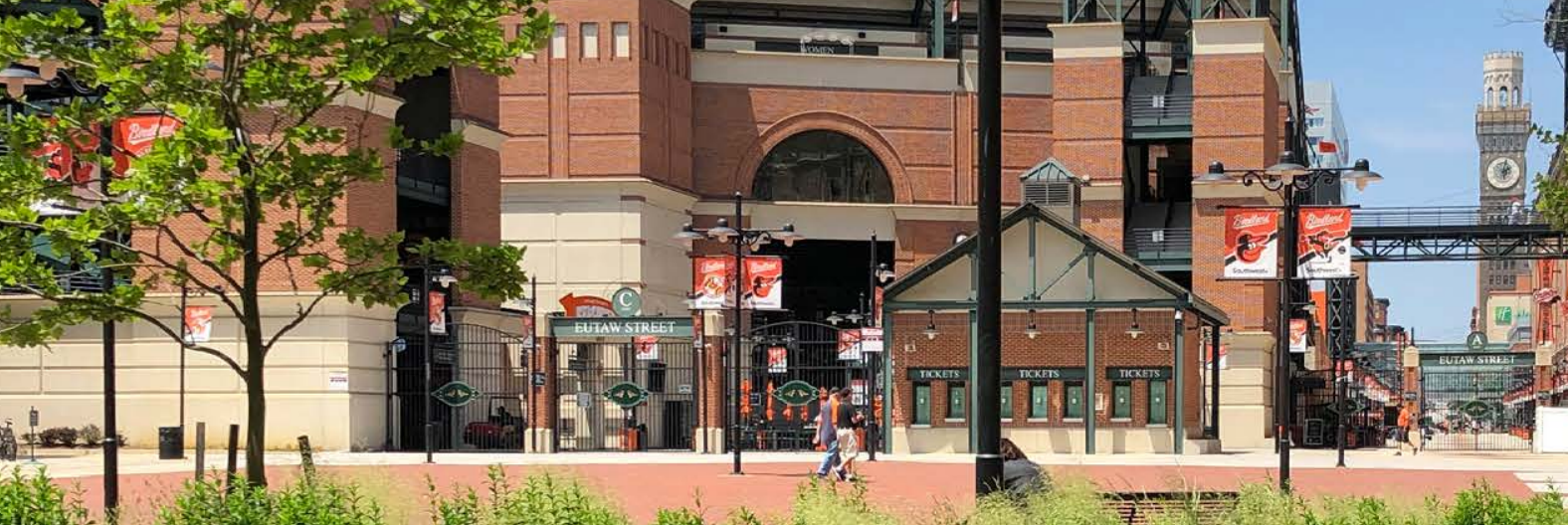

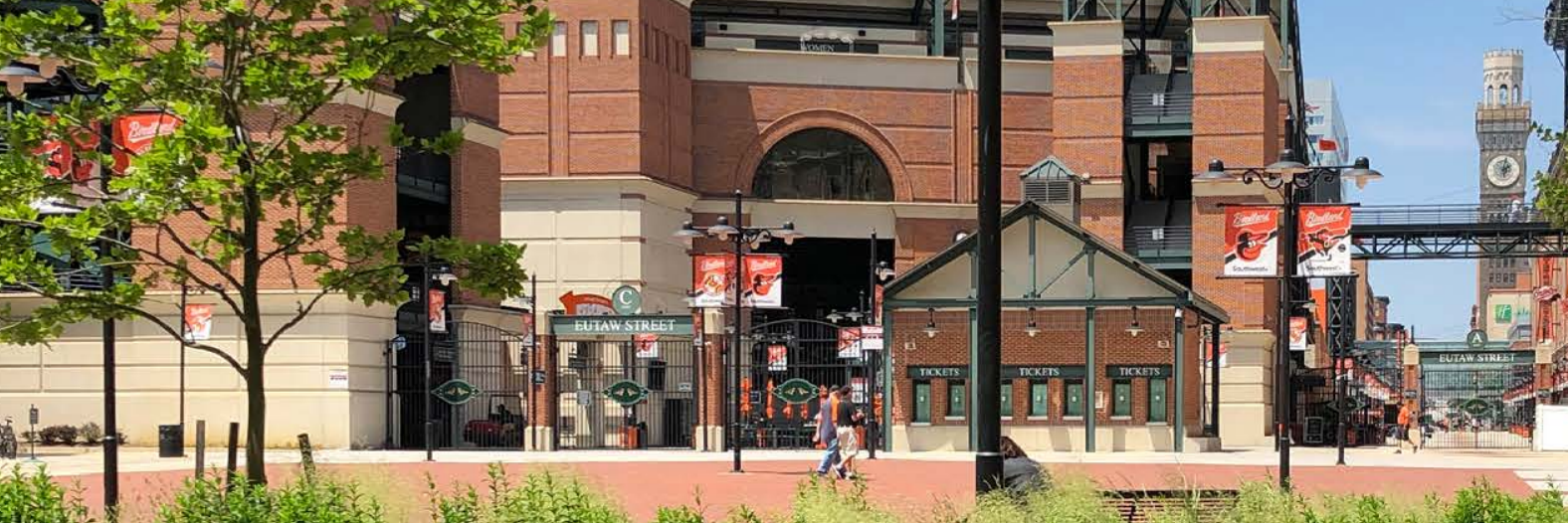

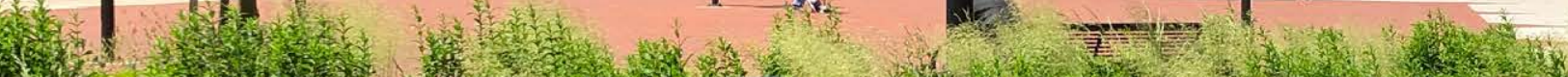

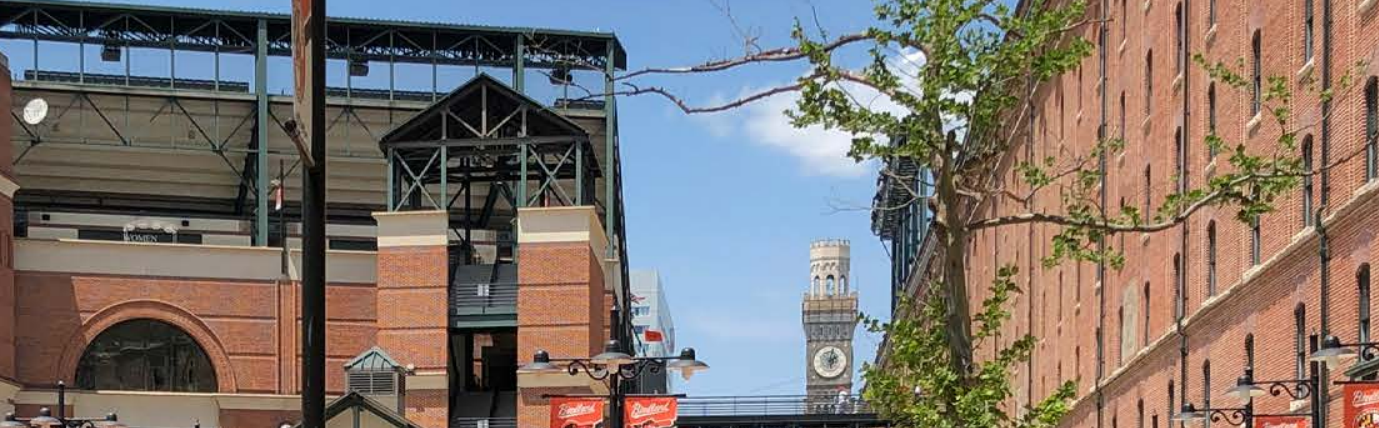

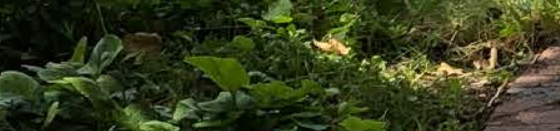

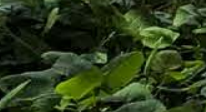

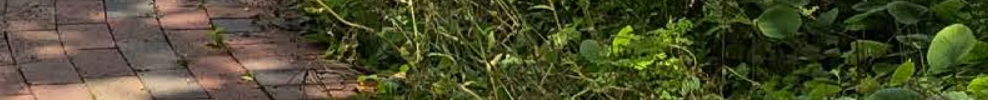

(2)

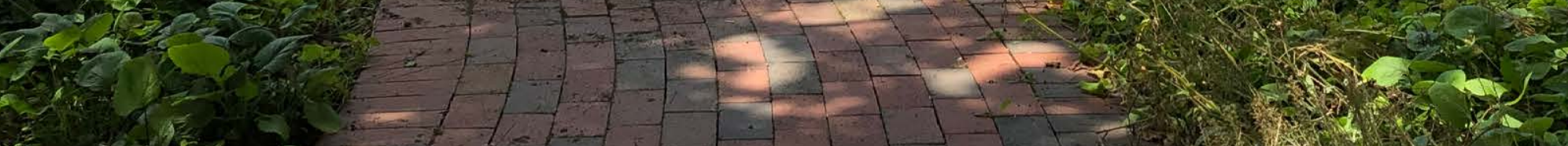

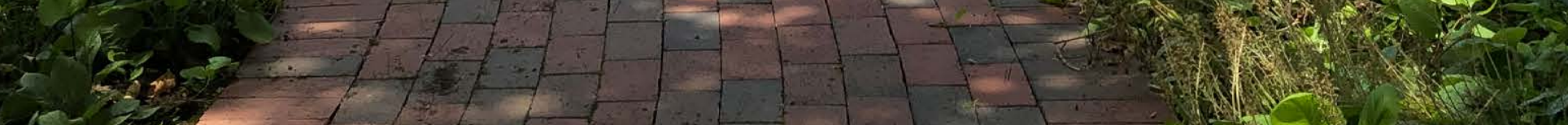

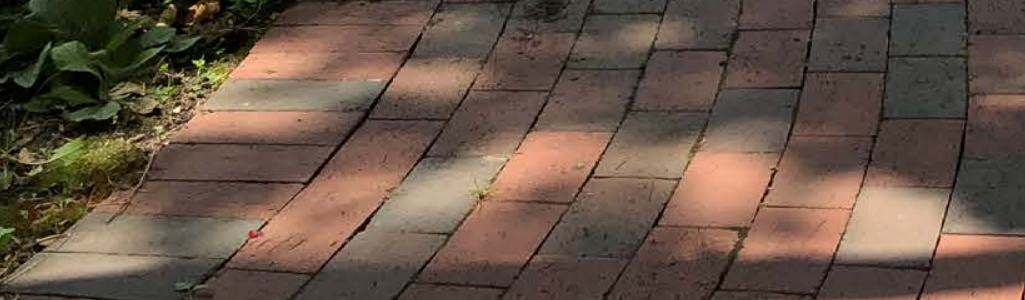




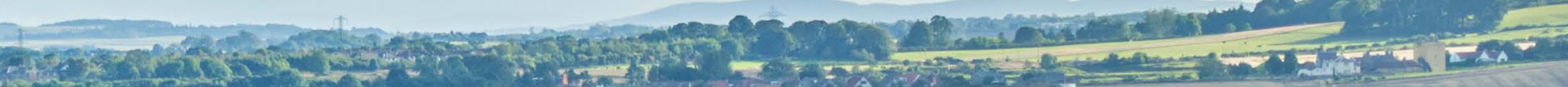
a z r

$$
\text { (1) =- }
$$

Cyts

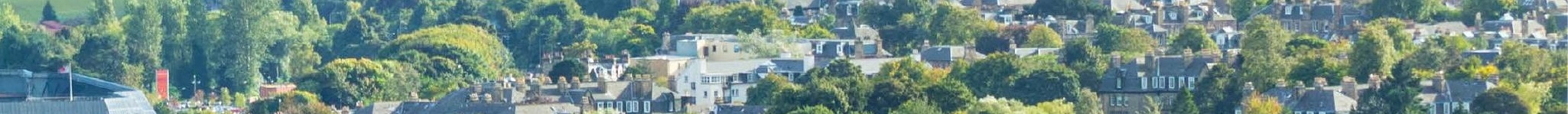

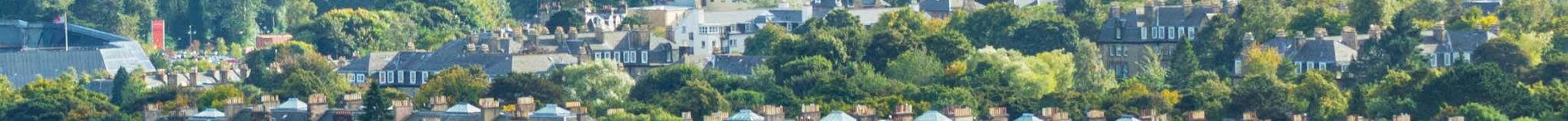

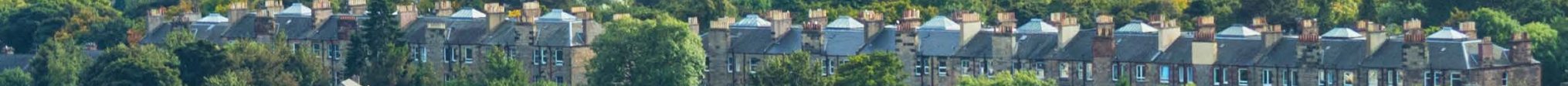

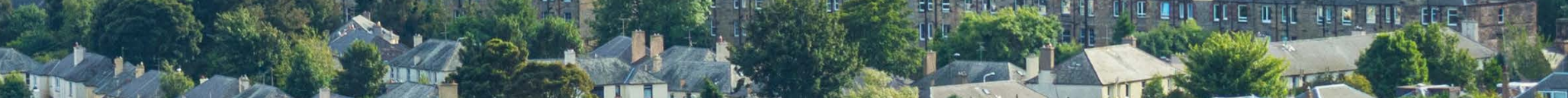

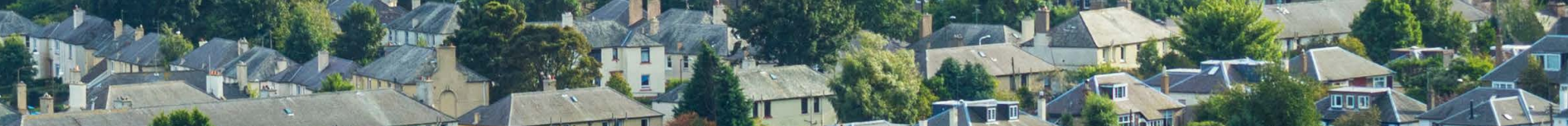

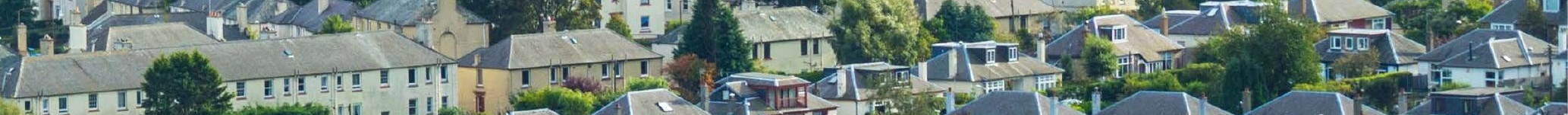

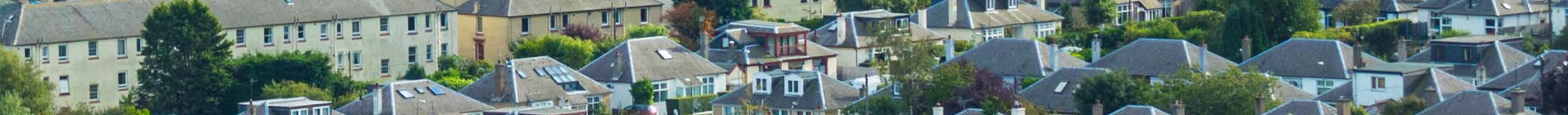

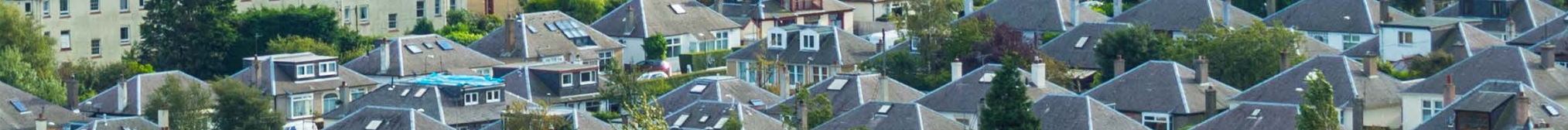

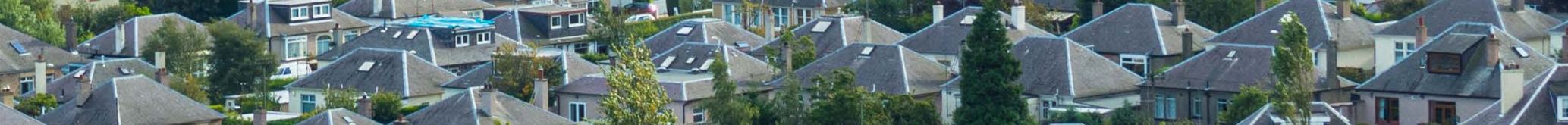

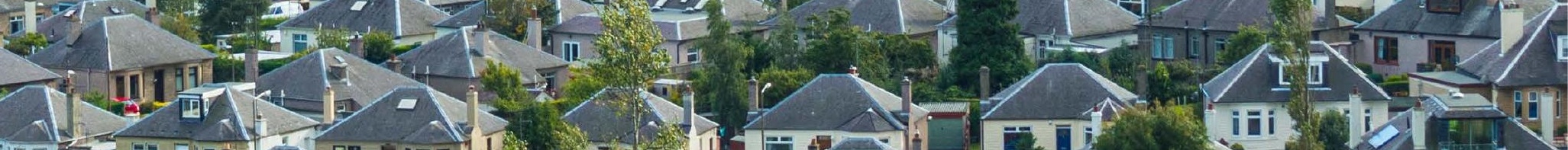

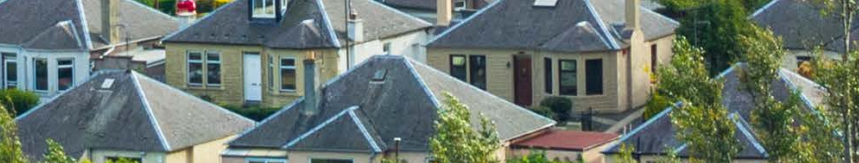

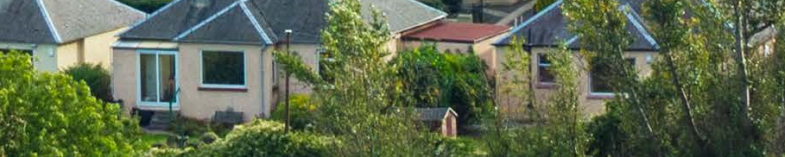
15.
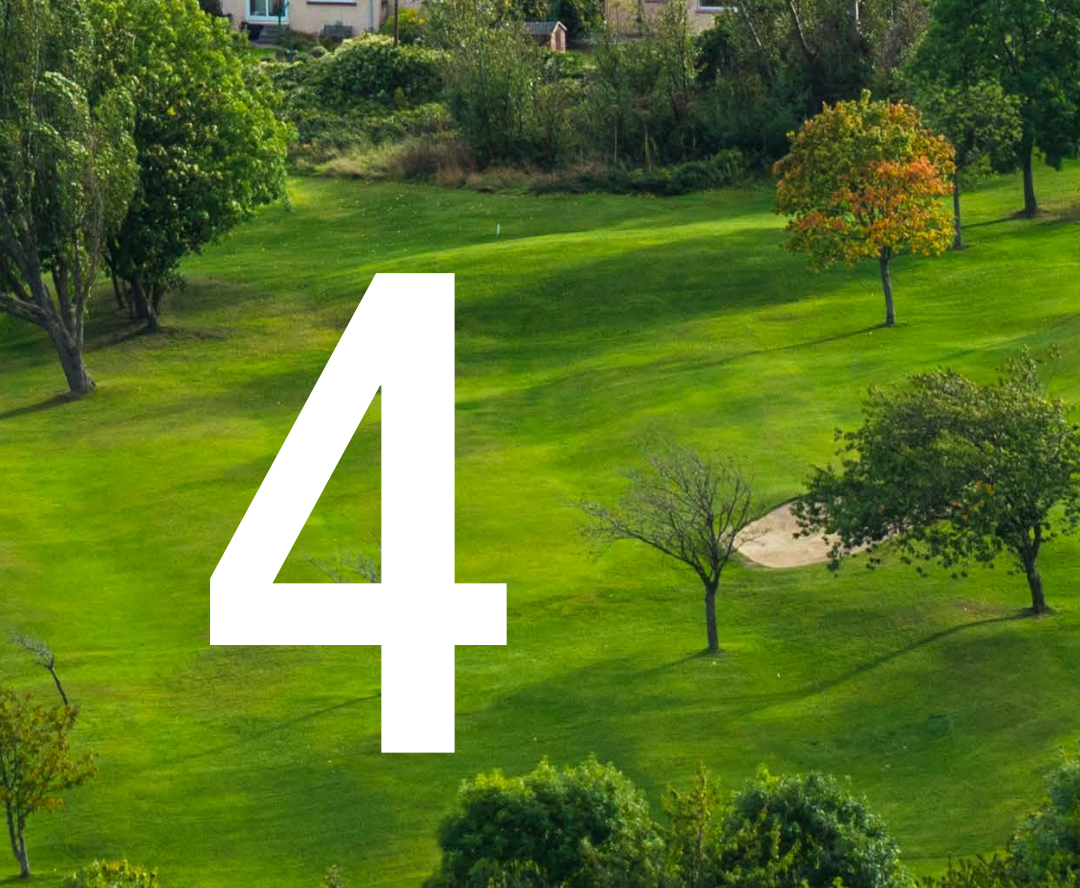

wathering

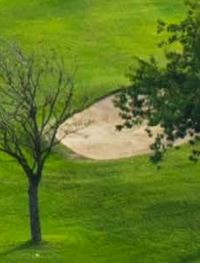

$\frac{1}{3}+2+5$

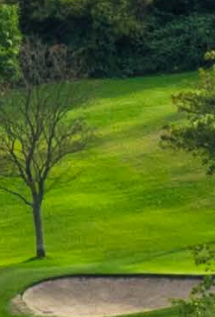




\section{Measuring success in building urban biodiversity}

Monitoring is an essential component of species and habitat management. Without monitoring, biodiversity trends, threats and opportunities would be difficult to identify. Monitoring enables the effective design and evaluation of conservation measures and can help to reveal the ecological performance of sports. With the appropriate tools at hand, monitoring the effects of sports interventions can be a positive and accessible way to both collect critical information and engage sports communities in understanding their environs.

The importance of biodiversity monitoring is enshrined in regulatory frameworks across the world, often implicitly as part of the environmental impact assessment (EIA) process. EIAs, which would apply to new venues and events, seek to identify, avoid and minimise negative environmental impacts of human activities. Monitoring can inform every step of the process: screening, scoping, impact analysis, mitigation, reporting, review, decision-making and post monitoring. Detailed guidance on how to mitigate the biodiversity impacts of sports events and new sports venues can be found in previous IUCN's Guides (Brownlie, 2019; Brownlie et al., 2020)

For monitoring biodiversity at existing venues, a number of considerations are worth taking into account. Since it is not possible to observe all species at a given site on a continuous basis, monitoring systems must be designed strategically. They must generate sufficient volumes of reliable data at appropriate intervals to enable credible assessment of impacts and progress that can meaningfully inform decision-making. Therefore, the selection and implementation of indicators should speak to the management objectives at a particular site and the potential impacts of site-level interventions. Monitoring may entail traditional manual surveys or make use of new technologies including low flying drones, camera traps and genetic bar coding.

If the intention of a monitoring system is to identify or measure causal factors of changes in biodiversity, then a broader suite of indicators may be warranted e.g. to measure human disturbance, noise, light and air pollution. In densely populated areas, it is especially important to pay attention to privacy laws and ensure that data collection efforts do not infringe on the rights of citizens.

A good example of a biodiversity monitoring system established by a sports institution can be found in France where Le Golf National has partnered with the French Natural History Museum to survey habitats (section 5.3).

A wealth of tools is available to support monitoring efforts at a range of scales. They comprise indicators for assessing biodiversity, ecosystem services, governance and management, which may be useful for sports institutions, land developers and city governments intent on improving urban nature. Deciding which tool to use depends largely on the size and potential impact of the project in question and the resources available. The below tools are listed in the order of increasing scope, technical requirements and implementation effort. Whilst primarily intended for use by city planners and environment agencies at the neighbourhood level upwards, many of the indicators that they comprise can be readily applied at the site level.

\section{- The IUCN Global Standard for Nature-} based Solutions seeks to enable the consistent and reliable scaling-up of 'nature-based solutions' (NbS), which are defined as "actions to protect, sustainably manage and restore natural or modified ecosystems that address societal challenges effectively and adaptively, simultaneously providing human well-being and biodiversity benefits" (IUCN, 2016; IUCN, 2020). The Standard comprises eight criteria: i) NbS effectively address societal challenges; ii) design of NbS is informed by scale; iii) NbS result in a net gain to biodiversity and ecosystem integrity; iv) NbS are economically viable; v) $\mathrm{NbS}$ are based on inclusive transparent and empowering governance processes; vi) NbS equitably balance trade-offs between achievement of their primary goal(s) and the continued provision of multiple benefits; vii) NbS are managed adaptively, based on evidence; and viii) $\mathrm{NbS}$ are sustainable and mainstreamed within an appropriate jurisdictional context. The 
criteria are supported by a set of indicators and a self-assessment tool. The Standard can be applied during the design, implementation and maintenance stages to ensure the efficacy, quality and credibility of nature-based solutions (IUCN, 2020).

- The Singapore Index on Cities' Biodiversity (CBI) is a self-assessment tool for cities to evaluate and monitor the progress of their biodiversity conservation efforts against their own individual baselines (National Parks Board, n.d.). The index contains a set of indicators divided into three categories: native biodiversity, ecosystem services provided by biodiversity, and governance and management of biodiversity. It is intended for use by local governments and encourages an implementation cycle of three years. Over the past decade, the index has been implemented in hundreds of cities worldwide. Learning from these experiences, the Singapore $\mathrm{CBI}$ is being updated and revised in view of a 2020 re-launch.

- $\quad$ The IUCN Urban Nature Index is composed of a set of indicators, metrics and methodologies to help cities understand their impacts on nature, set science-based targets for improvement, monitor progress and catalyse action. The index addresses three spheres of ecological impact - urban, regional and global - thereby offering a comprehensive evaluation of a city's ecological performance. It is intended for use by local governments on an ongoing basis. 


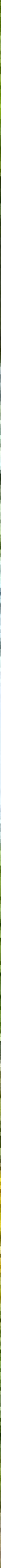

135 0

\section{and}

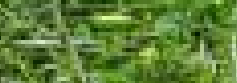

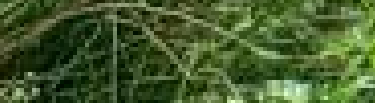

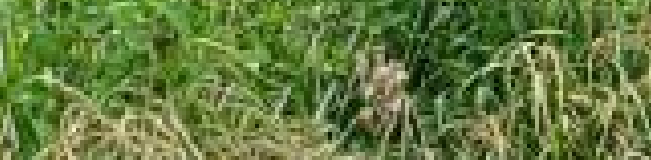

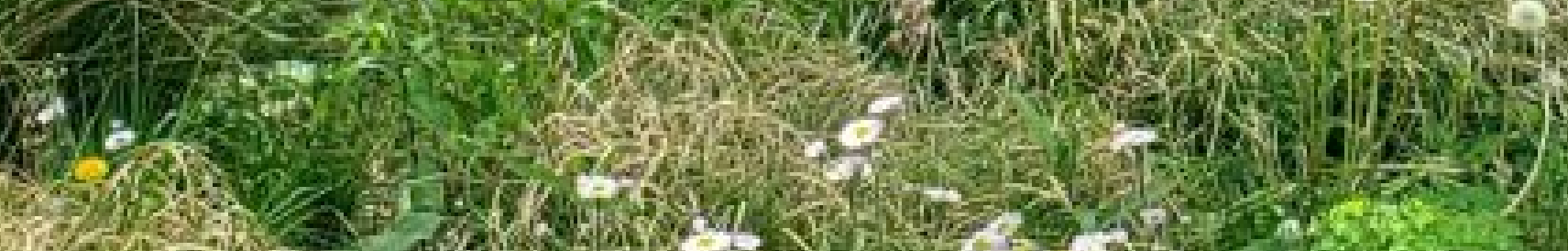

Sus

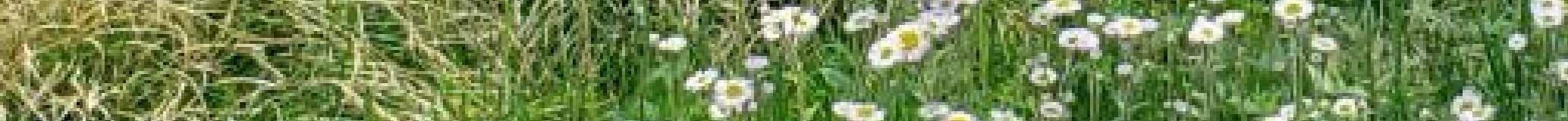

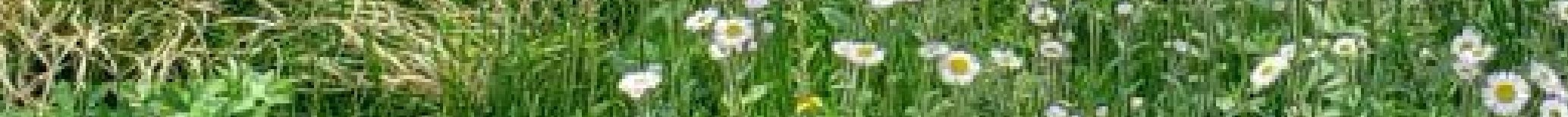

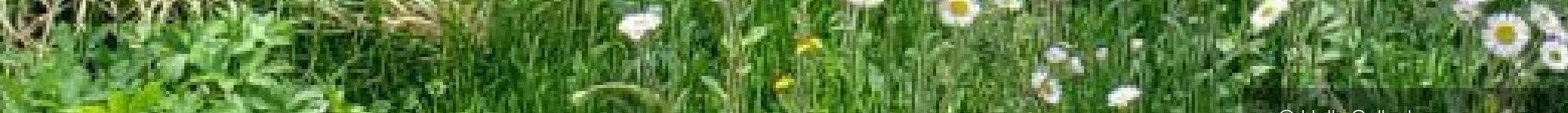

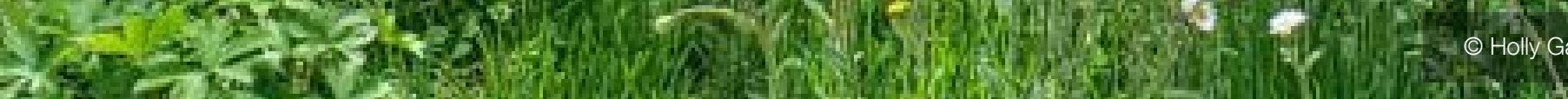

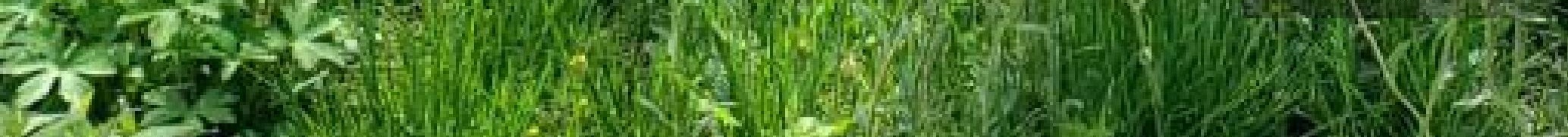




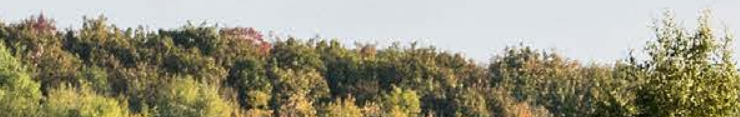

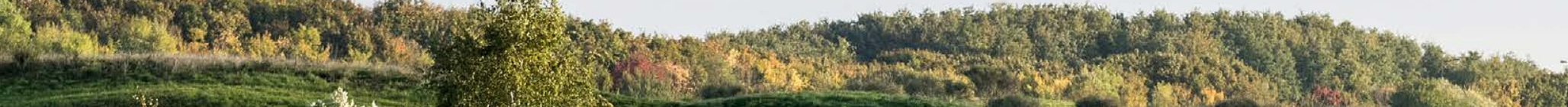

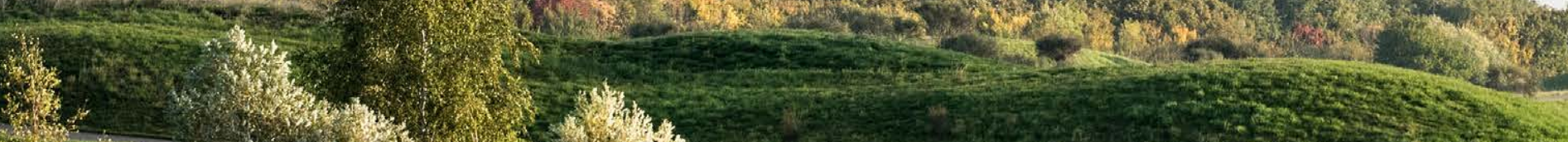

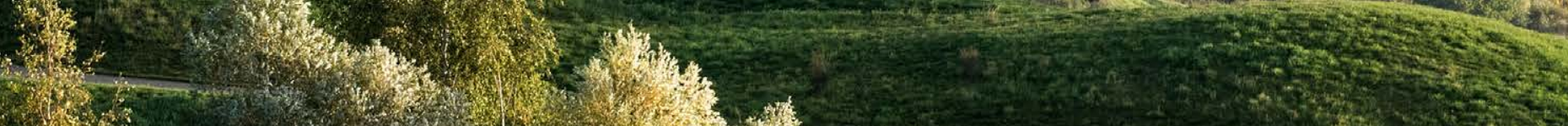

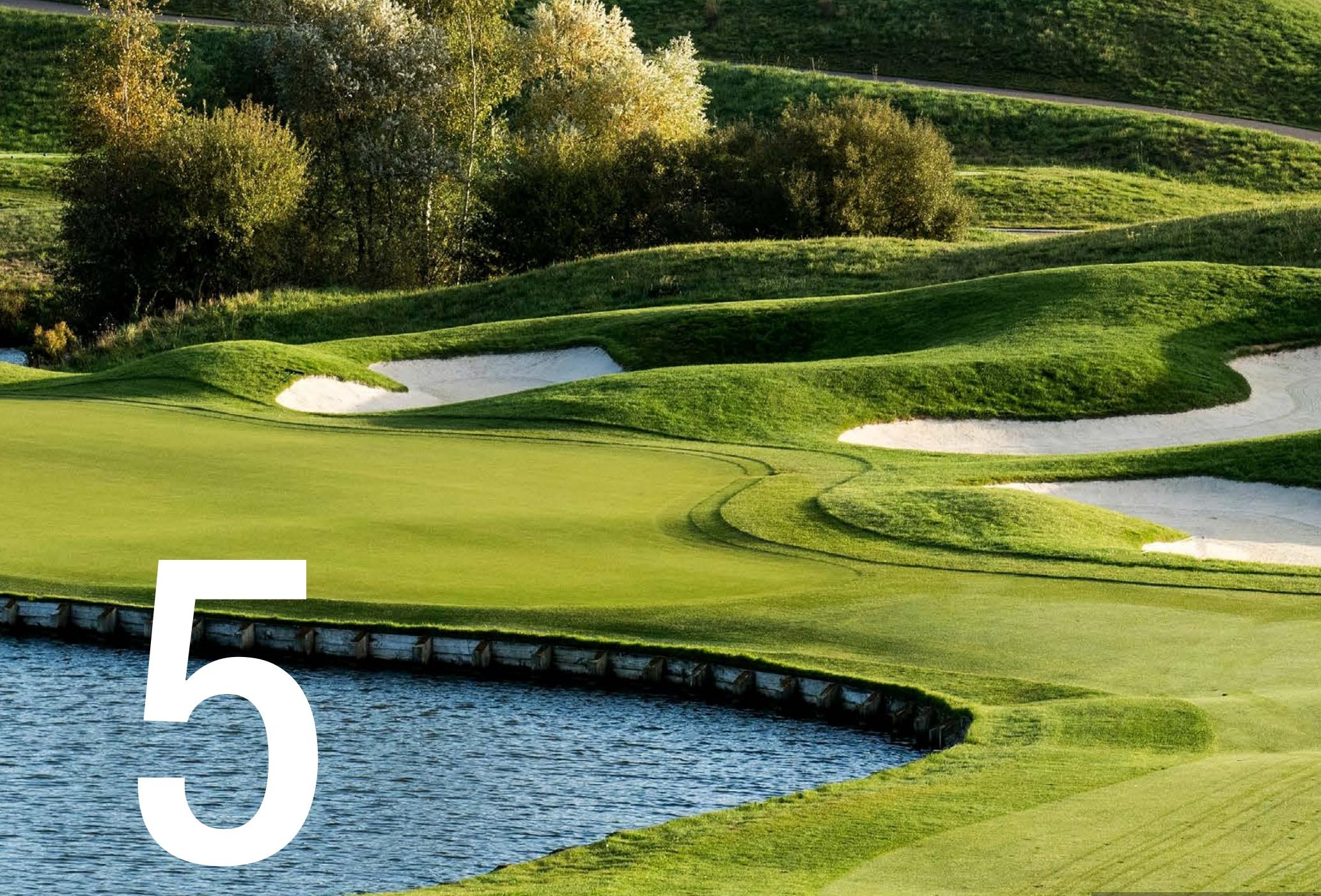

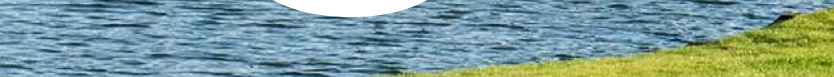




\section{Combining elements to support urban biodiversity: Selected case studies from Europe, North America, Australia and South Africa}

While each individual element in the Framework can impact biodiversity in the city, the greatest positive outcomes are achieved when multiple elements are combined. Evaluating the current status of each element at a particular location can identify priorities for biodiversity by showing features that are currently lacking and/or are most easily improved. For example, a large green space surrounded by dense urbanisation with low matrix quality and little connectivity might benefit most from a combination of green roofs, small pollinator gardens and green corridors in the surrounding area. These could be placed around local sporting fields, on the roofs of training centres or along active transportation corridors accessing event venues. Alternatively, a new venue constructed in a city located along important bird migration pathways might focus on providing access to water, landscaping with native vegetation for sheltering opportunities and using bird-friendly management practices.

The case studies described in this section illustrate examples of biodiversity actions taken by a variety of sports, from Olympic city planning to local projects at stadiums and practice facilities. These case studies from Europe, North America, Australia and South Africa give examples of possible achievements in a limited set of contexts, especially high-income countries, but do not represent all locations, sports, or possible opportunities.

These examples show how multiple elements of the Framework can be addressed through strategic interventions, revealing ways in which improvements to urban biodiversity elements can offer a better sporting experience for events participants and spectators alike. The interventions explored in the case studies range from large to small, and were often conducted with support and in collaboration with local government, conservation organisations, non-profits, environmental experts, schools and/or museums. Some were organised and carried out by individual venues or sports teams, and many have been supported and recognised by national or international sports federations. The potential for and the necessity of collaboration, support and incentivisation by sports at all levels should be considered when exploring ways to deploy the Framework elements. 


\subsection{France - Implementation of the seven biodiversity elements in planning for Olympic and Paralympic Games Paris 2024}

The Olympic Games development process is a significant opportunity to build biodiversity planning into urban revitalisation for sport. As Paris prepares to host the Olympic and Paralympic Games Paris 2024 (Box 4), SOLIDEO (Société de Livraison des Ouvrages Olympiques), the agency created to deliver the new venues for Olympic and Paralympic Games Paris 2024, is designing with the social and ecological legacy of the Games at the forefront (SOLIDEO, 2019). Major re-development is planned in La Seine-Saint Denis, situated north-east of Paris along the River Seine, for the new Olympic Village. SOLIDEO aims to develop this district as an example of sustainable design for future development, a vision that is propelled and enabled by the upcoming Olympic Games. The realisation of the Olympic works will transform the local perspective on biodiversity and show that it is possible to re-introduce biodiversity even in dense urban areas. Transformative development plans include each of the seven key elements of the Framework to support biodiversity in Paris.

\section{Patch size}

New green spaces will be added to the Olympic Village, which currently lacks public open space to benefit people and biodiversity. A total of approximately seven hectares of new green spaces are planned. These are meant to serve multiple purposes, including offering space for biodiversity and also promoting physical activities and sports. The goal is particularly true for the northern area of the Athlete's Plaza, which will include several thousand square metres of green space designed to play and practice sports. A nearby regional biodiversity hub exists at Parc Départemental Georges-Valbon, a 415-hectare preserve.

\section{Connections}

The Olympic Village will be located along the Seine River, a key ecological corridor for the region. One aim during re-development is to enhance the quality of the existing river corridor and extend smaller habitat corridors out from the river. Planning for the Olympic Village has included regional visions to expand and connect local green spaces, including the biodiversity hub at Parc Départemental GeorgesValbon. Existing and to-be-created biodiversity corridors along railways and bike paths will build connections for both people and nature. Within the Village itself, an ecological loop is planned to create a continuous green corridor through the built environment. The corridor will be several metres wide for most of its length. In addition to building physical connections for the movement of people and wildlife, re-development in this urban district also strives to build emotional and personal connections between the people of La-Seine-Saint-Denis, Paris and the local environment.

\section{Matrix quality}

A striking feature of the Olympic Village will be the rooftop gardens on the majority of new buildings, with the remaining rooftops used for solar panels or mixed green and solar uses. In addition to new ground-level habitat patches, the Olympic Village aims for high matrix quality to allow movement of wildlife and to provide habitat for smaller and more mobile creatures like pollinators and birds. Green roofs at different heights will be designed to support different habitat types, modelled after habitats that might be found in nature at different elevations. These green roofs will have a minimum soil depth of $30 \mathrm{~cm}$, making them able to support a wider range of plant species than shallower soil depths more often found on green roofs. Continued greening in the surrounding areas following the regional planning vision can further enhance matrix quality.

\section{Habitat diversity}

In addition to diverse rooftop habitats, the Olympic Village will be designed to contain five distinct native habitat types in close proximity. These habitats are based on the local soil characteristics present in different parts of the development area, and will contain plant communities chosen to thrive in different microhabitats. The mosaic of habitat types will provide a selection of shared habitat for animals, as well as showcasing a diversity of natural landscapes for people. 


\title{
Box 4. The biodiversity vision for Paris 2024
}

\author{
Contribution by the Olympic and Paralympic Games Paris 2024
}

Since its initial bidding to host the Olympic and Paralympic Games, Paris 2024 has been committed to lead the fight against climate change and to preserve biodiversity.

Sports are challenged by the ecological emergency: athletes experience the degradation of their natural playgrounds - rivers, mountains, oceans - and sports organisations are exposed to these upheavals. In the vision of Paris 2024, sports' incredible power of mobilisation must be on the front line to act, and its Games offer a shared goal for addressing these challenges. All stakeholders of Paris 2024: Organising Committee, the Olympic Buildings Delivery Authority (SOLIDEO), the Sports Movement and public institutions have committed to organising the Olympic and Paralympic Games of a new era; much more environmentally friendly and much more supportive.

This transformation has started with a sober Games concept. The concept of Paris 2024 is $95 \%$ based on existing or temporary equipment where, in general, the impact on biodiversity will be limited by the low pressure on habitats. The Olympic Aquatic Centre in Seine-Saint-Denis will be the only new Sports equipment built for these Games. Beyond the sobriety of the concept, the Organizing Committee has developed a specific preservation strategy to assess and manage its impacts over 5 pillars: biodiversity and ecosystems, landscapes, environmental health, carbon footprint and circular economy.

A vast majority of Paris 2024 venues will host events or celebrations in the heart of different cities, so urban biodiversity is a central element. The biodiversity approach of Paris 2024 includes "remarkable biodiversity" -to be preserved as much as possible by moving away from it- and "ordinary or daily biodiversity" -to be preserved by integrating it as much as possible into projects and to be highlighted in the eyes of the public.

Paris 2024 is engaged to go beyond preservation by identifying regeneration opportunities for the urban sites serving the Games. The analysis of these opportunities will be based on the 7 elements of the SFEl framework, and works have already started for the most emblematic equipment of the Games: the Olympic and Paralympic Village.

Above all, a housing district was conceived that will be used as accommodation for athletes. This ambitious project placing the preservation and development of biodiversity at the heart of its priorities is implemented by SOLIDEO.

\section{Native vegetation}

Planting guidelines for the Olympic Village emphasise native species, particularly those from native shrubland and mesophilic meadows, as well as those which will be resilient to future climate change and current urban conditions. For tree planting along walkways and corridors, plans recommend growing 60-100\% native species.

\section{Special resources}

Rain gardens, with a mix of wetland species, will be included in low lying areas of the Olympic Village to capture run-off and provide cool spaces for people to enjoy. These areas also provide special resources for wetland species, many of which are threatened by habitat loss. Special features will be added to green roofs, such as dead wood, rock piles and bug houses.

\section{Management}

While the development project is still in the planning stage, management goals and guidelines are an important consideration for the future. Potential conflicts between spaces for people and for nature will be addressed in the design stage such as by including wildlife-friendly lighting to enhance nighttime safety while minimising disturbance for nocturnal animals. In other areas, improvements made for people will also help support biodiversity such as a 
planned noise barrier between a local expressway and the Olympic Village. Planning also prioritises low upkeep needs in green space and provides for some spaces without human access to support more sensitive species.

\section{Useful source}

Société de Livraison des Ouvrages Olympiques (SOLIDEO) (2019). Olympic \& Paralympic

Village. https://www.ouvrages-olympiques.fr/ en/home

Figure 10. Paris 2020 Olympic Village
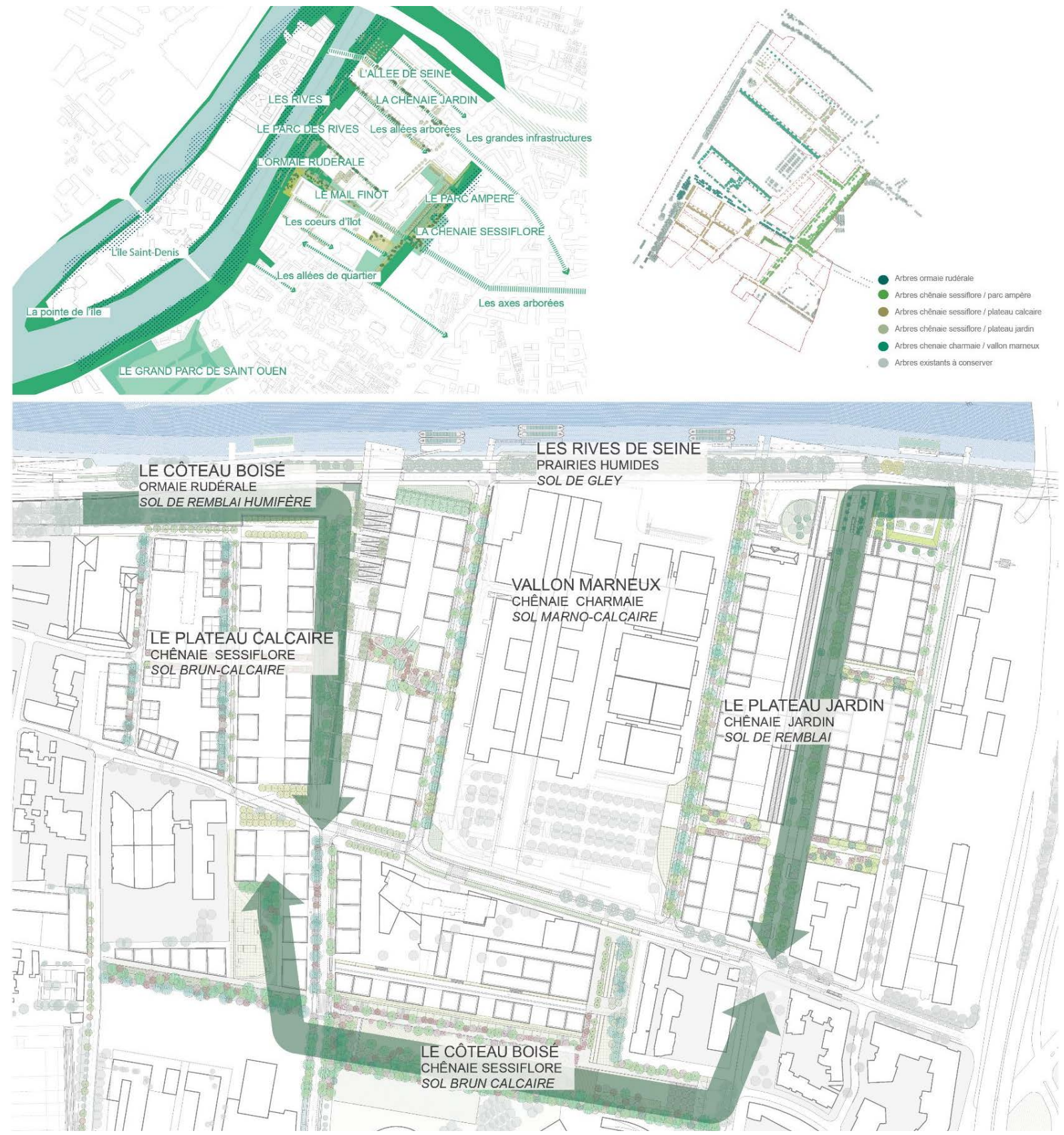

Source: SOLIDEO

Notes: An ecological loop is planned to create connectivity through the Olympic Village between new green spaces and the waterfront. 


\subsection{United Kingdom - Supporting biodiversity at the Olympic and Paralympic Games London 2012}

Biodiversity was one of five priority sustainability themes of the Olympic and Paralympic Games London 2012. The remediation and construction of the site of the Olympic Park (now known as Queen Elizabeth Olympic Park) provided for the establishment of a large urban habitat patch with 45 hectares of new wildlife habitat in addition to recreational space for visitors (Azzali, 2017). Prior to redevelopment, the park site was heavily impacted by invasive species and pollution from previous industrial use, and provided few social or ecological services. In preparation for the Olympic Games, several diverse habitats were restored in the park, including grassland, scrubland and wet woodland. The park was positioned to enhance regional connectivity along the Lee River Valley by extending a chain of existing green spaces from the Lee Valley Regional Park toward the River Thames (Olympic
Delivery Authority, 2008, p. 4). Corridors throughout the park maintain connectivity for wildlife around recreational facilities and development.

The positive attention generated by native wildflower meadows in the Olympic Park during the Games inspired further naturalistic wildlife-supporting features in the legacy phase of development, and the use of temporary infrastructure during the Games left space for additional features in the legacy phase. The Biodiversity Action Plan was compiled by the company for the delivery of Olympic Works (Olympic Delivery Authority) to guide park management. The plan outlined joint goals of biodiversity conservation, social well-being and economic welfare, emphasizing the provision of natural habitat and education of park visitors. It included a list of 'species aspirations', or particular species that the

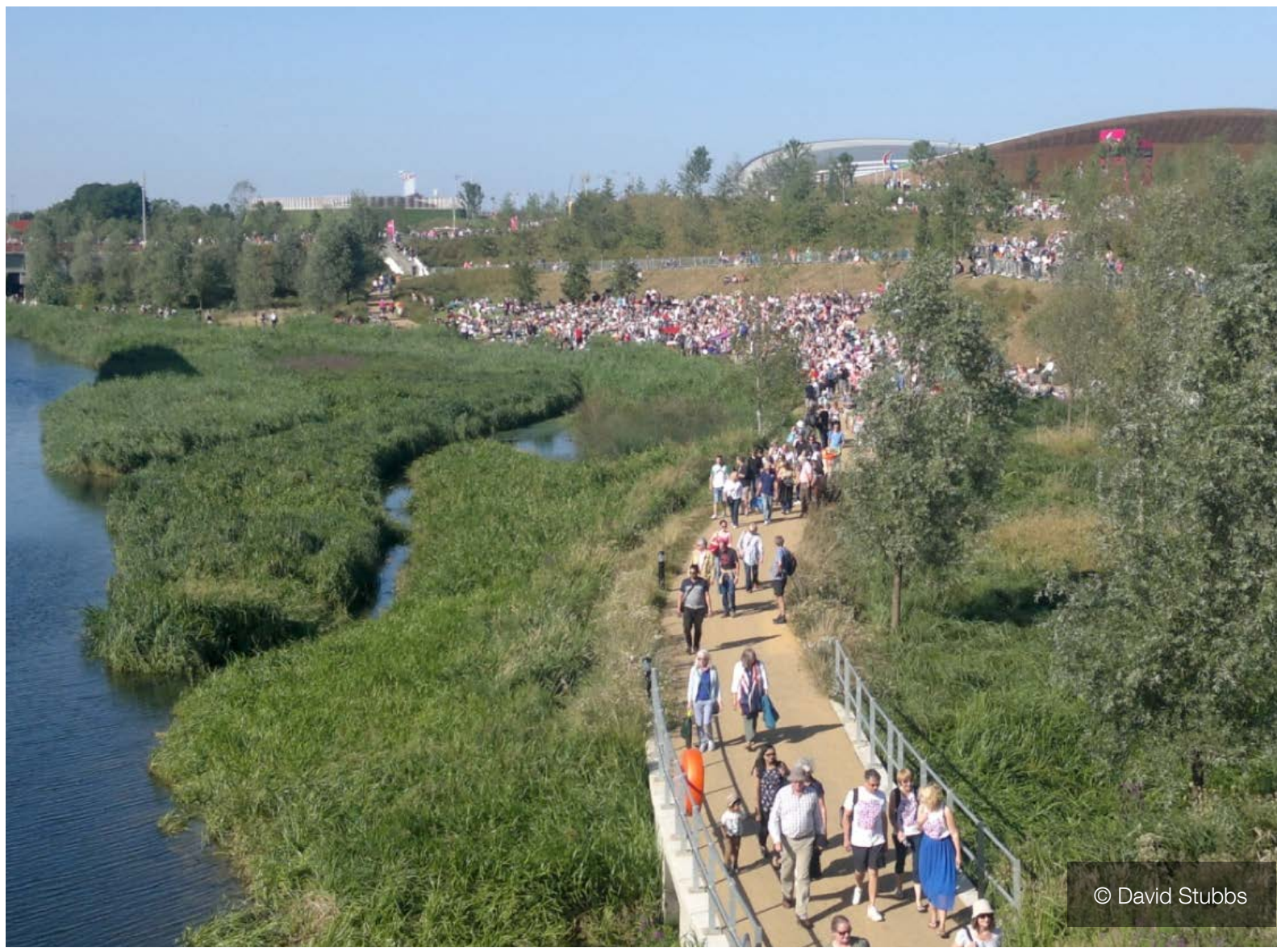

Restored wetlands at the London Olympic Park. 
park aimed to support, which facilitated planning to reach specific biodiversity goals. Continued monitoring has recorded six highly-protected "schedule one" bird species and 91 nationally scarce invertebrate species in the Olympic Park, as well as 7 different bat species and 20 butterfly species.

As part of species-specific goals, the park included special resources, such as bird and bat boxes, amphibian ponds, dead logs for beetles, kingfisher and sand martin nesting banks, and artificial otter holts (dens). While biodiversity provision in the Olympic Park was part of a large-scale revitalisation project, individual elements, such as siting and designing venues to maintain regional connectivity, use of native plants in high visibility areas to attract attention to biodiversity, and additional of special resources with particular goals in mind, could also be applied in smaller scale projects.

\section{Useful sources, links and materials}

Azzali, S. (2017). 'Queen Elizabeth Olympic Park an assessment of the 2012 London Games Legacies'. City, Territory and Architecture 4(11). https://doi.org/10.1186/s40410-017-0066-0

Foreign \& Commonwealth Office (2010). Going for Green - Parkland in the Olympic Park [video]. https://youtu.be/4_V-NB2v6zl

Lee Valley Regional Park Authority (n.d.). 'Lee Valley Regional Park is playing a leading role in delivering a lasting and enduring legacy from the London 2012 Olympic and Paralympic Games'. [website]. https://www.leevalleypark. org.uk/en/content/cms/corporate/ london-2012-legacy/
London Legacy Development Corporation (2013). Legacy Communities Scheme Biodiversity Action Plan 2014-2019. LCS-GLB-S106-APPBAP-001-V01, August 2013. https://www. queenelizabetholympicpark.co.uk/-/media/ Ildc/sustainability-and-biodiversity/legacycommunities-scheme-biodiversity-actionplan-2014-2019.ashx?la=en

Norris, C. (2017). Queen Elizabeth Olympic Park Biodiversity Action Plan Annual Monitoring Report 2016. https://www. queenelizabetholympicpark.co.uk/-/ media/biodiversity-action-plan-monitoringreport-2016.ashx?la=en

Olympic Delivery Authority (2008). Olympic Biodiversity Action Plan. https://www. queenelizabetholympicpark.co.uk/ /media/ Ildc/local\%20plan/local\%20plan\%20 examination\%20documents/local\%20 strategy\%20papers/ls4\%20legacy\%20 communities\%20scheme\%20olympic\%20 park\%20biodiversity\%20action\%20plan\%20 2008.pdf

Queen Elizabeth Olympic Park (2020). 'Rare Species Found in Latest Monitoring on Queen Elizabeth Olympic Park'. https://www. queenelizabetholympicpark.co.uk/media/ press-releases/rare-species-found-in-latestmonitoring-on-queen-elizabeth-olympic-park 


\subsection{France - Diverse habitats at Le Golf National}

Sustainability and conservation are important goals at Le Golf National in France, host of the annual French Open and the 2018 Ryder Cup, and scheduled to host the 2022 World Amateur Team Championships and the 2024 Paris Olympic golf events. Located just outside of Paris at the confluence of natural, industrial and urban land uses, the 139-hectare course extends an existing large habitat patch and provides diverse, high-quality habitat in addition to the three courses on-site (the championship Albatros course, the 18-hole parkland Aigle course and the Urba 7-hole executive course). Original construction of the course in early 1990 converted former intensive agricultural land with little biodiversity value into a premier sport facility capable of supporting a range of species. The French Golf Federation and the Natural History Museum collaborate to conduct biodiversity surveys at the course and identify indicators of ecological quality. They have identified more than 350 species during these surveys, including 13 rare species
(Munoz Vega, 2018). It supports high biodiversity with high habitat diversity: 10 different EUNISclassified habitats ${ }^{7}$ are present on the site, including three rare habitats. In addition, connectivity among habitats has been maintained by careful siting of corridors and habitat patches throughout the courses to allow for wildlife movement.

Several special resources are provided in the course as well, including amphibian hibernacula (winter shelters), dead trees for cavity-nesting birds and piles of large rocks extracted during course development which serve as habitat for lichens and which may also support nearby bats. A mix of traditional Agrostis and native Poa grasses is used for putting greens, with additional native grasses included in un-mowed rough areas. Management practices such as reduced chemical inputs and maintenance of unmowed buffer areas around water features and habitat patches support and compound other biodiversity efforts.

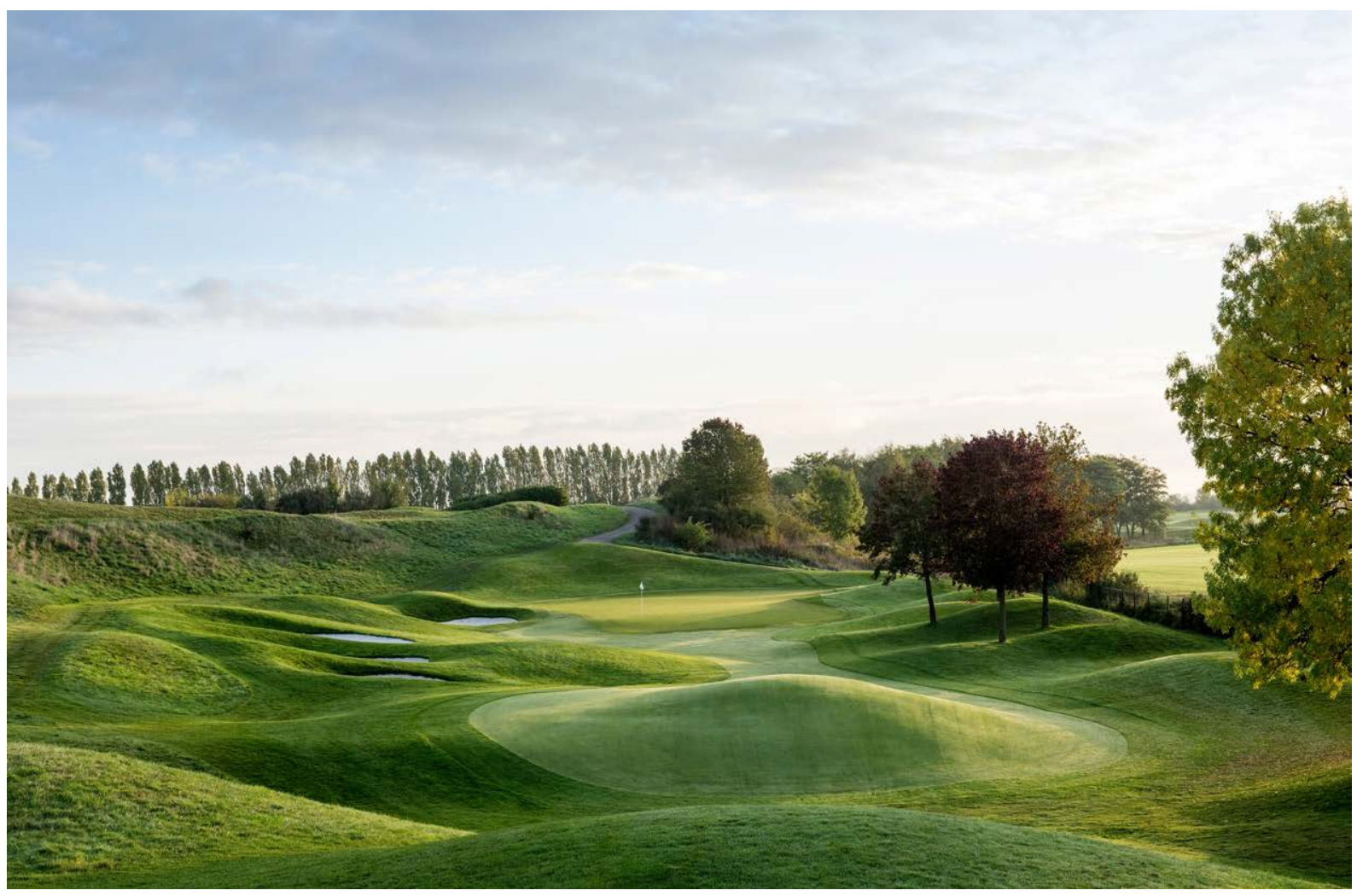

The Albatros Course at Le Golf National.

7 For further information, please see: https://eunis.eea.europa.eu/habitats.jsp 
The conservation initiatives at Le Golf National not only support a range of species, but also provide a special and unique venue for golfers and spectators to enjoy. The biodiversity monitoring programme established by the Natural History Museum at Le Golf National continues to inform management practices and is being emulated at other courses across the country.

\section{Useful sources, links and materials}

Le Golf National (n.d.). 'Le Golf National retains GEO certified accolade'. Le Golf National [website]. https://www.golf-national.com/en/ geo-certified/
Munoz Vega, P. (2018). GEO Certified@ Independent Verification Report. Executive Summary. GEO Foundation. https:// sustainable.golf/assets/0005/6919/LGN_first_ renewal_verification_PMV_2018.pdf

Owen, G. (2019). 'How the Ryder Cup accelerated a nationwide biodiversity project'. Published on 1 Mar. 2019. The Sustainability Report [website] (1 March 2019). https:// sustainabilityreport.com/2019/03/01/howthe-ryder-cup-accelerated-a-nationwidebiodiversity-project/ 


\subsection{Australia - Rowers and restoration at Spring Creek, New South Wales}

In New South Wales, Australia, members of the Kinross Wolaroi School Rowing Programme launched a project to restore degraded land around the Spring Creek reservoir. The city-owned reservoir, where rowers from the school come to practice, is separated from agricultural land by only a small strip of vegetation composed mostly of non-native and invasive plants. These plants consume more water than the native species, further exacerbating the effects of ongoing drought conditions, which have reduced the reservoir to 30\% of its capacity. Run-off from nearby farming compromises water quality, which is a problem for local rowers as well as for two endangered duck species observed at the reservoir. In order to create a beautiful, healthy area for sport and high-quality habitat for birds, rowers presented a restoration plan to the city council for support. Following the guidance of an environmental consultant and with funding from the city, the team hosted community workdays to clear invasive species from a section of the shore and plant native plants.
The effort provided opportunities to engage parents of student rowers in the sport, and additional work is planned to tie restoration efforts with school curricula and further increase the size of the high-quality habitat patch around the reservoir. Removal of thirsty non-native trees has lowered the demand on the drought-stressed reservoir, leaving more water to support biodiversity and rowing activities. Urban river sites are often degraded, and improvement efforts like those seen at Spring Creek can have significant impacts on local biodiversity. To incentivise future sustainability and conservation efforts by the rowing community, the World Rowing Federation (FISA) recognises exceptional contributions like the Spring Creek project with the World Rowing Sustainability Award (FISA, 2020). Furthermore, FISA provides rowers with guidelines to emphasise positive biodiversity impacts in event and venue planning through their sustainability goals (FISA, n.d.). In this way, the sports federation, local sports team, and host city can work together to support positive biodiversity outcomes.

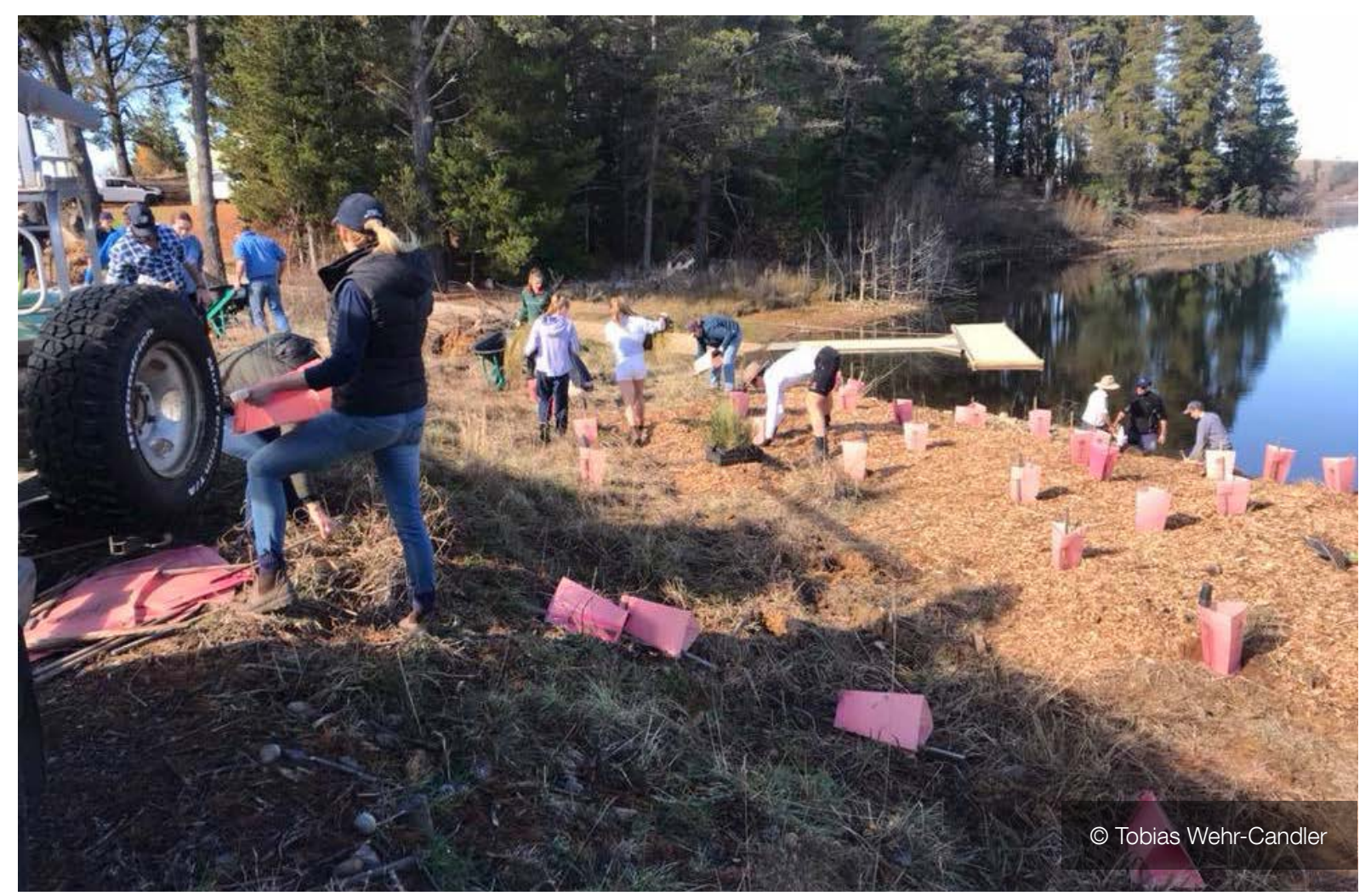

Volunteers install native plants around the Spring Creek reservoir on a planting and learn-to-row day. 
Useful sources, links and materials

Conversation with Tobias Wehr-Candler, Kinross Wolaroi School, 10 February 2020.

World Rowing Federation (FISA) (2019).

'Sustainability Award finalists demonstrate rowers action'. FISA [website] (6 November 2019). http://www.worldrowing.com/news/ sustainability-award-finalists-demonstrateaction
(2020). 'Custodians of the water Australia's Spring Creek Regeneration Project'. FISA [website] (1 January 2020). http://www. worldrowing.com/news/custodians-the-wateraustralia-spring-creek-regeneration-project

(n.d.). 'FISA's Environmental Policy'. FISA. http://www.worldrowing.com/environment/ fisa-environmental-policy/ 


\subsection{Canada - Habitat Island at the Vancouver 2010 Olympic Village}

As part of the development of the Olympic Village for the Olympic and Paralympic Winter Games Vancouver 2010, a new island was constructed in the highly urban Lower False Creek inlet to create a habitat patch for fish and other wildlife. The Olympic Village was constructed in a former industrial area with degraded shoreline, high pollutant concentrations and low biodiversity value (Wernick et al., 2012). To offset an area of degraded shoreline filled for the construction of the Olympic Village, the developers designed Habitat Island, a new island adjacent to the Olympic Village site, with features including a naturalistic shoreline and native vegetation.

Special resources, including intertidal habitat and naturalised wetlands in Hinge Park, which connects Habitat Island with the Olympic Village site, were also added to increase the biodiversity value of the area.

Since its construction, these habitats have hosted a variety of wildlife, including a pair of beavers and their offspring (Scalza, 2016). The value of the area for biodiversity was further improved during the Olympic Village construction process through the inclusion of green roofs on over $50 \%$ of the building footprint, improving overall matrix quality for birds and flying insects. In this way, re-development associated with new construction for sport was able to positively impact both aquatic and terrestrial biodiversity in a highly urban context by converting degraded industrial land into liveable habitat for both athletes and wildlife.

\section{Useful sources, links and materials}

Millenium Water (2010). The Southeast False Creek Olympic Village, Vancouver, BC. https:// millenniumdevelopment.com/Olympic-Village/ documents/globeAwards2010.pdf

Scalza, R. (2016) 'Urban Beavers Move into Vancouver's Olympic Village'. Inside Vancouver [blogpost] (6 January 2016). https://www. insidevancouver.ca/2016/01/06/urbanbeavers-move-into-vancouvers-olympic-village/

Vancouver Board of Parks and Recreation (2016). Biodiversity Strategy. https:// parkboardmeetings.vancouver. ca/2016/20160201/REPORT_ BiodiversityStrategy20160201.pdf

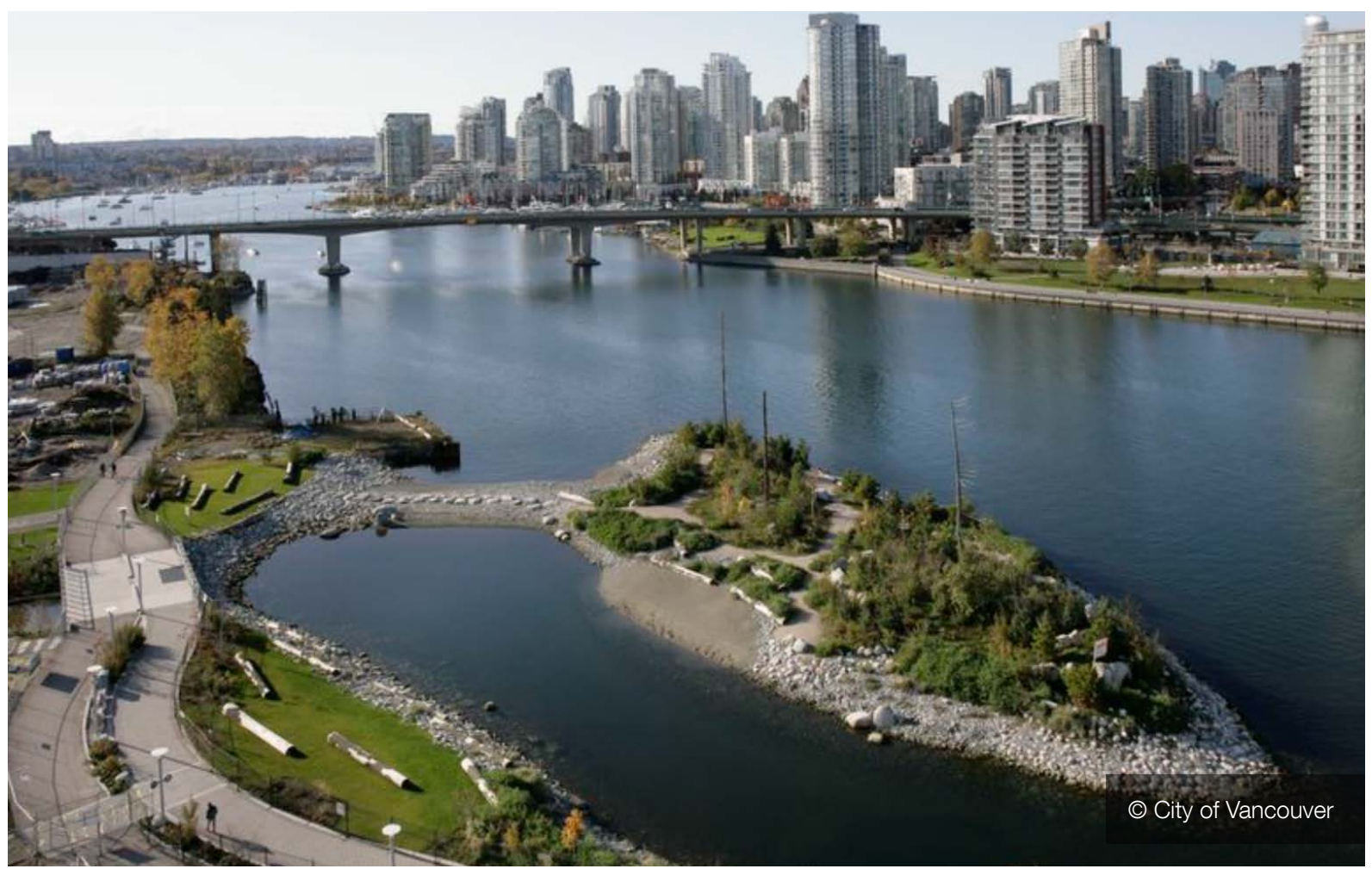

The constructed Habitat Island. 
Vancouver Organizing Committee for the 2010

Olympic and Paralympic Winter Games

(VANOC) (2010). Vancouver 2010 Sustainability

Report 2009-10. https://stillmed.olympic.org/

Documents/Reports/Official\%20Past\%20

Games\%20Reports/Winter/2010/ENG/

Sustainability.pdf
Wernick, B.G., Nikl, L.H. and Adams, M.A. (2012), 'From Brown Shore to Green Shore: Redevelopment of the Southeast False Creek lands in Vancouver, Canada'. Environmental Impact 162: 401-412. https://doi.org/10.2495/ EID120351 


\subsection{Multiple places - Stadiums and green roofs}

Indoor sports facilities and stadiums are often located in highly developed areas, where there may be few habitat patches to support biodiversity and where green roofs can provide important improvements to matrix quality. Sports facilities in the United States, such as Levi's Stadium in Santa Clara (National Football League), Fenway Park in Boston (Major League Baseball) and St. Vincent's Training Center in Indianapolis (National Basketball Association), have installed green roofs on their stadiums, either as part of the original design (Levi's Stadium and St. Vincent's Training Center) or as a retrofit on an existing facility (Fenway Park). This improvement trades unused rooftop space for green spaces that can provide a range of benefits, including temperature regulation, water retention, food production and habitat provision. Each of these stadiums includes food gardens as part of their green roof design and is used to provide some stadium concessions and special farm-to-table menus. The rooftop gardens also feature sections of native plants to support biodiversity. Green roofs may form a small part of the overall built footprint and mitigation of other negative impacts should be prioritised as well. However, in cases such as Levi's Stadium, which was constructed primarily on paved land in a highly urban area, even the addition of small features can be an improvement when combined with practices such as sustainable sourcing and water recycling.

In Vancouver, Canada, the West building of the Convention Centre, added in preparation for its role as the Main Media Center for the Olympic and Paralympic Winter Games Vancouver 2010, installed the largest green roof in Canada. It was landscaped with a mix of native plants and grasses, and also hosted four honeybee hives which pollinate plants on the roof and provide honey for the on-site kitchen (Vancouver Convention Centre, n.d.). In some cities, green roofs are required on new construction, where careful design can make these rooftops beautiful and useful green spaces. Living walls, such as the flowering wall at the All England Lawn Tennis Club which hosts the Wimbledon Championship in the United Kingdom,

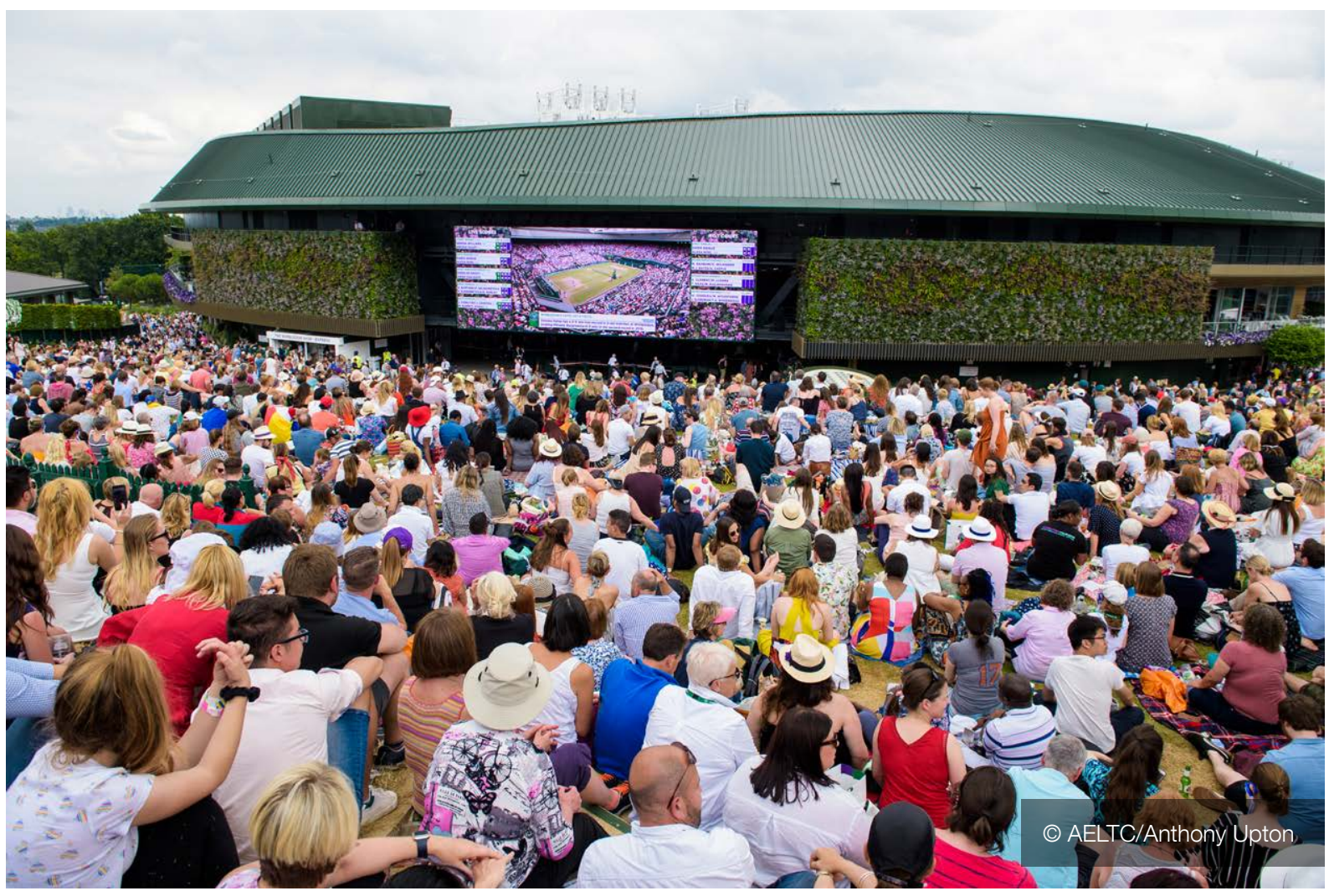

View of the No. 1 Court living wall at the Championships, Wimbledon. 
can also support pollinators and other small species, and present a striking visual display for fans (Rose, 2019). At Target Field, home of the Minnesota Twins (Major League Baseball) in the United States, a living wall provides the batter's eye backdrop and offers an opportunity to support biodiversity (Nelson, 2019). Together, these relatively small features can form networks of usable habitat for foraging or moving through the city for flying animals and insects, increasing urban connectivity as well as matrix quality.

\section{Useful sources, links and materials}

Climate Action (2018). 'The 5 most sustainable sports venues in the world'. Climate Action [website] (4 January 2018). http:// www.climateaction.org/news/the-5-mostsustainable-sports-venues-in-the-world

Greenroofs.com (n.d.). 'Vancouver Convention Centre Expansion Project'. Greenroofs. com [website]. https://www.greenroofs. com/projects/vancouver-convention-centreexpansion-project/

(n.d.). 'Fenway Farms'. Greenroofs.com [website]. https://www.greenroofs.com/ projects/fenway-farms/

Levi's Stadium (2016). Behind the Scenes of Levi's Stadium's Sustainability. Levi's Stadium [website] (22 June 2016). https://www. levisstadium.com/2016/06/behind-the-scenesof-levis-stadiums-sustainability/

NBA and Warner Media (2017). Pacers, St. Vincent Unveil St. Vincent Center. National Basket Association [website] (24 August 2017). https://www.nba.com/pacers/news/ pacers-st-vincent-unveil-st-vincent-center
Nelson, J. (2019). 'New 'living wall' at Target Field will help batters see the ball'. Bring Me The News [website] (7 January 2019). https:// bringmethenews.com/minnesota-sports/newliving-wall-at-target-field-will-help-batters-seethe-ball

OMNI Ecosystems (n.d.). 'Pacers Training Facility'._ OMNI Ecosystems [website]. https://www. omniecosystems.com/pacerstrainingfacility

Rose, M. (2019). 'Living Wall Entry at The No.1 Court Wimbledon'. Biotecture [website] (21 June 2019). https://www.biotecture.uk.com/ new-living-wall-installation-at-the-no-1-courtwimbledon/

StormwateReport (2019). 'Target Field, home of the Minnesota Twins, unveils plans for enormous 'living wall". StormwateReport [website] (1 February 2019). https://stormwater. wef.org/2019/02/target-field-home-ofminnesota-twins-unveils-plans-for-enormousliving-wall/

Vancouver Convention Centre (n.d.). 'Functional, Beautiful and 'Green". Vancouver Convention Centre Sustainability [website]. https://www. vancouverconventioncentre.com/about-us/ sustainability

Velazquez, L. (2019). 'Levi's Stadium Greenroof \& Rooftop Farm'. Greenroofs.com Featured Projects [website] (30 September 2019). https://www.greenroofs.com/2019/09/30/ featured-project-levis-stadium/ 


\subsection{United States - Oriole Garden at Camden Yards}

In collaboration with American Major League Baseball's Baltimore Orioles and Maryland Stadium Authority, the National Wildlife Federation and National Aquarium designed and installed the Oriole Garden focused on the native bird who serves as the team mascot, the Baltimore oriole (Icterus galbula). The garden was established in 2016 at the Maryland Stadium Authority's Oriole Park at Camden Yards Sports Complex in downtown Baltimore, Maryland. It is located near the stadium entrance, where it can be enjoyed by fans, athletes and employees. The garden covers over 10,000 square feet and includes more than 30 species of perennial native plants, which attract pollinators, butterflies and birds, including the Baltimore oriole (National Wildlife Federation, n.d.). In addition to benefiting wildlife, the garden also serves as a demonstration space to show visitors an example of Maryland native plant landscaping. The stadium itself is located less than a mile from two other large green spaces (M\&T Bank Stadium and Carroll Park), and thus greening efforts on the Oriole Park grounds can improve matrix quality and connectivity in conjunction with other local green spaces. In addition to featuring native gardens to support wildlife, both Oriole Park and M\&T Bank Stadium are LEED Gold certified (M\&T Bank Stadium, n.d.; U.S. Green Building Council, 2018). This includes integrated pest management practices to reduce chemical inputs and run-off, which have detrimental impacts on nearby Chesapeake Bay. The native plant garden at Oriole Park has co-benefits of promoting team spirit, providing habitat for orioles and other birds and insects, and creating a beautiful

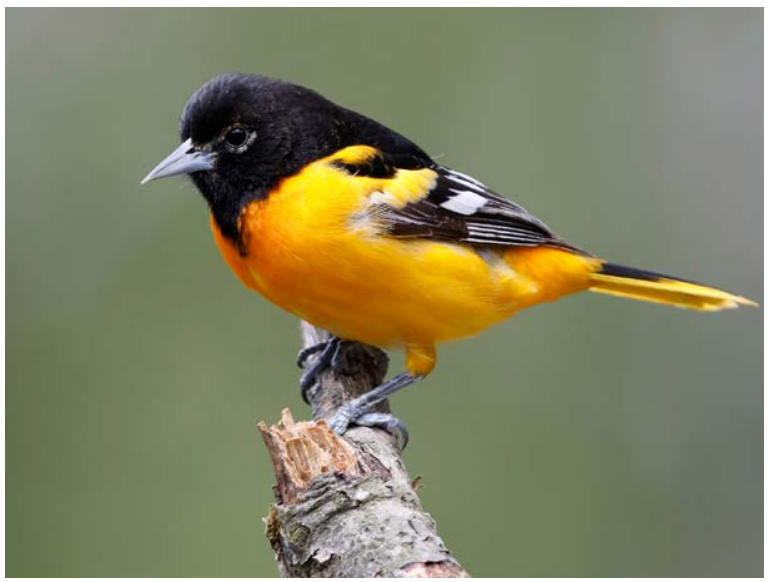

A Baltimore oriole, the team mascot that a stadiumgarden was designed to support. () Shutterstock space for fans to enjoy. It is one part of the sustainability agenda for the Maryland

\section{Useful sources, links and materials}

Communication with Holly Gallagher, National Wildlife Federation, 31 January 2020.

M\&T Bank Stadium (n.d.). 'M\&T Bank Stadium Information'. M\&T Bank Stadium [website]. https://www.baltimoreravens.com/stadium/ information

Major League Baseball (2016). 'The NWF and the Baltimore Orioles dedicate new Oriole Garden at Camden Yards'. Major League Baseball [website] (26 May 2016). https://www.mlb. com/official-information/terms-of-use

National Wildlife Federation (NWF) (n.d.). 'Oriole Garden at Camden Yards'. NWF [website]. https://www.nwf.org/Garden-for-Wildlife/ Create/Real-Wildlife-Habitat-Gardens/ Oriole-Garden

(n.d.). 'Oriole Garden Fact Sheet'. NWF [website]. https://www.nwf.org/ /media/PDFs/ Regional/Chesapeake/Oriole-Garden-FactSheet-2016.ashx

U.S. Green Building Council (2018). 'Orioles Park'. USGBC [website]. https://www.usgbc.org/ projects/orioles-park?view=scorecard

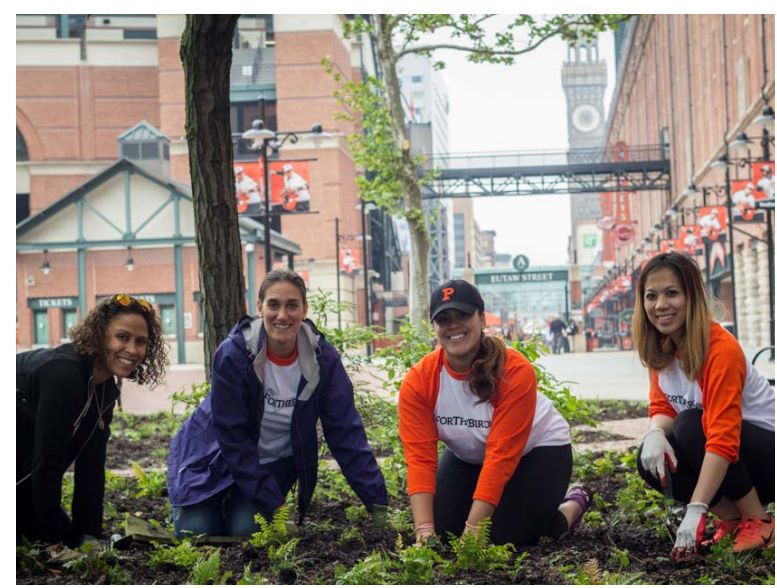

Volunteers help plant native vegetation at the Oriole Garden. (c) Carolyn Millard 


\subsection{Multiple places - Sports and tree planting}

Tree planting is one of the most common biodiversity-related efforts made in conjunction with sporting events. Examples include tree planting by European Athletics in association with the Lisbon Cross Country Championships to symbolise participating nations and the extensive planting effort by UEFA to plant trees in 12 host countries for the 2020 EURO Tournament. Several sports teams have launched initiatives to plant trees associated with their specific goals: Twigs for Twigs by the Montreal Canadiens, who plant 10 trees for every hockey stick broken in a game; Trees for Threes in which trees are planted for every three point basket scored by professional American basketball teams, including the Milwaukee Bucks and the Dallas Mavericks, as well as college teams at Xavier University and University of Louisiana at Lafayette; and Break a Bat, Plant a Tree in which American baseball teams, such as the Arizona Diamondbacks, support tree planting goals every time the pitcher breaks the bat of an opposing player.
While some of these initiatives have goals of offsetting carbon emissions and aiding reforestation in rural areas, relatively small tree planting efforts can be impactful in urban environments where trees can provide valuable shade and air quality benefits to people while supporting local ecology. Large urban trees act as special resources for biodiversity and improve quality of life for urban residents. In addition, urban trees can help improve matrix quality by greening the urban environment. Continued tree care is essential in order to ensure lasting positive legacies, thus collaborations and funding for maintenance should be secured at the time of planting. Many sports teams have formed partnerships with local tree planting non-profits, cities and schools to provide trees where they are needed most, choose the most appropriate trees for a particular location and establish plans for ongoing stewardship of new trees.

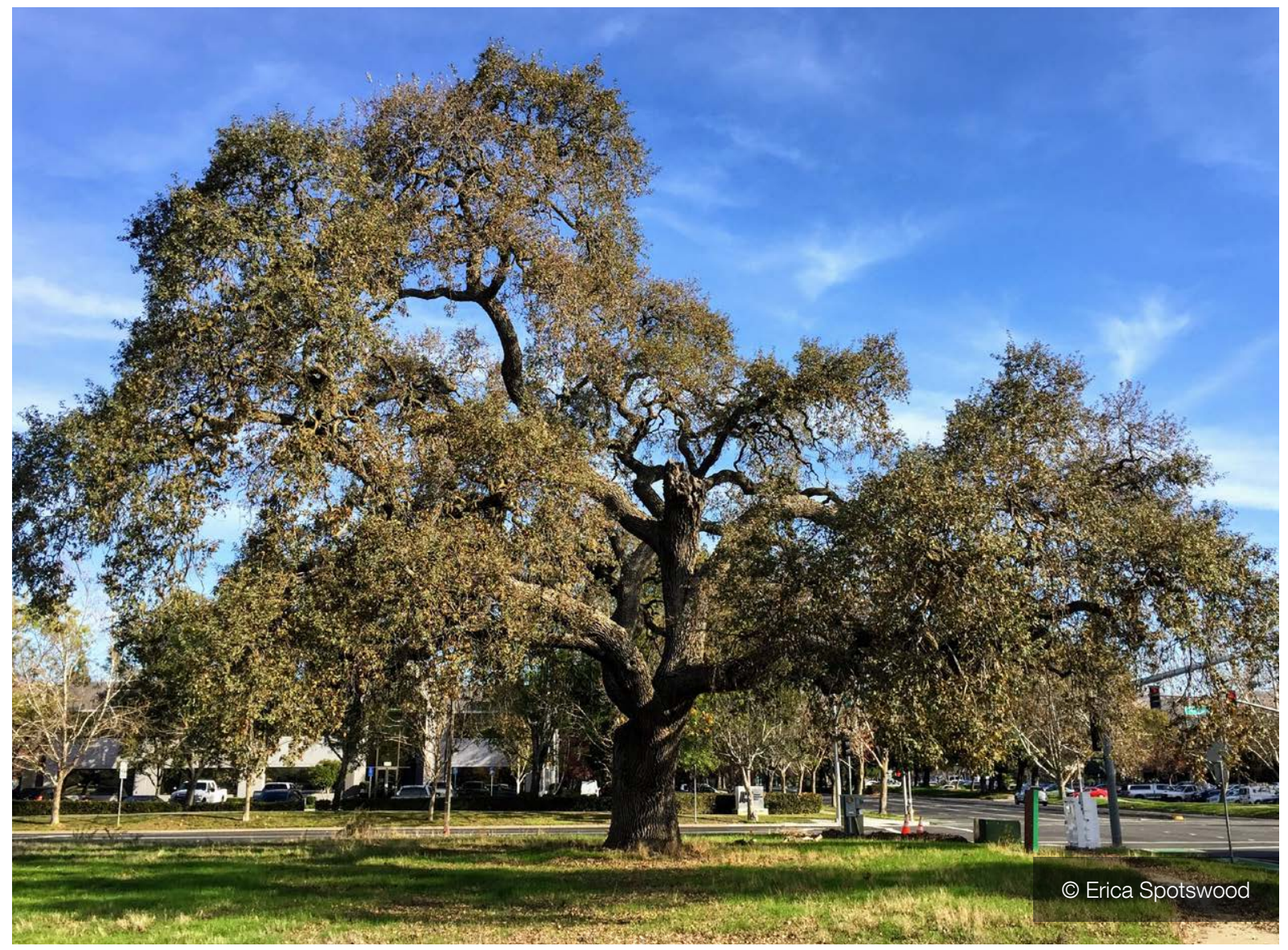

A Valley Oak tree providing shade and resources in the urban environment. 


\section{Useful sources, links and materials}

Arizona Diamondbacks (n.d.). 'Break a Bat, Plant a Tree'. Arizona Diamondbacks [website]. https://www.mlb.com/dbacks/community/ partner-outreach-impact/plant-a-tree

Daily Advertiser (2019). 'Shooting 3's, planting trees: UL basketball points lead to more trees on campus'. Daily Advertiser [website] (12 December 2019). https://eu.theadvertiser.com/ story/news/local/2019/02/07/ragin-cajunsbasketball-trees-for-threes/2801659002/

European Football Association (UEFA) (2019). UEFA announces climate action for EURO 2020. UEFA [website] (24 September 2019). https://www.uefa.com/insideuefa/socialresponsibility/news/0255-0f8e700075c461482c5c5c8b-1000--uefa-announcesclimate-action-for-euro-2020/?referrer=\%2Finsi deuefa\%2Fnews\%2Fnewsid\%3D2625426
Montreal Canadiens (n.d.). Montreal Canadiens [website]. https://www.nhl.com/canadiens/ community/goal-is-green

NASCAR (n.d.). 'NASCAR Takes Root: The Largest Tree-Planting Program in Sports Continues to Grow'. NASCAR [website]. https://green.nascar.com/news-media/nascartakes-root-the-largest-tree-planting-programin-sports-continues-to-grow/

Xavier University (2018). 'Formica Corporation and Xavier Basketball Extend Threes for Trees Program'. Xavier University [website] (7 November 2018). https://goxavier.com/ news/2018/11/7/mens-basketball-formicacorporation-and-xavier-basketball-extendthrees-for-trees-program.aspx 


\subsection{United States - Monarchs in the rough on golf courses}

The United States Golf Association (USGA) has supported and encouraged the expansion of minimally-managed green spaces outside of playing areas on golf courses. The conversion of unused areas in the rough into spaces with native vegetation has a number of ecological, economic and aesthetic benefits. Through the Monarchs in the Rough program, the USGA encourages the development of monarch butterfly and overall pollinator habitat by providing golf course managers with milkweed (a special resource for monarch butterflies) and wildflower seeds to convert one acre of land into pollinator habitat. Reduced management in the forms of water, fertilizer and pesticide applications helps maintain habitat quality while also reducing costs for venues owners and operators. Golfers enjoy experiencing natural habitats, particularly when signage is provided to explain the benefits of alternative management actions for wildlife, as well as materials signalling the importance a course places on sustainability and biodiversity protection, can have reputational benefits.

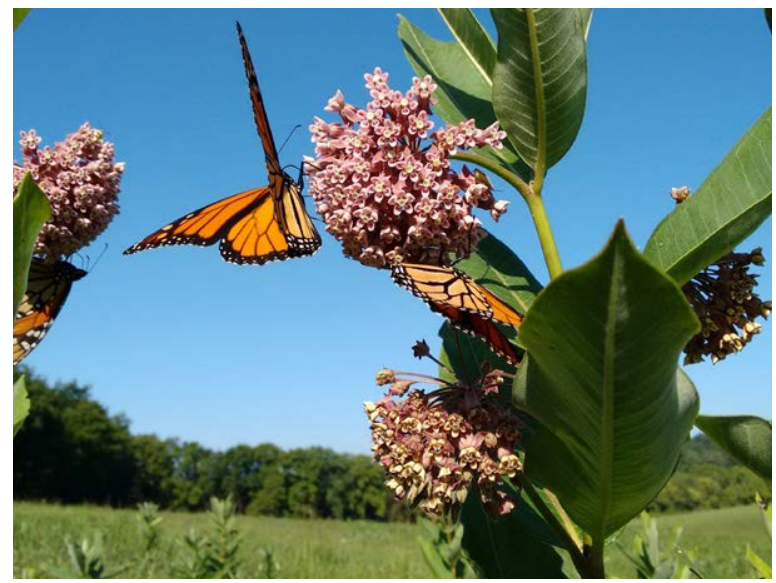

A monarch butterfly on a milkweed plant. @ Shutterstock
The USGA promotes biodiversity conservation efforts at courses by supporting research and the distribution of resources, such as seed and care information through media, individual consulting services and external programmes. Additionally, the USGA has cultivated partnerships with other organisations such as Audubon International, which supports and informs scientific guidelines and recognises success by designating golf courses as Certified Audubon Cooperative Sanctuaries, if they meet a set of environmental management criteria. Certification can come with economic benefits: research has found a price premium for golf courses certified as wildlife sanctuaries (Limehouse et al., 2010). Positive examples and best practice guidelines are collected and distributed through in-person consulting, online and through the Green Section Record, a regular USGA publication giving course managers specific guidance on appropriate actions to take and how to avoid problems encountered by other managers when implementing changes to support nature (USGA, n.d.).

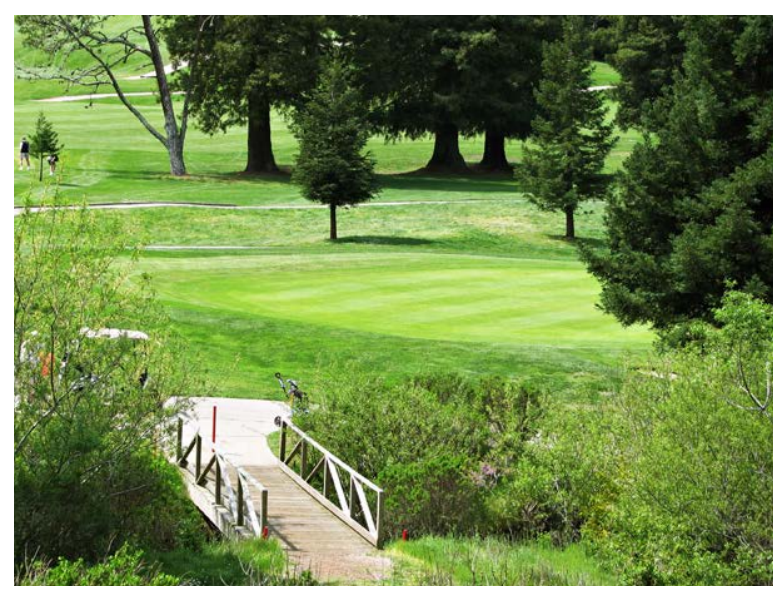

Golf courses can incorporate natural vegetation in out-of-play areas. (C) Shutterstock 


\section{Useful sources, links and materials}

Audubon International (n.d.). 'Audubon Cooperative Sanctuary Program for Golf'. Audubon International [website]. https:// auduboninternational.org/acsp-for-golf/

Dobbs, E.K. and Potter, D.A. (2015). 'Forging Natural Links with Golf Courses'. American Entomologist 61: 116-123. https://doi. org/10.1093/ae/tmv021

Limehouse, F.F., Melvin, P.C. and McCormick, R.E. (2010). 'The Demand for Environmental Quality: An Application of Hedonic Pricing in Golf'. Journal of Sports Economics 11(3): 261-286. https://doi. org/10.1177\%2F1527002509337801
Monarchs in the Rough (n.d.). 'The monarch butterfly is a wonder of the world'.

Monarchs in the Rough [website]. https:// monarchsintherough.org/

United States Golf Association (USGA) (2017). 'Best Management Practice Case Studies'. USGA [website]. https://www.usga.org/ content/usga/home-page/course-care/waterresource-center/bmp-case-studies.html

United States Golf Association (USGA) (n.d.). 'USGA Green Section Record'. USGA [website]. https://www.usga.org/course-care/ green-section-record.html 


\subsection{South Africa - Habitat conservation at the Kenilworth Racecourse}

The Kenilworth Racecourse is a well-established horse racing venue in Cape Town, South Africa, which has been functioning for over 130 years. The 52 ha interior area of the track has been preserved since the course was developed and is now a protected patch of rare fynbos habitat. Fynbos, meaning 'fine bush' in Afrikaans, is one of the Cape Floristic Region most important habitats. Access to this patch is strictly limited to manage it as a high-quality conservation area, protected by the surrounding racetrack infrastructure. Over 300 native plant species, including several threatened species, live within the reserve and support a range of animal communities. Sixteen wetlands provide special resources to amphibians.

\section{Useful sources, links and materials}

Kenilworth Racecourse. http://itsarush.co.za/ kenilworth-racecourse/
Kenilworth Racecourse Conservation Area. https://krca.co.za/

Kenilworth Racecourse Conservation Area. 2014. Open Green Map. https://www.opengreenmap. org/greenmap/cape-town-green-map/

kenilworth-racecourse-conservation-area-3245

Anderson, P. M. L., Avlonitis, G., \& Ernstson, H. 2014. Ecological outcomes of civic and expertled urban greening projects using indigenous plant species in Cape Town, South Africa. Landscape and Urban Planning, 127, 104-113.

Poulsen, Z. Kenilworth Racecourse:

Refuge for a flora on the edge.

https://www.capetownbotanist.com/

kenilworth-racecourse-refuge-for-flora/

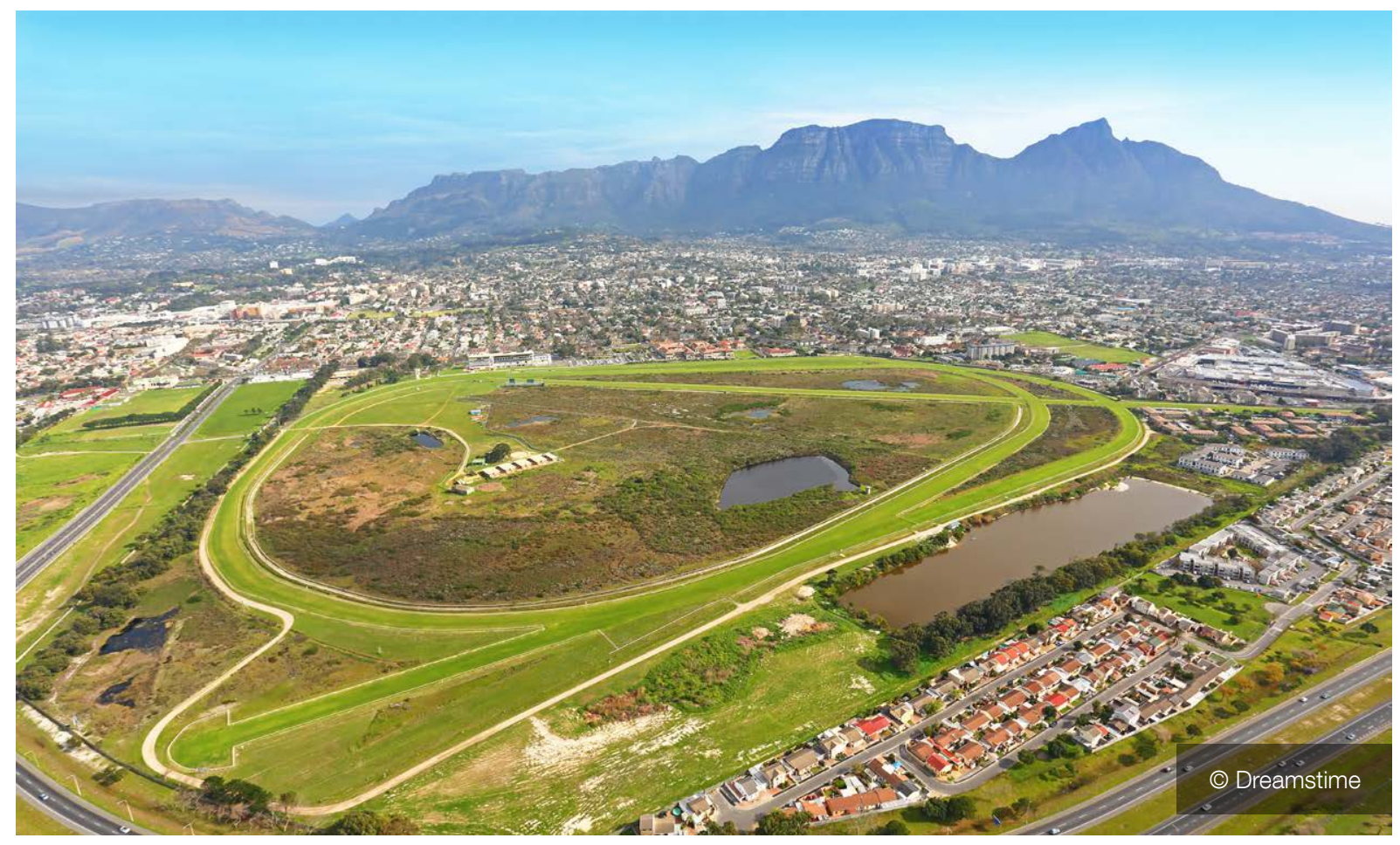

The Kenilworth Racecourse. 


\subsection{South Africa - Showcasing local biodiversity outside Cape Town Stadium}

Green Point Park in Cape Town, South Africa is a recreational green space redesigned as part of the construction of the Cape Town Stadium ahead of the 2010 FIFA World Cup. Within this park, the Biodiversity Showcase Garden was designed as an educational demonstration garden to highlight the unique fynbos habitat historically found in the Cape Town region. This garden was developed to show the use of native plants in landscaping and to emphasize the diversity of species native to Cape Town ecosystems. Green Point Park is primarily managed for recreational and social benefits rather than for wildlife; however, the use of native plants, interactive signage, and artistic representation of local animals fills the important role of educating visitors about the natural ecosystem and connecting them with the local environment.

\section{Useful sources, links and materials}

Biodiversity Showcase Garden in Green Point, Cape Town

World Cup Legacy - Green Point Park, Cape Town. https://www.southafrica.net/gl/en/travel/ article/world-cup-legacy-green-point park-cape-town

Krasny, M.E., C. Lundholm, S. Shava, E. Lee, and H. Kobori. 2013. Urban Landscapes as Learning Arenas for Biodiversity and Ecosystem Services Management. T. Elmqvist et al. (eds.), Urbanization, Biodiversity and Ecosystem Services: Challenges and Opportunities: A Global Assessment, DOI 10.1007/978-94-007-7088-1_30

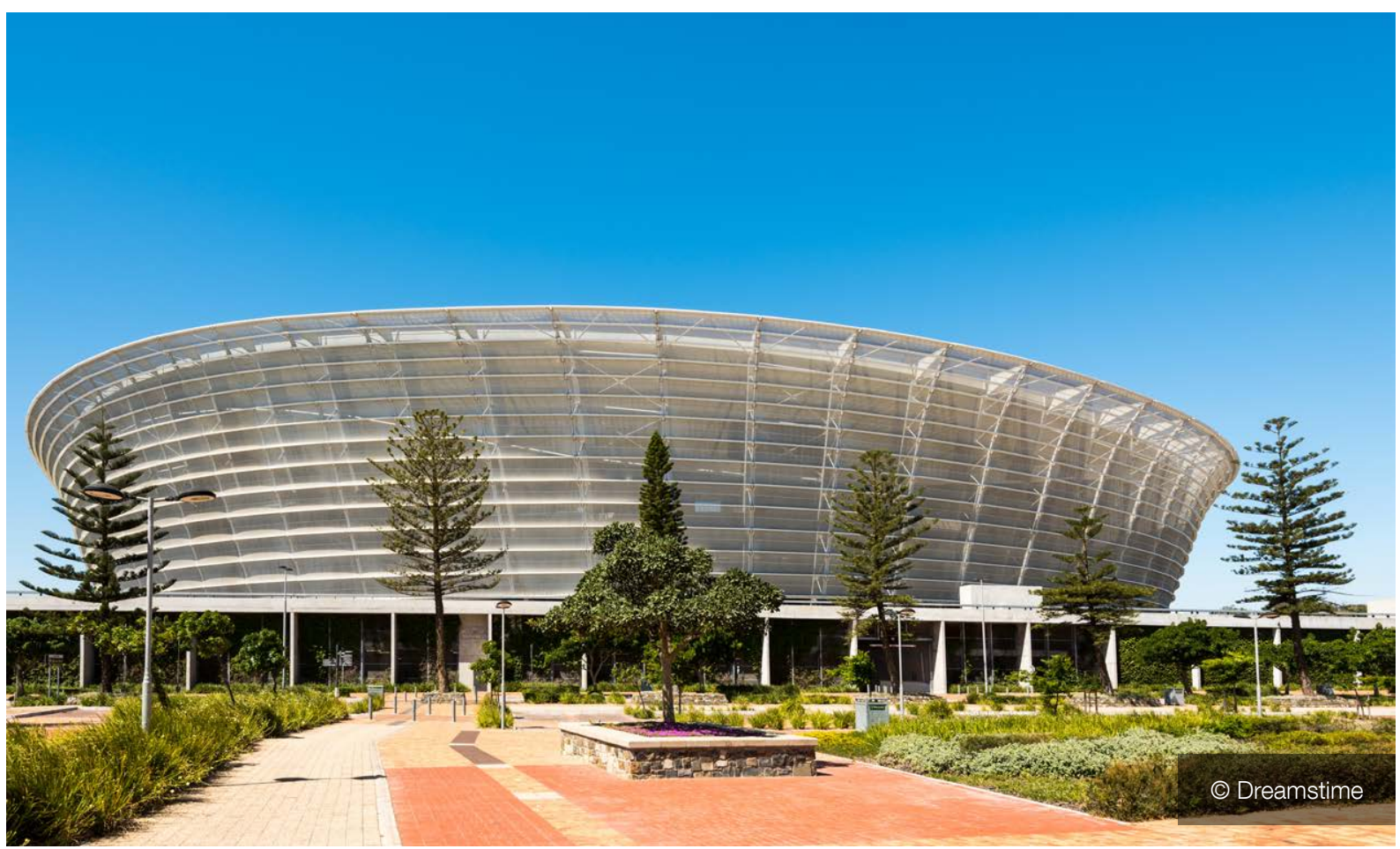

Green Point Park at the Cape Town Stadium. 


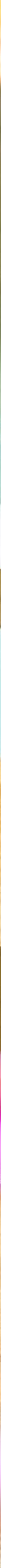

W 1

1.

3072 - 1 - 5 -

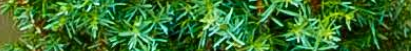

2.

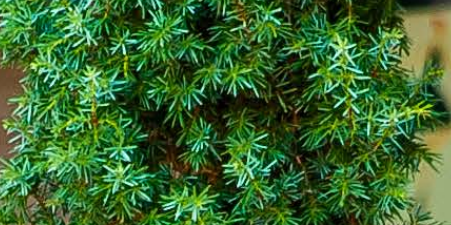




\section{Conclusions - Every little action counts}

The loss of biodiversity, with around one million animal and plant species threatened with extinction, is risking our economies, livelihoods, food security, health and quality of life worldwide. Diverse and innovative measures are needed to halt and reverse this decline and to restore where possible what has been lost (IPBES, 2019), and specifically investing in nature and nature-based solutions has to become the norm if we want to successfully address the ecological crisis we are currently experiencing. The magnitude of the challenge calls for the collaboration and contribution of all actors, including nonstate actors, such as businesses, local authorities, civil society organisations and individual citizens. Everybody can play a role, and every little action can count.

This Guide has been written to inspire increased collaboration between local authorities and sports stakeholders. The use of nature in cities to enhance the quality of life will benefit both urban residents and athletes in urban areas, transforming investments to a win-win situation. Even a small 'element' can make a difference, especially if integrated in a larger, long-term vision of urban regeneration through nature. Furthermore, the need to obtain the full support of local communities for mega-sport events is an opportunity for local authorities and sports events owners and event organisers to align the proposed events with social priorities, thus leaving positive legacies to the host cities.

Sports event owners, venue owners and operators and local organising committees can help create a positive narrative of how sports can contribute to biodiversity conservation and demonstrate that
- even in urban contexts - sports can be an important ally in addressing the biodiversity crisis.

In this context, sports stakeholders - from event owners, venue owners and operators and local organising committees - can and should play a role in enhancing urban biodiversity, after having effectively mitigated their direct and indirect impacts on nature.

Small actions (Box 5), implemented at the venue level, can make a difference - whether it is planting native trees, choosing the right management regime, providing bird-nests or materials for birds to build their own nests. These actions, if integrated in a larger vision, can deliver systemic outcomes, especially if event owners, venue owners and operators, and local organising committees collaborate with city authorities. Using sport events as leverage for urban regeneration initiatives can offer venues and sports events an opportunity to integrate natural features and mobilise sports fans in becoming 'nature' fans.

The benefits of these actions can be compounded through partnerships. Cooperation and partnerships between sport ground managers and conservation bodies should be also proactively pursued for their great value added from a technical and social perspectives. Furthermore, partnerships aimed at creating shared management approaches between different sport venues as well as between sport venues and non-sport greenspaces would also expand the potential biodiversity conservation outcomes of the initiatives taken by sport stakeholders. 


\section{Box 5. Every little action counts. An overview of actions to promote biodiversity in cities associated to sports events and venues}

Sports event owners, venue owners and operators and local organising committees can start with a number of actions to promote biodiversity in cities. When building a new venue, renovating an existing space or planning an event, consider the following features in addition to the effective mitigation of the negative impacts associated to the sport venue or event:

\section{Patch size:}

- Preserve and conserve existing natural vegetation within sport venues

- Create venues in areas where little green space exists

\section{Connections:}

- Take advantage of marathons and cycling events to improve green infrastructure along the route, such as street trees

- Develop green active mobility corridors around venues

\section{Matrix quality:}

- Use grass rather than artificial turf

- Install native plants around sport venues and fields

- Add green roofs and living walls on sport buildings

\section{Habitat diversity:}

- Include multiple habitat types around venues, such as water features, meadows and shrubs

- Develop vegetated patches with multiple layers, such as grass, shrubs and tree canopy

\section{Native vegetation:}

- Choose native plants for outdoor landscaping

- Remove invasive species, especially along waterways

- Select native species as mascots

- Organise education events to connect fans with native species

\section{Special resources:}

- Install bird boxes or materials suitable for nest-building

- Create rain gardens in parking lots and around fields and courts

- Create wildflower meadows and gardens for pollinators

- Retain dead trees, fallen logs and leaf litter where possible

\section{Management:}

- Install bird safe windows

- Reduce night time lighting where possible and use wildlife friendly lighting where necessary

- Reduce mowing and chemical input on or around the edges of maintained lawns 


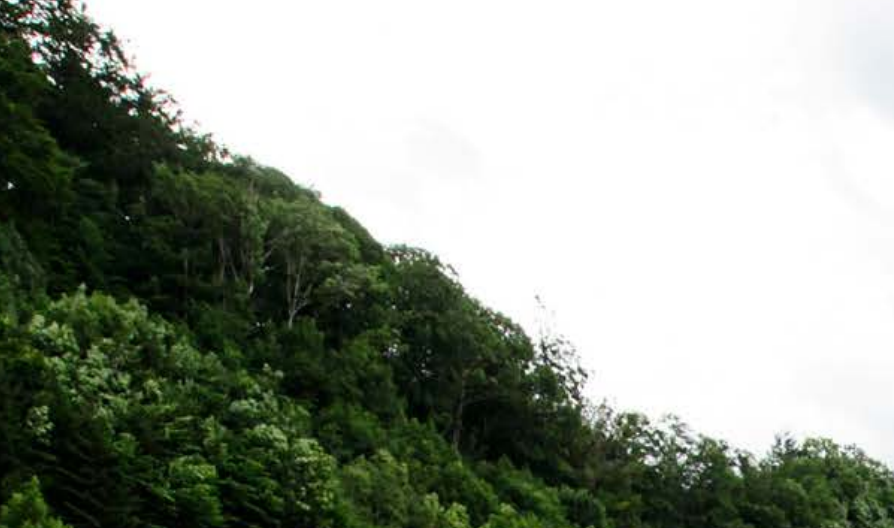

1

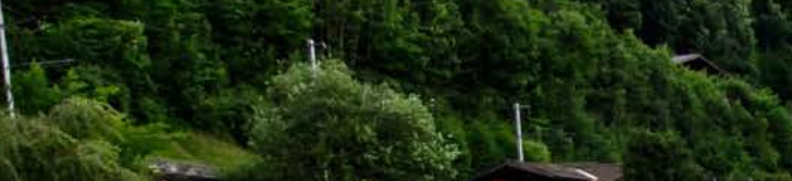

17?

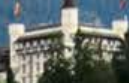

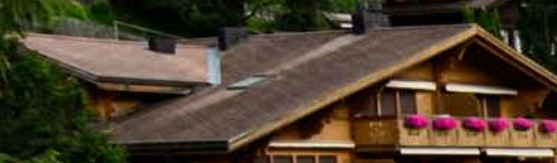

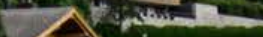

axtriment

turentins

$-70$

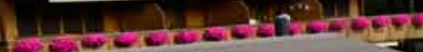

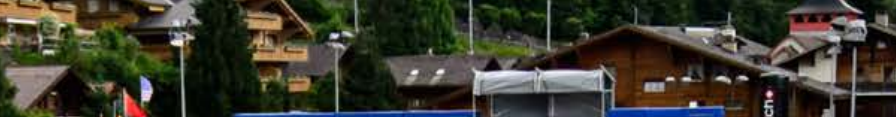

Minn and

(2) 3

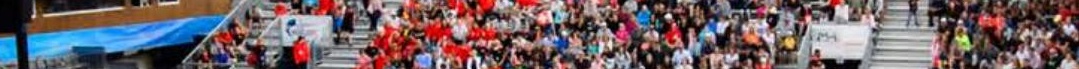

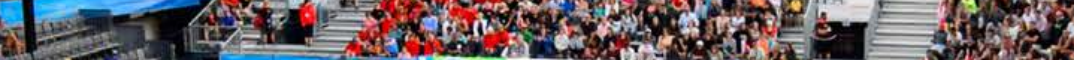

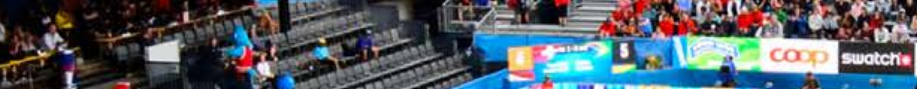

on Mtos. n.

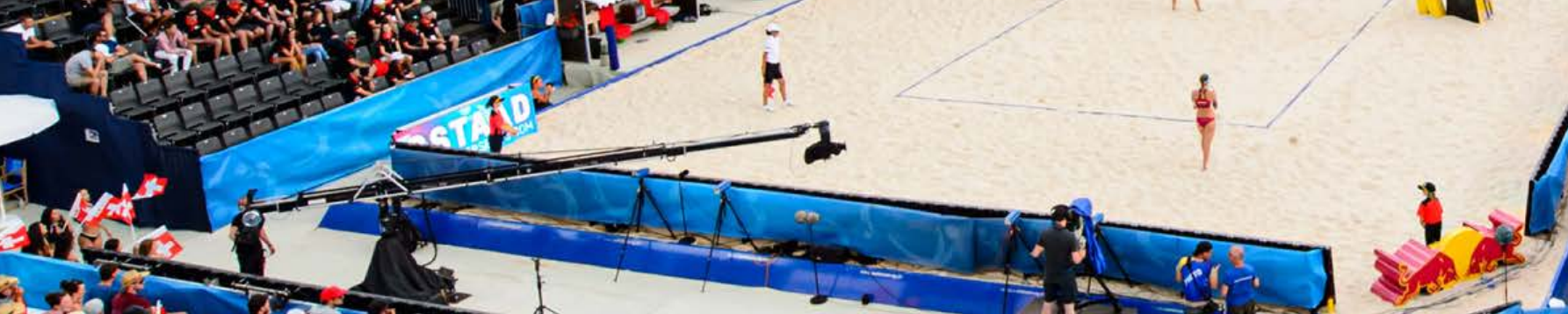

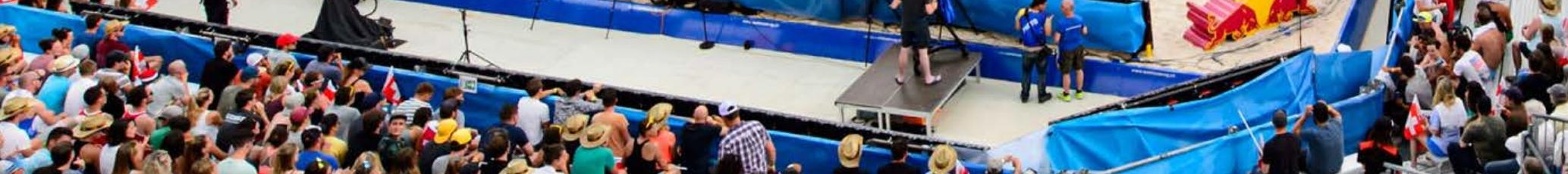

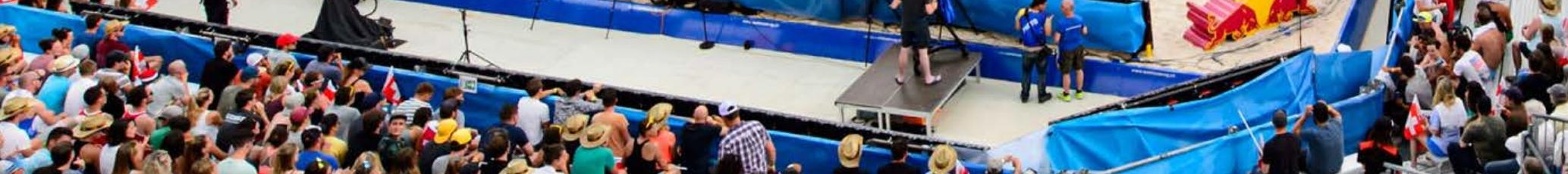

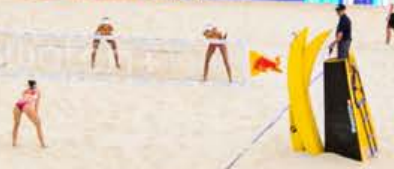

2010

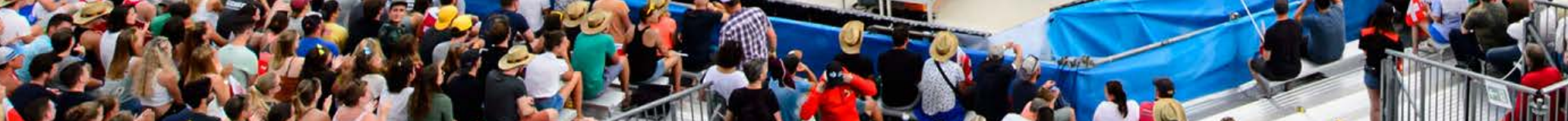

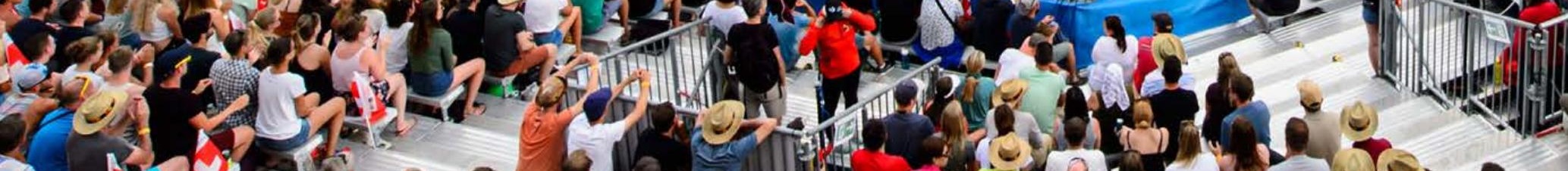

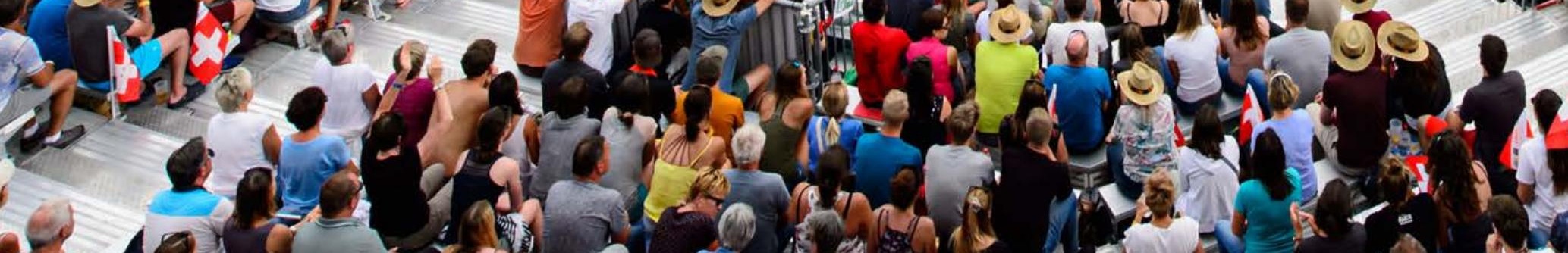

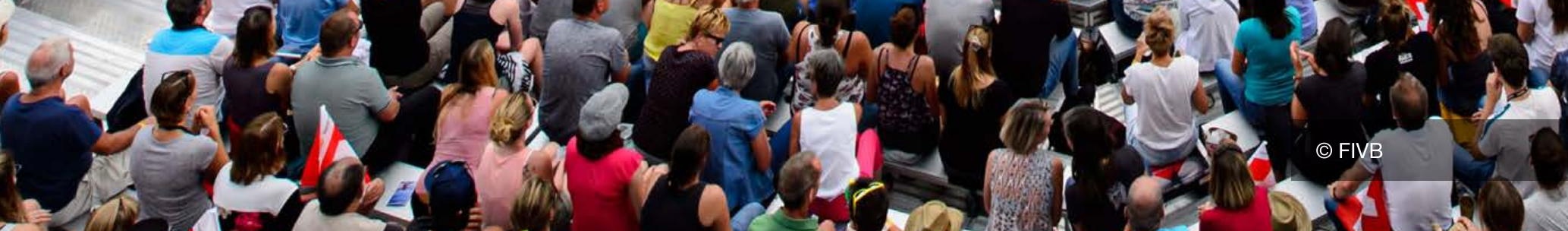




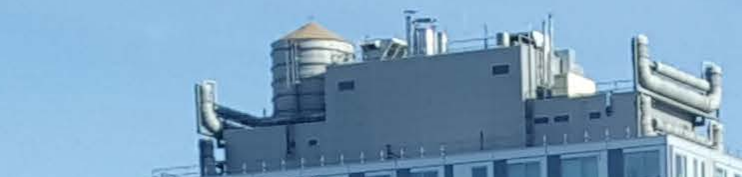

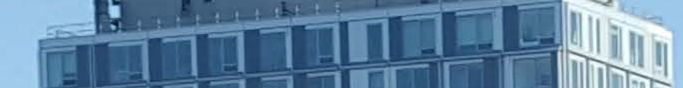

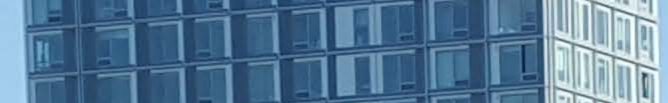

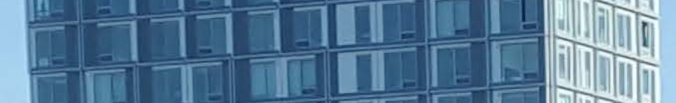

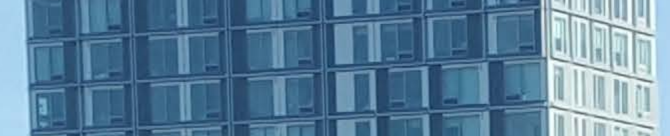
de

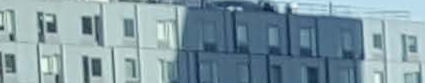

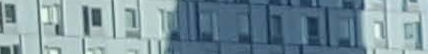
㗁

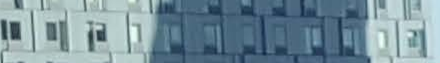

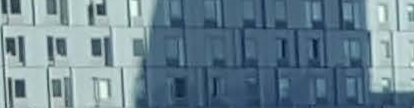
ii) ie

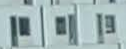
기 |시 Lin. IItad
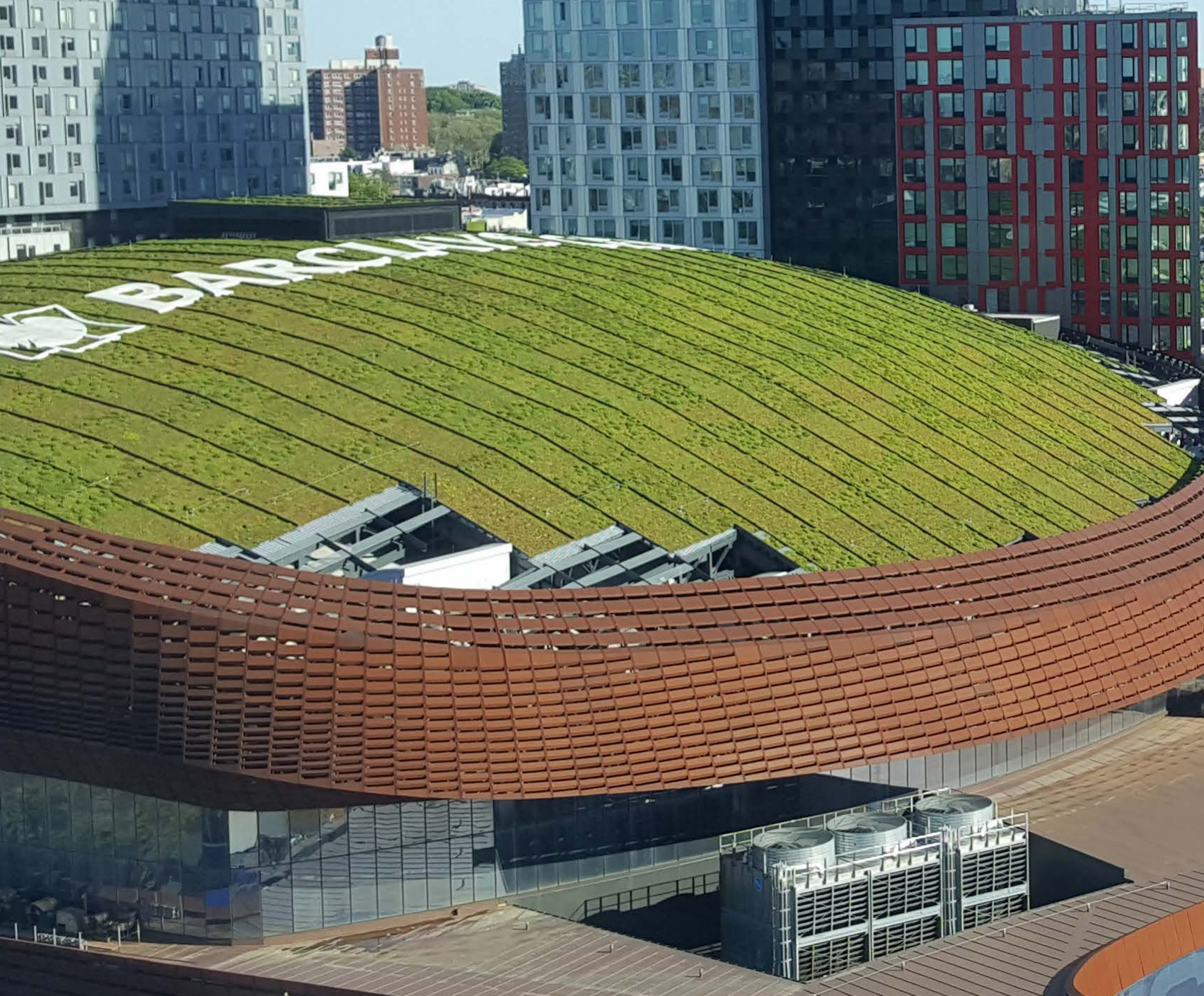

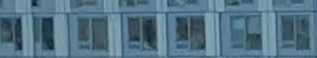
II I. II II ] II LI

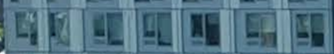
.

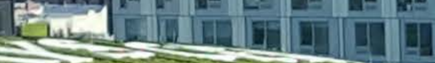

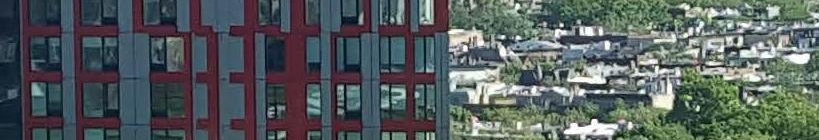

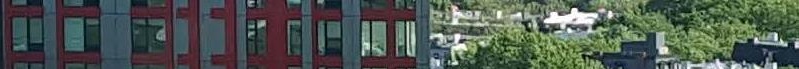

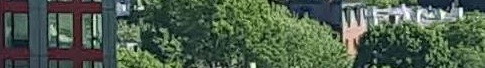
II II II

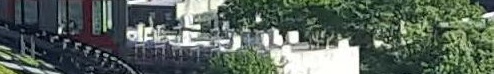

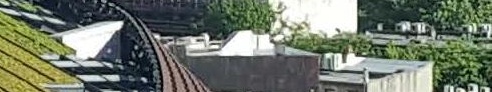

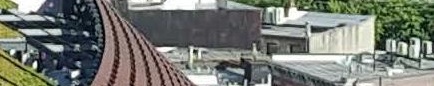

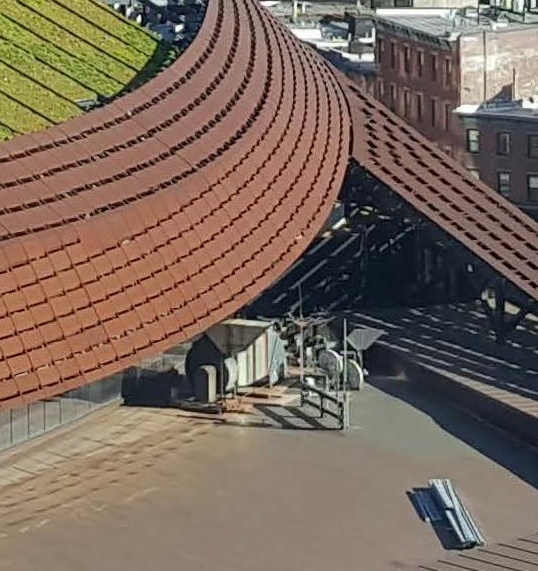




\section{References}

\section{Introduction}

McDonald, R., Colbert, M., Hamann, M., Simkin, R., Walsh, B., Ascensão, F., Barton, M., Crossman, K., Edgecomb, M., Elmqvist, T., Gonzalez, A., Güneralp, B., Haase, D., Hillel, O., Huang, K., Maddox, D., Mansur, A., Paque, J., Pereira, H., Sharp, R. (2018). Nature in the Urban Century: A global assessment of where and how to conserve nature for biodiversity and human wellbeing. Arlington, VA, USA: The Nature Conservancy. Available at: https://www.nature.org/content/dam/tnc/nature/en/ documents/TNC_NatureintheUrbanCentury_FullReport.pdf

The Nature Conservancy (TNC) (2016). Outside our Doors: the benefits of cities where people and nature thrive. Seattle, WA, USA: TNC. Available at: https://www.nature.org/content/dam/tnc/nature/en/ documents/Outside_Our_Doors_report.pdf

United Nations Conference on Trade and Development (UNCTAD) (2019). Handbook of Statistics. Available at: https://unctad.org/en/PublicationsLibrary/tdstat44_en.pdf

\section{Chapter 2}

Baum, K.A., Haynes, K.J., Dillemuth, F.P. and Cronin, J.T. (2004). 'The matrix enhances the effectiveness of corridors and stepping stones'. Ecology 85(10): 2671-2676. Available at: https://doi. org/10.1890/04-0500

Beninde, J., Veith, M. and Hochkirch, A. (2015). Biodiversity in cities needs space: A meta-analysis of factors determining intra-urban biodiversity variation. Ecology Letters 18(6): 581-592. Available at: https://doi.org/10.1111/ele.12427

Cox, D.T.C., Bennie, J., Casalegno, S., Hudson, H.L., Anderson, K. and Gaston, K.J. (2019). 'Skewed contributions of individual trees to indirect nature experiences'. Landscape and Urban Planning 185: 28-34. Available at: https://doi.org/10.1016/j.landurbplan.2019.01.008

Francis, R.A. (2018). 'Artificial lawns: Environmental and societal considerations of an ecological simulacrum'. Urban For Urban Green 30: 152-156. Available at: https://doi.org/10.1016/j. ufug.2018.02.002

Gaston, K.J., Davies, T.W., Bennie, J. and Hopkins, J. (2012). 'Reducing the ecological consequences of night-time light pollution: Options and developments'. Journal of Applied Ecology 49(6):1256-1266. Available at: https://doi.org/10.1111/j.1365-2664.2012.02212.x

Hill, M.J., Biggs, J., Thornhill, I., Briers, R.A., Gledhill, D.G., White, J.C. Wood, P.J. and Hassall, C. (2017). 'Urban ponds as an aquatic biodiversity resource in modified landscapes'. Global Change Biology 23(3):986-999. Available at: https://doi.org/10.1111/gcb.13401

Livesley, S.J., McPherson, E.G. and Calfapietra, C. (2016). 'The Urban Forest and Ecosystem Services: Impacts on Urban Water, Heat, and Pollution Cycles at the Tree, Street, and City Scale'. Journal of Environmental Quality 24:119-124. Available at: https://doi.org/10.2134/jeq2015.11.0567

McCullough, B.P. and Kellison, T.B. (2016). 'Go Green for the Home Team: Sense of Place and Environmental Sustainability'. The Journal of Sustainability Education. Available at: http://www.jsedimensions.org/wordpress/content/ go-green-for-the-home-team-sense-of-place-and-environmental-sustainability-in-sport_2016_02/ 
San Francisco Estuary Institute (SFEI) (2019). Making Nature's City: A science-based framework for building urban biodiversity. A product of the Healthy Watersheds, Resilient Baylands project. Funded by San Francisco Bay Water Quality Improvement Fund, EPA Region IX. SFEI Publication \#947, San Francisco Estuary Institute, Richmond, CA, USA: Available at: https://www.sfei.org/sites/default/files/ biblio_files/Making\%20Natures\%20City\%20SFEl\%20190905\%20lowres.pdf

Sartore-Baldwin, M. and McCullough, B. (2019). 'Examining Sport Fans and the Endangered Species Who Represent Their Affiliated Team Mascots'. Society \& Animals. Available at: https://doi. org/10.1163/15685306-12341605

Stagoll, K., Lindenmayer, D.B., Knight, E., Fischer, J. and Manning, A.D. (2012). 'Large trees are keystone structures in urban parks'. Conservation Letters 5:115-122. Available at: https://doi. org/10.1111/j.1755-263X.2011.00216.x

Taylor, L. and Hochuli, D.F. (2015). 'Creating better cities: how biodiversity and ecosystem functioning enhance urban residents' wellbeing'. Urban Ecosystems 18:747-762. Available at: https://doi. org/10.1007/s11252-014-0427-3

Tews, J., Brose, U., Grimm, V., Tielbörger, K., Wichmann, M. C., Schwager, M. and Jeltsch, F. (2004). 'Animal species diversity driven by habitat heterogeneity/diversity: the importance of keystone structures'. Journal of Biogeography 31(1):79-92. Available at: https://doi. org/10.1046/j.0305-0270.2003.00994.x

Threlfall, C.G., Mata, L., Mackie, J.A., Hahs, A.K., Stork, N.E., Williams, N.S.G. and Livesley, S.J. (2017) Increasing biodiversity in urban green spaces through simple vegetation interventions. Journal of Applied Ecology 54(6):1874-1883. Available at: https://doi.org/10.1111/1365-2664.12876

Watson, C.J., Carignan-Guillemette, L., Turcotte, C., Marie, V. and Proulx, R. (2019). 'Ecological and economic benefits of low-intensity urban lawn management'. Journal of Applied Ecology 57(2): 436446. Available at: https://doi.org/10.1111/1365-2664.13542

\section{Chapter 3}

Balmford, A., Green, J.M.H., Anderson, M., Beresford, J., Huang, C., Naidoo, R., Walpole, M. and Manica, A. (2015). 'Walk on the Wild Side: Estimating the Global Magnitude of Visits to Protected Areas'. PLoS Biology 13(2): e1002074. Available at: https://doi.org/10.1371/journal.pbio.1002074

BBC (2013). 'Watermead County Park mice to live in tennis balls'. BBC [website] (26 April 2013). Available at: https://www.bbc.com/news/uk-england-leicestershire-22314712 [accessed 23 Mar. 2020].

Campelli, M. (2019). 'UEFA invests in cookstoves to compensate for Euro 2020 carbon emissions'. The Sustainability Report [website] (2 December 2019). Available at: https://sustainabilityreport. com/2019/12/02/uefa-invests-in-cookstoves-to-compensate-for-euro-2020-carbon-emissions/

(2020). 'Wimbledon to generate renewable energy as part of net zero carbon ambition'.

The Sustainability Report [website] (10 February 2020). Available at: https://sustainabilityreport. com/2020/02/10/wimbledon-to-generate-renewable-energy-as-part-of-net-zero-carbon-ambition/

Chongo, J. (2017). 'Promoting biodiversity conservation through the School Games National Festival in Mozambique'. The Biodiversity Finance Initiative [website] (11 September 2017). Available at: https://www.biodiversityfinance.net/news-and-media/ promoting-biodiversity-conservation-through-school-games-national-festival 
Department of Environment, Food and Rural Affairs (Defra) (2019). 'Government to mandate 'biodiversity net gain". Defra Press Office [blogpost] (13 March 2019). Available at: https://deframedia.blog.gov. uk/2019/03/13/government-to-mandate-biodiversity-net-gain/

Dudley, N. (ed.) (2008). Guidelines for Applying Protected Area Management Categories. Gland, Switzerland: IUCN. x + 86pp. WITH Stolton, S., P. Shadie and N. Dudley (2013). IUCN WCPA Best Practice Guidance on Recognising Protected Areas and Assigning Management Categories and Governance Types, Best Practice Protected Area Guidelines Series No. 21, Gland, Switzerland: IUCN. Available at: https://portals.iucn.org/library/node/30018

Friends of Karura Forest (2016). Community Forest Association 2015 Report. A Year in Review. Nairobi, Kenya. Friends of Karura Forest. Available at: http://www.friendsofkarura.org/wp-content/ uploads/2016/05/Annual-Report-2015_reduced.pdf

Garcia-Falgueras, A. (2015). 'Psychological Benefits of Sports and Physical Activities'. British Journal of Education, Society \& Behavioural Science 11(4): 1-7.

Good Net Project (n.d.). 'Ghost nets to good nets'. Good Net Project [website]. Available at: https:// goodnetproject.com/EN

International Federation of Football Associations (FIFA) (2018). 'More than half the world watched recordbreaking 2018 World Cup'. FIFA [website] (21 December 2018). Available at: https://www.fifa.com/ worldcup/news/more-than-half-the-world-watched-record-breaking-2018-world-cup

International Olympic Committee (IOC) (2019), 'Olympic Champion Hannah Mills launches \#BigPlasticPledge'. IOC [website] (13 September 2019). Available: https://www.olympic.org/news/ olympic-champion-hannah-mills-launches-bigplasticpledge

International Union for Conservation of Nature (IUCN) (2008). 'Protected Areas'. IUCN [website]. Available at: https://www.iucn.org/theme/protected-areas/about

Le Roux, B. (2016). 'Sharks Rugby supports Rhinos without Borders'. Rhinos without Borders [website] (9 March 2016). Available at: http://www.rhinoswithoutborders.com/ sharks-rugby-supports-rhinos-without-borders/

Lewa Wildlife Conservancy (2010). Lewa Marathon: Catalyst for Conservation in Northern Kenya. Available at: https://web.archive.org/web/20100202031433/http://www.lewa.org/lewa_marathon.php

Luftige Begegnungen (n.d.). 'Airy Encounters Project'. Luftige Begegnungen [website]. Available at: http:// www.luftige-begegnungen.de/deutsch/luftige-begegnungen/ziele/

Luscombe, R. (2020). 'Florida hunters capture more than 80 giant snakes in Python Bowl'. The Guardian [website] (30 January 2020). Available at: https://www.theguardian.com/us-news/2020/jan/30/ florida-python-bowl-challenge-capture-snakes

McDonald, R., Colbert, M., Hamann, M., Simkin, R., Walsh, B. (2018). Nature in the Urban Century: A global assessment of where and how to conserve nature for biodiversity and human wellbeing. Arlington, VA, USA: The Nature Conservancy Available at: https://www.nature.org/content/dam/tnc/ nature/en/documents/TNC_NatureintheUrbanCentury_FullReport.pdf

McDonald, R.I., Forman, R.T.T., Kareiva, P., Neugarten, R., Salzer, D. and Fisher, J. (2009). 'Urban effects, distance, and protected areas in an urbanizing world'. Landscape and Urban Planning 93(1): 63-75. Available at: https://doi.org/10.1016/j.landurbplan.2009.06.002 
Oh, H.-J. and Lee, C.-E. (2016). 'An Exploratory Study on the Value Preservation of Bukhansan National Park'. Journal of Global Business and Trade 12(2): 29-41. Available at: https://doi.org/10.3390/ su9081306

Ol Pejeta Conservancy (2018). 'Last Male Standing Cricket Tournament'. OI Pejeta Conservancy [website]. Available at: https://www.olpejetaconservancy.org/last-male-standing-cricket-tournament/

Project Aware (2020). 'Dive against debris'. Project Aware [website]. Available at: https://www. projectaware.org/diveagainstdebris

Save the Waves Coalition (n.d.) 'World Surfing Reserves'. Save the Waves Coalition [website]. Available at: https://www.savethewaves.org/programs/world-surfing-reserves/

Shedd Aquarium (n.d.). Kayak for Conservation. Shedd Aquarium [website]. Available at; https://www. sheddaquarium.org/programs-and-events/kayak-for-conservation [accessed 23 Mar. 2020].

Teisl, M.F. and O'Brien, K. (2003) Who cares and who acts? Outdoor recreationists exhibit different levels of environmentalism. Environment and Behavior 35(4):506-522. Available at: https://doi.org/10.1177/0 013916503035004004

The Guardian (2020) 'Ace idea: Nick Kyrgios leads the way as sport gets behind bushfire relief efforts'. The Guardian [website] (3 January 2020). Available at: https://www.theguardian.com/sport/2020/ jan/02/kyrgios-stosur-and-others-pledge-200-per-ace-to-bushfire-relief-efforts

Toledo Institute for Development and Environment (TIDE) Belize (n.d.). 'Freshwater Cup'. Available at: http://tidebelize.org/freshwater-cup/

Tour de France (n.d.). 'Around Sustainable Development'. Tour de France [website]. Available at: https:// www.letour.fr/en/around-sustainable-development

Trzyna, T. (2014). Urban protected areas: profiles and best practice guidelines. Best Practice Protected Area Guidelines Series No. 22. Gland, Switzerland: IUCN. xiv + 110pp. Available at: https://portals. iucn.org/library/node/44644

United Nations Environment Programme (UNEP) (2018). 'Climate change is wiping out the secret to Fiji's international rugby success'. UNEP [website] (25 September 2018). Available at: https://www.unenvironment.org/news-and-stories/story/ climate-change-wiping-out-secret-fijis-international-rugby-success

WildAid (n.d.), 'Athlete and WildAid ambassador for sharks, elephants, rhinos'. WildAid [website]. Available at: https://wildaid.org/ambassadors/yao-ming/

Wildlife Trust of India (2014). 'Cricket tournament supports wildlife conservation'. Wildlife Trust of India [website] (7 April 2014). Available at: https://www.wti.org.in/news/ cricket-tournament-supports-wildlife-conservation/

World Wide Fund for Nature (WWF) - UK (n.d.). 'We've saved a billion trees in the Amazon with Sky - now we're setting our sights on the world's oceans'. WWF-UK [website]. Available at: https://www.wwf. org.uk/who-we-are/who-we-work-with/sky

\section{Chapter 4}

Building with Nature (n.d.). High quality spaces for people and wildlife. Building with Nature [website]. Available: https://www.buildingwithnature.org.uk/ 
Grant, G. (2017). Urban Greening Factor for London. The Ecology Consultancy: London. Available: https://www.london.gov.uk/sites/default/files/urban_greening_factor_for_london_final_report.pdf.

International Union for Conservation of Nature (IUCN) (2016). 'Defining Nature-based Solutions'. IUCN World Conservation Congress 2016 Resolution 069-EN. Gland, Switzerland: IUCN. Available at: https://portals.iucn.org/library/node/46486

(2018). 'IUCN launches global alliance for greener cities'. IUCN [website] (24 September 2018). Available at: https://www.iucn.org/news/secretariat/201809/ iucn-launches-global-alliance-greener-cities

(2020). Guidance for using the IUCN Global Standard for Nature-based Solutions. A user-friendly framework for the verification, design and scaling up of Nature-based Solutions. First edition. Gland, Switzerland: IUCN. Available at: https://doi.org/10.2305/IUCN.CH.2020.09.en

(2020). IUCN Global Standard for Nature-Based Solutions. First edition. Available at: https://www. iucn.org/theme/ecosystem-management/our-work/a-global-standard-nature-based-solutions and https://doi.org/10.2305/IUCN.CH.2020.08.en

National Parks Board (n.d.). 'Singapore Index on Cities' Biodiversity'. National Parks Board [website]. Available at: https://www.nparks.gov.sg/biodiversity/urban-biodiversity/ the-singapore-index-on-cities-biodiversity

\section{Glossary}

Business and Biodiversity Offsets Programme (BBOP) (2012). Glossary. $2^{\text {nd }}$ updated edition. Washington, DC, USA: BBOP. Available at: https://www.forest-trends.org/wp-content/uploads/imported/bbop_ updated_glossary_6-july-12_v1-pdf.pdf

Convention on Biological Diversity (CBD) (n.d.). 'What are Invasive Alien Species?'. Convention on Biological Diversity [website]. Available at: https://www.cbd.int/invasive/WhatarelAS.shtml

Hesselink, F., Goldstein, W., van Kempen, P.P., Garnett ,T. and Dela, J. (2007). Communication, Education and Public Awareness (CEPA). A toolkit for National Focal Points and NBSAP Coordinators. Montreal, Canada: Secretariat of the Convention on Biological Diversity and IUCN. Available at: https://www. cbd.int/cepa/toolkit/2008/cepa/index.htm and https://portals.iucn.org/library/node/9260

United Nations (UN) (1992). Convention on Biological Diversity. Available at: https://www.cbd.int/doc/ legal/cbd-en.pdf

\section{Conclusions}

Intergovernmental Science-Policy Platform on Biodiversity and Ecosystem Services (IPBES) (2019). 'Summary for policymakers - Global Assessment'. In: Global assessment report on biodiversity and ecosystem services of the Intergovernmental Science-Policy Platform on Biodiversity and Ecosystem Services. S. Díaz, J. Settele, E.S. Brondizio E.S., H.T. Ngo, M. Guèze, J. Agard, A. Arneth, P. Balvanera, K.A. Brauman, S.H.M. Butchart, K.M.A. Chan, L.A. Garibaldi, K. Ichii, J. Liu, S.M. Subramanian, G.F. Midgley, P. Miloslavich, Z. Molnár, D. Obura, A. Pfaff, S. Polasky, A. Purvis, J. Razzaque, B. Reyers, R. Roy Chowdhury, Y. J. Shin, I.J. Visseren-Hamakers, K.J. Willis, and C.N. Zayas (eds.). IPBES secretariat, Bonn, Germany. Available at: https://www.ipbes.net/ global-assessment-report-biodiversity-ecosystem-services

International Finance Corporation (IFC) (2012). 'Performance Standard 6. Biodiversity Conservation and Sustainable Management of Living Natural Resources (January 1, 2012)'. Biodiversity Conservation and Sustainable Management of Living Natural Resources (2012). Washington, DC, USA: IFC.

Available at: www.ifc.org/ps6 




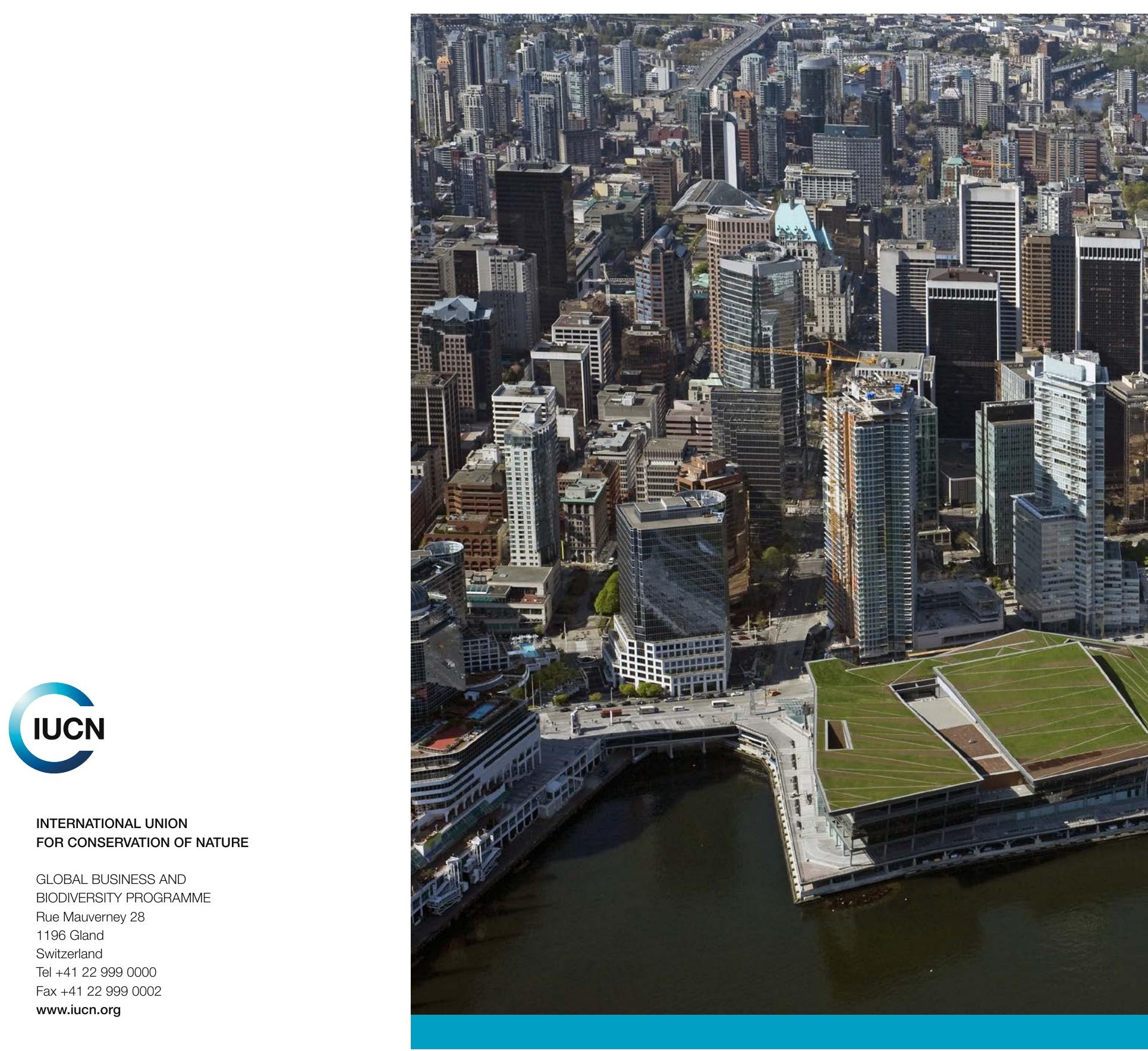

